NBSIR 75-819

\title{
SENSITIVE ISOTROPIC ANTENNA WITH FIBER-OPTIC LINK TO A CONVENTIONAL RECEIVER
}

E.B. Larsen

J.R. Andrews

E.E. Baldwin

Electromagnetics Division Institute for Basic Standards National Bureau of Standards Boulder, Colorado 80302

September 1976

Final Report

ECOM Contract No. 74-93095

Prepared for U.S. Army Electronics Command AMSEL-NL-C

Fort Monmouth, New Jersey 



\section{SENSITIVE ISOTROPIC ANTENNA WITH FIBER-OPTIC LINK TO A CONVENTIOHAL RECEIVER}
E.B. Larsen
J.R. Andrews
E.E. Baldwin

Electromagnetics Division. Institute for Basic Standards National Bureau of Standards

Boulder, Colorado 80302

September 1976

Final Report

ECOM Contract No. 74-93095

Prepared for

U.S. Army Electronics Command

AMSEL-NL-C

Fort Monmouth, New Jersey

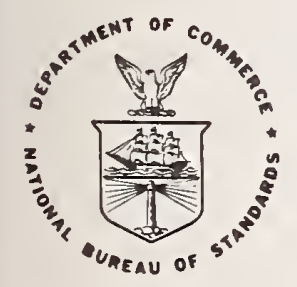

U.S. DEPARTMENT OF COMMERCE, Elliot L. Richardson, Secretary Edward O. Vetter, Under Secretary

Dr. Betsy Ancker-Johnson, Assistant Secretary for Science and Technology

NATIONAL BUREAU OF STANDARDS, Ernest Ambler, Acting Director 

INTRODUCTION-

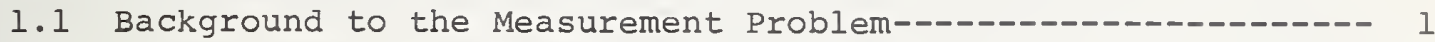

1.2 Objectives of the ECOM/NBS Contract--------------------- 3

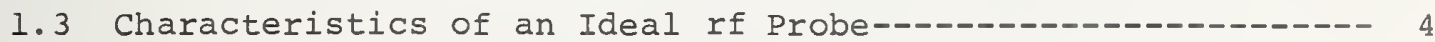

2. TECHNICAL APPROACH-----_-

3. OPTICAL TRANSMISSION LINKS--------------------------------- 7

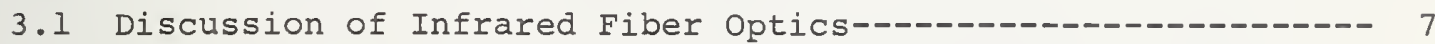

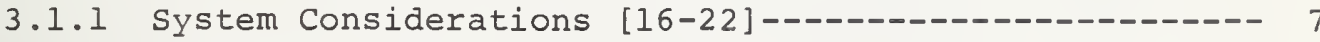

3.1.2 Infrared Sources [23]--- 7

3.1.3 Fiber Transmission Lines [24, 25 and 26]----------- 9

3.1.4 Infrared Photodetectors-_-_- 10

3.2 Tests of Fiber-Optic Components---n-- 10

3.3 Measurements of Two Infrared Optoelectronic Links--.-.---.-- 12

3.3.1 Performance of a Radiated System---_-_-_-_-_-_ 12

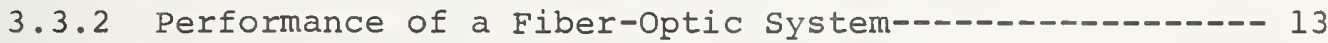

4. FIELD STRENGTH AND ANTENNA CALIBRATIONS--------------------- 14

4.1 Discussion of Field Strength Meters----_--_-_---_--------- 14

4.2 Auxiliary Calibration of the Receiver as a Tunable rf

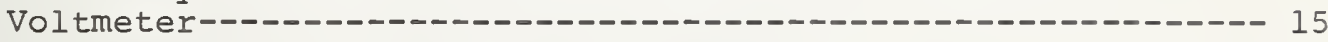

4.3 Standard Field Setup Used to Calibrate the Active Antenna--- 16

5. DESIGN OF A SINGLE-DIPOLE FIBER-OPTIC ACTIVE ANTENNA------------ 17

5.1 Description of the Dipole Unit and APD Circuit-_-_-_-_-_--- 17

5.2 Preliminary Tests of the Active Dipole System-_........... 18

5.3 Effects of Noise and Receiver Bandwidth on Sensitivity

[30 and 31]--n- 18

5.4 Measurements of the System Sensitivity------------------- 20

5.4.1 Sensitivity of the Active Dipole------------------ 20

5.4.2 Effect of Using an Antenna Resonating Inductor------- 21

5.4.3 Effect of Non-coherence in the Fiber Bundle---.------ 22

5.5 Overall Antenna Performance vs. Frequency: Tangential

Sensitivity, Linearity, Dynamic Range and Antenna Factor---- 23

5.6 Overloading of the Active Antenna System by a Strong

Interfering Signal-_- 
6. DESIGN AND FABRICATION OF THE COMPLETE ISOTROPIC ANTENNA AND

CONTROI UNIT-

6.1 Description of the system- 25

6.2 Avalanche Photodiode Circuitry- 26

$6.3 \mathrm{rf} / \mathrm{IR}$ Calibrator Circuit-

6.4 Interface with the EMC-25 Recelver- 28

6.5 Vector Magnitude Analog Computer- 29

$6.6 \mathrm{X}-\mathrm{Y}-\mathrm{Z}$ Measurement Sequencer-

6.7 Auxiliary Equipment-

7. SUMMARY AND CONCLUSIONS- 33

8. RECOMMENDATIONS AND FUTURE PLANS- 36

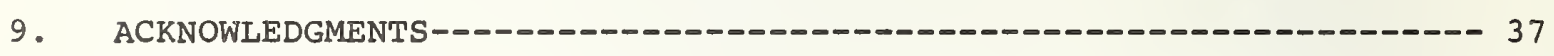

10. REFERENCES- 
Figure

1

2

3 Block diagram of the broadband, isotropic, fiber-optic antenna system developed at NBS-

4 Typical emission spectra or response of various optical sources and detectors--

5 Intensity of radiation vs. forward current for a typical infrared LED-- - - -

6 Measured performance of avalanche photodiode No. 2 at an ambient temperature of $28^{\circ} \mathrm{C}-\ldots$

7 Instrumentation for an experimental radiated communications link-

8 Performance of the experimental radiated link at a signal frequency of $25 \mathrm{MHz}---50$

9 Simplified schematic of the instrumentation for measuring rf attenuation of the fiber-optic link---

10 Attenuation vs. frequency of the fiber-optic system-------- 52

11 Block diagram of a typical EMI receiver-_-

12 Nominal antenna factor for a thin $\lambda / 2$ dipole and $50 \Omega$ receiver---

13 Instrumentation for calibrating a receiver to measure $\mathrm{CW}$ voltage----

14 Linearity of the receiver used (EMC-25, Band 11, narrow bandwidth, $25 \mathrm{MHz}$ )

15 Instrumentation used to establish a known E field in the TEM cell for calibrating the active dipole--

16 TEM transmission cell used to generate a known EM field for calibrating transfer probes and active antennas------------- 59

17 Schematic diagram of the rf amplifier and LED circuit in each active dipole antenna--

18 Equivalent circuit of the active antenna--------------- 61

19 Simplified schematic of the avalanche photodiode circuitry-- 62

20 Test setup for observing the system gain, frequency response and step response--- 
21 Signals received in the laboratory by a prototype active dipole. (Horizontal scan from DC to $200 \mathrm{MHz}$, spectrum analyzer bandwidth $=3 \mathrm{kHz}$.

22 Degradation of TV picture caused by the fiber-optic link---- 65

23 Measured sensitivity of the $31 \mathrm{~cm}$ active dipole and fiber-optic link, before optimization of the rf amplifier. (Length of fiber guide $=2 \mathrm{~m}$, LED current $=5 \mathrm{~mA}$, APD current $=80 \mu \mathrm{A})$

24 Tangential sensitivity of the active dipole system; comparison of $A P D$ and PMT infrared sensors. (Length of fiber guide $=2 \mathrm{~m}$, LED current $=5 \mathrm{~mA}$ )

25 Measured sensitivity of the active dipole system using the optimized rf amplifier of figure 17. (Length of fiber guide $=2 \mathrm{~m}, \mathrm{LED}$ current $=5 \mathrm{~mA}, \mathrm{APD}$ current $=80 \mu \mathrm{A}) \ldots \ldots$

26 Theoretical insertion loss caused by connecting a $7 \mu \mathrm{H}$ inductor and resistor across the center gap of the $31 \mathrm{~cm}$ dipole. (See sketch on page 21)

27 Tangential sensitivity of the active dipole system; effect of connecting an inductor across the dipole gap-...-. 71

28 Overall performance of the active dipole and fiber-optic link at four signal frequencies. (Length of fiber guide $=10 \mathrm{~m}$, LED current $=16 \mathrm{~mA}, \mathrm{APD}$ current $=40 \mu \mathrm{A}$ )----- 74

29 Tangential sensitivity of the active dipole system. (Length of fiber guide $=10 \mathrm{~m}, \mathrm{LED}$ current $=16 \mathrm{~mA}, \mathrm{APD}$ current $=40 \mu \mathrm{A})$

30 Dynamic range or antenna factor of the active dipole system. (Length of fiber guide $=10 \mathrm{~m}, \mathrm{LED}$ current $=16 \mathrm{~mA}, \mathrm{APD}$ current = $40 \mu \mathrm{A})$

31 Instrumentation for measuring strong-signal desensitization of the active dipole system--

32 Photograph of the isotropic antenna-

33A Block diagram of the isotropic antenna control unit

(Part 1)

33B Block diagram of the isotropic antenna control unit (Part 2)

Photograph of the antenna control unit chassis-_.-.-.--

35 Photograph of the complete fiber-optic antenna measurement system including the crossed dipoles, fiber guides, control unit and conventional receiver 
Schematic of the rf/IR calibrator circuit----

39 Interface circuitry between the control unit and the EMC-25 receiver--0--

40 Measured response of the EMC-25 receiver to pulses for the three possible detection modes.:- 88

41 Schematic of the vector magnitude "analog computer," board 1 of $3--\left(\begin{array}{c} \\ 1\end{array}\right.$

42 Schematic of the vector magnitude "analog computer," board

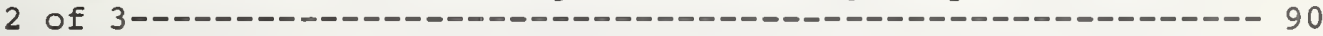

43 Schematic of the vector magnitude "analog computer," board 3 of $3--------1$

44 Schematic of the measurement sequencer circuitry----------- 93

45 Timing diagrams of the measurement sequencer control signals--

46 Timing diagrams of the measurement sequencer interval signals---

47 Schematic of the charger for the Nicd batteries----------- 96

48 Power supplies on the control unit chassis---_----------- 97

49 Schematic of the \pm 15 volt regulated power supply--------- 98

50 Interconnecting cables between the control unit, EMC-25

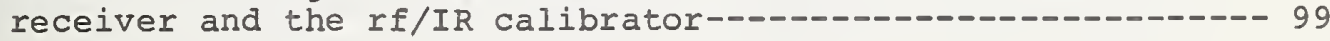


Sensitivity requirements for measuring narrowband signals according to MIL-STD-461/462--

Characteristics of fiber-optic and radiated infrared communication links---

Specified CW characteristics of some typical LED's-------- 47

Specified characteristics of some typical photodetectors---- 47

Specified characteristics of the EMC-25 receiver---------- 54

Bandwidth of the EMC-25 FIM receiver in narrowband selec-

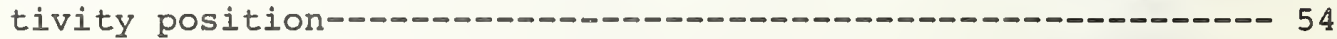

Frequency response test of the prototype antenna system. (Input signal $=-80 \mathrm{dBm}$, Spectrum analyzer bandwidth $=$

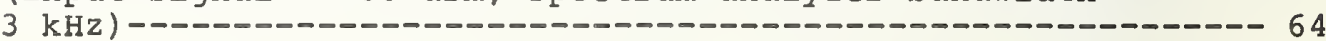

Required $E$ field for the given receiver indication $(S+N) / N$. (Frequency $=25 \mathrm{MHz}$, fiber waveguide $=$ type no. $1,2 \mathrm{~m}$ long) 66

Description of the parallel-resonating coils used with the final active antenna--

Measured performance of the fiber-optic antenna system------ 72 Measured performance of the fiber-optic antenna system with an inductor across the dipole gap--

Desensitization of the active dipole system; measurements of a "desired" signal at $75 \mathrm{MHz}$ in the presence of an "interfering" signal at $100 \mathrm{MHz}$ 


\section{ABSTRACT}

A broadband, active, isotropic receiving antenna was developed at NBS for the frequency range $15 \mathrm{kHz}$ to $150 \mathrm{MHz}$. It was designed for use with a conventional receiver to measure weak, near-zone electric fields of unknown polarization, such as leakage emanations from electronic equipment placed within a shielded enclosure. The antenna system consists of three mutuallyorthogonal active dipoles, each $31 \mathrm{~cm}$ long by $3.5 \mathrm{~cm}$ diameter. The entire frequency range of each of the three field components is amplified and used to modulate a high-speed light emitting diode (LED) located inside the dipole. The modulated infrared (IR) signals are guided through glass fibers 10 meters long which connect the "isolated" dipoles to avalanche photodiodes at the far end of the fiber guides. These photodetectors recover the rf modulation from the IR carrier for input to the receiver.

The fiber-optic antenna system described in this paper has high sensitivity (down to $10 \mu \mathrm{V} / \mathrm{m}$ ) and fast response time ( $r f$ modulations up to $150 \mathrm{MHz}$ ). The readout indication at each receiver frequency is proportional to the Hermitian magnitude of $E$, which is the root-sum-square value of three orthogonal E field components at the measurement point. The linear dynamic range of the antenna system depends on the receiver bandwidth and signal frequency. It is 70 to $75 \mathrm{~dB}$ at frequencies between 0.02 and $2 \mathrm{MHz}$ (for $0.5 \mathrm{kHz}$ receiver bandwidth), 60 to $70 \mathrm{~dB}$ between 2 and $25 \mathrm{MHz}$ (for $5 \mathrm{kHz}$ receiver bandwidth) and 40 to $55 \mathrm{~dB}$ between 25 and $200 \mathrm{MHz}$ (for $50 \mathrm{kHz}$ bandwidth).

Key words: Electromagnetic compatibility; fiber optics; field strength measurement; isolated EMC antenna; sensitive isotropic probe.

\section{INTRCDUCTION}

\subsection{Background to the Measurement Problem}

Improved receiving antennas are required in order to make meaningful measurements of near-zone fields and permit rapid surveying without requiring time-consuming multiple orientations of the pickup antenna. The radio frequency (rf) sensor should be small and operate without metal transmission lines to minimize distortion of the field being measured. This would permit more accurate measurement of electromagnetic interference (EMI) radiated by nearby sources within a shielded enclosure, avoiding errors caused by large antennas located close to equipment racks or enclosure walls. As reported in the literature, errors of 40 to $50 \mathrm{~dB}$ can occur when measuring radiated ernissions inside screen rooms [1 and 2]. 1

${ }^{1}$ Figures in brackets indicate the literature references at the end of this paper. 
The errors in measuring fields inside shielded rooms are caused mainly by conductive surfaces which set up multipath reflections and standing-wave resonances in these high Q "cavities." Also, the impedance characteristics and effective length of the pickup antennas used are altered by close proximity to the equipment under test and to the metal enclosure. Limited success at solving this measurement problem has been reported for frequencies above $200 \mathrm{MHz}$ by using absorbent walls and "hooded" antennas [3 and 4]. Measurements below $200 \mathrm{MHz}$ may suffer large errors but improved techniques are being studied [5 and 6]. Figure 1 shows a typical setup for measuring radiated emissions inside a shielded room.

Two recent developments now permit more accurate measurements of electric field strength in the near zone of antennas or the leakage field of unknown sources. The first development is an "isolated" antenna system, that is, one having electric isolation (no metallic conductors) between the antenna and receiver. The other development also features electrical isolation but combines it with an rf sensor having isotropic response [7]. The latter property is desirable for making measurements in shielded enclosures because the pickup is independent of field orientation. Thus it is not necessary to determine experimentally the antenna orientation of maximum response, or map an elliptically polarized field, or make separate measurements of three orthogonal electric field components.

Two different techniques are presently employed to fabricate an isolated rf probe. One uses a high resistance transmission line such as carbonimpregnated plastic to convey the detected antenna pickup to a high impedance, direct current (dc) readout meter [8]. This type of probe is generally used to map high level fields and search for possible rf hazards in the range of $l$ to $1000 \mathrm{~V} / \mathrm{m}$. In this case the total rf pickup, at all frequencies, is detected at the center of the dipole and no attempt is made to measure the amplitude as a function of frequency.

A second and newer technique for achieving electrical isolation between an (active) antenna and receiver makes use of a fiber-optic transmission link [9]. An earlier fiber-optic system [10 and 1l] uses an "optical transmitter" consisting of a single $48 \mathrm{~cm}$ dipole, rf amplifier, and light emitting diode (LED). The glass fiber "waveguide" is coupled to an "optical receiver," using a semiconductor photodiode or photomultiplier tube to detect the modulated infrared signal. A similar approach is used for the probe developed at the National Bureau of Standards (NBS). However, the NBS antenna uses three orthogonal dipoles to achieve an isotropic response. Also, the electronic package of each active dipole (rf amplifier, LED, battery, etc.) is contained entirely within the dipole. 
Isotropic probes have been employed in the past, but only for measuring intense fields. The rf sensors consist of 3 mutually-orthogonal dipoles and their associated detectors. The sensitive antenna described in this paper represents a different design philosophy in which both the amplitude and frequency information are preserved, and phase information could be recovered if desired. This contrasts with the usual type of "hazard" probe in which only the amplitude (energy density) is measured.

\subsection{Objectives of the ECOM/NBS Contract}

The overall objective of this project sponsored by the U.S. Army Electronics Command (ECOM) is to develop a broadband, isotropic receiving antenna with high sensitivity for measuring weak rf emanations from electronic equipment in a screen-room environment. The frequency range of interest is $15 \mathrm{kHz}$ to $200 \mathrm{MHz}$. In order to avoid the large ambient fields of radio and TV stations at a field site, it is often necessary to make these tests inside a shielded enclosure. The antenna should thus permit measurement of the absolute magnitude of weak "leakage" fields having arbitrary polarization. Also, it is desired that the antenna system be compatible for use with a conventional field intensity meter (FIM) so as to measure level vs. frequency.

The limits for REO2 narrowband electric-field (E) emissions are specified in MIL-STD-461 [12 and 13]. The desired measurement sensitivity for the receiver system is given by figure 21 of MIL-STL-461A or figure 10 of MIL-STD-416B, reproduced here as figure 2. As shown, the specified limit of radiated field strength varies with frequency, being most stringent at $25 \mathrm{MHz}$ where it is $10 \mu \mathrm{V} / \mathrm{m}$ or $20 \mathrm{~dB}$ above $1 \mu \mathrm{V} / \mathrm{m}(20 \mathrm{~dB} \mu \mathrm{V} / \mathrm{m})$. The limit at $15 \mathrm{kHz}$ (low frequency end of spectrum) is $35 \mathrm{~dB} \mu \mathrm{V} / \mathrm{m}$ and at $200 \mathrm{MHz}$ (high frequency end) is $34 \mathrm{~dB} \mu \mathrm{V} / \mathrm{m}$. Thus, one important objective is to design an isolated antenna with sufficient sensitivity to measure these low field levels.

A typical test setup for measuring radiated emission according to MILSTD-461 uses a vertical monopole antenna above a small horizontal ground plane. The vertical whip is placed one meter from the equipment under test (EUT). This specified distance is in the near zone of the EUT source (< $1 \lambda$ ) for frequencies below $200 \mathrm{MHz}$. The resulting wave impedance is thus not necessarily $377 \Omega$, the field polarization is not necessarily vertical, and the perturbing effects of the antenna or coax cables are unknown. The pickup antenna developed at NBS is an attempt to reduce these problems. It uses three mutually-orthogonal balanced dipoles as an isotropic field sensor. Each dipole has a length of $31 \mathrm{~cm}$ and a diameter of $3.5 \mathrm{~cm}$. 
Some characteristics of an ideal antenna for surveying near-zone electric fields can be listed as follows:

(1) Isotropic sensor -- The E field response should be independent of angular orientation and field polarization.

(2) Isolated sensor -- The antenna should not require a conducting transmission line. If a transmission line is used, it should be "invisible" to avoid perturbation of the rf field being measured. (The NBS probe uses a glass fiber line to convey information between the antenna and receiver.)

(3) Broad bandwidth -- The sensor should cover a large frequency range with no required tuning.

(4) Flat response -- The antenna factor should be independent of the signal frequency to be monitored.

(5) Small sensor -- The probe sensor should be small in order to minimize scattering. If dipoles are used, they should be electrically short rather than resonant, thus not requiring adjustment of length. ( $A$ $31 \mathrm{~cm}$ dipole is "short" up to about $200 \mathrm{MHz}$.)

(6) High sensitivity -- The antenna response should be adequate to measure the very weak radiated fields specified in MII-STD-461, that is, field strength as low as $10 \mu \mathrm{V} / \mathrm{m}$.

(7) Low noise response -- The internal noise of the active antenna should be low because the ultimate sensitivity is controlled by signal-to-noise ratio rather than by the amplifier gain.

(8) Large dynamic range -- The active antenna should have a wide range between the weakest measurable field and the strongest field with acceptable overloading.

(9) Fast response time -- The overall response time of the receiver system should be short, permitting rapid spatial probing and rapid frequency scanning. (The NBS-designed system is quite slow due to the long response time of the EMI receiver used.)

(10) Good stability -- The measurement system should be stable with respect to both time and environmental conditions.

In addition to the characteristics listed above, it is desirable that the sensor measure a scalar rather than a vector quantity. This is inherent in the concept of an isotropic probe. The meter indication of the measurement system designed at NBS is a quantity known as the Hermitian magnitude of the electric field, defined in section 2 . 


\section{TECHNICAL APPROACH}

The approach used for the sensitive isotropic probe is shown in the block diagram of figure 3. The frequency range is $15 \mathrm{kHz}$ to about $200 \mathrm{MHz}$. Each separate dipole of the isotropic antenna is electrically short (rather than self resonant) in order to achieve a large bandwidth. A field effect transistor (FET) is used for the input stage in each highly-reactive dipole. All signal frequencies induced in each dipole are amplified by a broadband amplifier and applied to a forward-biased LED. The resulting rf-modulated infrared emissions from the three LED's are transmitted via glass fiber lines to photodetectors in an electronic instrumentation package located near the antenna-input terminal of a conventional EMI receiver. The small antenna package and fiber-optic guides do not significantly perturb the field being measured.

The equivalent circuit of each pickup dipole is essentially a voltage source in series with a capacitance. The induced open-circuit voltage (Voc) is approximately equal to the product of the field strength $\mathrm{E}$ and the halfdipole length. In other words, at frequencies up to $200 \mathrm{MHz}$ :

$$
V_{O C}=E L_{\text {eff }} \cong E \frac{L_{a}}{2}
$$

where: $L_{\text {eff }}=$ Effective length of each dipole

$\mathrm{L}_{\mathrm{a}}=$ Physical length of each dipole.

The actual input level $\left(\mathrm{V}_{\text {in }}\right)$ to the FET rf amplifier is reduced by a capacitive voltage-divider effect, as given by the equation:

$$
v_{\text {in }} \cong v_{o c}\left(\frac{c_{a}}{c_{a}+c_{g}+c_{i}}\right)=v_{o c}\left(\frac{c_{a}}{c_{a}+c_{s}}\right)
$$

where: $\quad c_{a}=$ Effective antenna source capacitance $\cong 3 \mathrm{pF}$

$\mathrm{C}_{\mathrm{g}}=$ Stray capacitance at the center gap of the dipole $\cong 1 \mathrm{pF}$

$C_{i}=$ Input capacitance of the FET stage $\cong 2 \mathrm{pF}$

$c_{s}=$ Total shunt capacitance $=C_{g}+c_{i} \cong 3 \mathrm{pF}$.

The isotropic field sensor consists of three mutually-orthogonal dipoles, each $31 \mathrm{~cm}$ long, with approximately a common center. Because the induced signal currents are at right angles to each other, the dipoles respond independently to the impressed field. That is, the current on one dipole does not induce an unbalanced potential across the gaps of the other two dipoles. The induced voltages developed across the center gaps of the individual dipoles are given by:

$$
V_{x}=E_{x} L_{\text {eff }}, \quad V_{y}=E_{y} L_{\text {eff }} \text { and } V_{z}=E_{z} L_{\text {eff }}
$$


where $E_{X}, E_{Y}$, and $E_{z}$ are the amplitudes of the E-field components along the three orthogonal dipoles. An effective field strength magnitude |E| can be defined as the root-sum-of-squares (RSS) value of electric field according to the equation

$$
|E|=\sqrt{E_{x}^{2}+E_{y}^{2}+E_{z}^{2}}
$$

The scalar quantity $|E|$ is known as the Hermitian magnitude of the electric field. It is proportional to the square root of the electric-field energy density at the measurement point. Each dipole of the isotropic probe must be calibrated in a known "standard" field. The induced voltages from the three dipoles are processed electronically according to eq. (4).

Since a good E-field sensor must be able to measure close to a source or scattering surface without perturbing the field, it is necessary that the scattering from the probe be small. This criterion is satisfied by an antenna made of electrically-short dipoles. It has been shown experimentally [14] and theoretically [15] that the scattering cross section of a dipole decreases rapidly as the length decreases below $1 / 2$ wavelength. A $31 \mathrm{~cm}$ dipole, which is self resonant at about $500 \mathrm{MHz}$, can therefore be used at all frequencies of interest in this project.

A sketch of each untuned, broadband, receiving dipole is shown as follows:

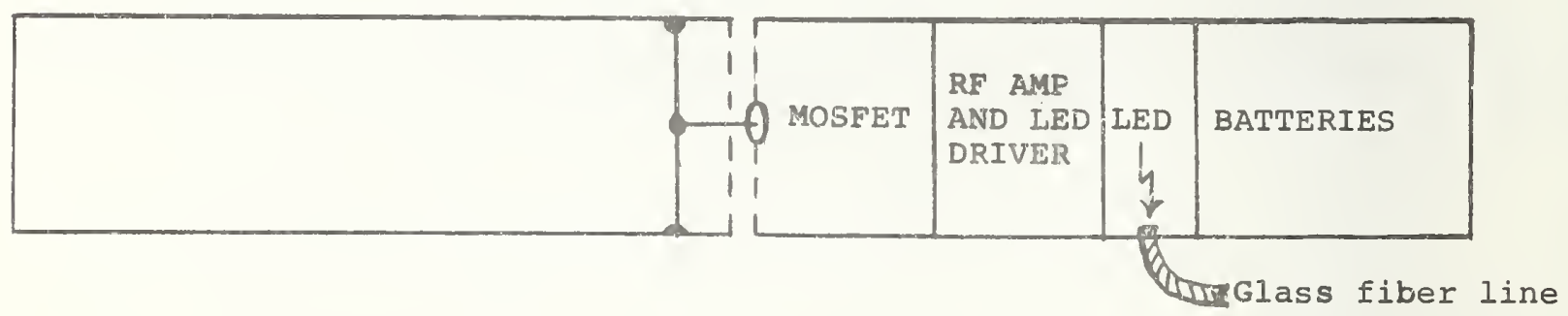

Figure 3 on page 43 is a block diagram of the isotropic-antenna receiving system. The received signal for each of the three channels is timemultiplexed by an rf switch at the antenna input of the conventional EMI receiver. The dc outputs from the receiver (synchronized with the rf input switch) are processed to give a dc voltage proportional to the Hermitian magnitude of the field. This voltage is used to drive a field-strength readout meter which is separate from the regular meter of the EMI receiver.

The sensitivity requirements for measuring field strength specified in MIL-STD-461/462 are shown in figure 2. These field limits, plus the resulting requirements for measuring antenna voltage, are listed in table 1 for several frequencies. 


\subsection{Discussion of Infrared Fiber Optics}

The type of electrically-isolated isotropic antenna described in this report depends for its success on using a fiber-optic link between the pickup antenna and receiver. This approach is relatively new for EMI antennas. A discussion of infrared fiber optics is therefore included early in this report.

\subsubsection{System Considerations [16 to 22]}

The building blocks for one type of active antenna system with fiberoptic link are shown in figure 3. The basic components are: pickup antenna, rf amplifier, optical source and means to modulate this source with the rf signal, fiber transmission line, and a photodetector at the receiver to recover the rf modulation. Table 2 lists some of the advantages of using an optical link between the antenna and receiver. At the present state-of-theart there are some disadvantages to fiber-optic commuications, and these are also listed in table 2. However, opto-electronic systems are receiving considerable attention for various uses and a few of these proposed applications are listed in table 2, including isolated links to EMI antennas.

It could be mentioned that as the "carrier" frequency increases, the usable modulation band also increases. An infrared (IR) carrier is thus theoretically capable of transmitting a huge signal bandwidth. Also, when using fiber-optic lines, the transmission loss is independent of the rf modulation frequency. This is because the modulation frequency is such a small percentage of the carrier (IR) frequency. By contrast, the attenuation in coaxial cable increases rapidly as the frequency increases. For example, the attenuation of rf signals in a 10 meter length of $R G-8 \mathrm{~A} / \mathrm{U}$ coaxial cable is about $0.05 \mathrm{~dB}$ at $1 \mathrm{MHz}$ and $2.5 \mathrm{~dB}$ at $1 \mathrm{GHz}$.

\subsubsection{Infrared Sources [23]}

A good IR source for use in an isolated antenna system is a semiconductor light emitting diode. An LED emits radiation through the mechanism of electron-hole recombination in the PN junction region. Figure 4 shows typical emission spectra of IR LED and laser sources, comparing them with the response curves of silicon photodetectors and the human eye. Note that 1 micron $=1$ micrometer $=1000$ nanometers $=10,000$ angstrom units. 
Gaseous lasers are also being used for optical communications, but they generally have high cost, large size, short life, and large voltage and power requirements. In addition, they cannot be modulated easily or directly. Therefore, an LED is considered the optimum source for a fiber-optic system, especially if it must be battery operated and contained inside a small rf probe. Gallium Arsenide (GaAs) is the oldest and most highly developed semiconductor material used for LED's.

At the beginning of the NBS ECOM contract in mid 1974, two types of solid-state laser diodes had been described in the literature, but were not available commercially. One type (neodymium-doped yttrium aluminum garnet) required an intricate external modulator, which precluded its use in an isolated antenna. The other type (single heterostructure gallium arsenide) could not operate continuously at room temperatures. In the past, semiconductor laser diodes were not able to produce coherent continuous-wave (CW) radiation except at liquid nitrogen temperatures. At room temperature they were limited to pulse-type operation because of internal heating. Very recently, however, $C W$ injection laser diodes for room temperature operation have been announced (double heterostructure gallium aluminum arsenide).

Some of these have been received for testing at NBS. However, they were not available in time for use in this project. Also, the battery current requirement for laser operation is high, and the lifetime is unpredictable and relatively short.

Above the lasing threshold of a GaAs diode, there is a steep rise in the IR output and thus much higher efficiency. In the remainder of this report a diode operated above this threshold will be referred to as a "laser diode," and a sub-iaser diode will simply be called an LED.' The term efficiency as applied to an optoelectronic emitter is defined as follows:

$$
\text { Power conversion efficiency }=\frac{\text { Optical power output }}{\text { Electrical power input }} \text {. }
$$

An ordinary LED has low efficiency according to the above definition, typically about 18. Also, as indicated in figure 4, the spectral line of an LED is relatively broad, typically about $35 \mathrm{~nm}$ for an LED and about $2 \mathrm{~nm}$ for a laser diode. This causes velocity spread in a long transmission line and thus limits the maximum usable modulation frequency. In addition, an LED radiates into a larger solid angle than a laser diode. The radiation angle is typically about $30^{\circ}$, making it difficult to focus or couple the IR radiation into a propagating mode of the glass filament. The coupling loss into a fiber is about $15 \mathrm{~dB}$ greater for an LED than for a laser diode. Also, laser diodes are inherently much faster than LED's, permitting higher modulation frequencies. The maximum theoretical overall efficiency of an (LED/glass fiber/photodiode) system is about 0.0001 , or a reduction in carrier power of about $40 \mathrm{~dB}$. 
One major advantage of the LED source is that it can be modulated directly and easily by varying the forward current through the diode. No external modulator is required; the rf signal is simply superimposed on the dc "bias" current. As indicated in figure 5, the intensity of the IR radiation is proportional to the LED drive current. When the rf signal is larger than the dc bias, severe clipping results. An increase in drive current then produces only a small increase in radiation intensity. This point of non-linearity is the upper limit of the dynamic range for the transmission system.

Table 4 gives the characteristics of a few commercially-available highspeed LED's. These values are the CW specifications according to the manufacturers' literature.

\subsubsection{Fiber Transmission Lines [24, 25 and 26]}

The transmission of light inside a fiber is by a process of mu?tiple internal reflections. The maximum angle for total internal reflection is given by Snell's law of refraction. The numerical aperture (NA) of a fiber guide is a measure of the acceptance cone of radiation into the end of the guide from an external source. The larger it is, the greater is the fraction of light trapped inside the fiber guide. (NA) is defined as the sine of the critical angle $\theta_{c}$, the maximum acceptance angle between the ray and the fiber axis. It is given by:

$$
(N A)=\sin \theta_{C}=\sqrt{\left(n_{2}\right)^{2}-\left(n_{1}\right)^{2}}
$$

where: $\mathrm{n}_{2}=$ Index of refraction of the core material

$\mathrm{n}_{1}$ = Index of refraction of the cladding.

Similar to rf waveguides, an optical fiber can propagate either in a single mode (if the diameter is small enough) or in many modes. A typical single-mode fiber for IR wavelengths has a core diameter of about $2 \mu \mathrm{m}$. As indicated in [17-26], this type of fiber has the lowest loss. However, the small core size makes it difficult to couple energy into the fiber and only coherent laser sources are coupled efficiently.

Multimode fibers have a core diameter of about $100 \mathrm{\mu m}$. This permits easier coupling to less expensive sources such as LED's. However, the number of propagating modes increases as the (NA) and fiber diameter increase. The different modes propagate with different velocities, causing dispersion of the signal and a lower possible modulation frequency. In spite of this limitation, large multimode fibers appear to be the optimum guide for use with an LED source, especially for short transmission lines such as those used between an antenna and EMI receiver. The typical coupling loss between an LED and a fiber bundle is 20 to $25 \mathrm{~dB}$. 


\subsubsection{Infrared Photodetectors}

Demodulation of an IR signal carried in a fiber waveguide can be accomplished with either a photomultiplier tube (PMT) or a semiconductor photodetector. Both types were evaluated in this project. The detector chosen is a silicon avalanche photodiode (APD). This type of semiconductor photodiode is operated with a high reverse bias voltage. As the bias approaches the breakdown voltage, hole-electron pairs created by the absorbed IR photons generate additional pairs by avalanche multiplication. This process is similar to electron multiplication in a photomultiplier tube; that is, an APD is the solid-state equivalent of a PMT. The avalanche effect produces a multiplication factor (current gain) up to about 100 . For linear operation the output current must be proportional to the input IR power.

The APD multiplication process also creates additional noise, mainly shot noise. There is an optimum reverse bias voltage (or APD current) which results in sufficient gain and highest signal-to-noise ratio. This optimum value must be determined experimentally for each length and type of fiber guide, and for each set of operating conditions. Table 5 gives the characteristics of a few commercially available photodetectors, according to the manufacturers' specifications.

\subsection{Tests of Fiber-Optic Components}

Initial experimental work dealt with evaluation of the opto-electronic components required in the infrared link between the antenna package and EMI receiver. One commercially available LED appeared to be the most promising on the basis of a published risetime of $1 \mathrm{~ns}$, which is equivalent to a $350 \mathrm{MHz}$ bandwidth. However, the fastest measured risetime was $12 \mathrm{~ns}$ ( $30 \mathrm{MHz}$ ) for this LED. The test setup consisted of a $1 \mathrm{~ns}$ risetime pulse generator, a 150 ps avalanche photodiode, a 420 ps rf amplifier, and a 700 ps oscilloscope. The measurement system risetime was $1.3 \mathrm{~ns}$. The relationship between the 10-908 risetime $\left(T_{r}\right)$ and the $-3 \mathrm{~dB}$ bandwidth (BW) is given by the expression:

$$
\left(T_{Y}\right)(B W) \cong 0.35
$$

The optical output of an LED is quite weak, typically about $500 \mu w$ at a bias current of $50 \mathrm{~mA}$. Considerable rf amplification is required after the photodiode to observe the rf signal on an oscilloscope. The efficiency of an LED is quite low, typically $1 \%$ ( $\mathrm{m}$ w optical output/mw electrical input). Also, the output beam from an LED is broad, at least when compared to a laser. The $-3 \mathrm{~dB}$ beamwidth is typically $30^{\circ}$. A lens system was used in our early tests to focus the LED output onto the photodiode. 
Photodetectors from several manufacturers were evaluated for transient response using a mode-locked dye laser (30 ps risetime) or a pulsed GaAs laser diode (150 ps risetime). Several PIN photodiodes and avalanche photodiodes were tested. Both types produced good linearity for analog applications,but (in our system) the PIN diodes did not produce as good an overall noise figure as the APD's.

Also, a photomultiplier tube was compared with the solid-state avalanche photodiode. It had been reported in the literature that a PMT is capable of higher speed and sensitivity than an APD. For this reason a series of tests was made using a phototube which has maximum sensitivity near the desired wavelength of $0.9 \mathrm{~nm}$. We determined an optimum value of PMT anode current, which is a function of the PMT anode voltage and luminous flux. A current of $10 \mu \mathrm{A}$, produced by an anode voltage of $700 \mathrm{~V}$, gave the highest signal-tonoise ratio in our system. The PMT was able to sense a weaker infrared beam than the APD, but the speed and rf signa? sensitivity were greater (in our system and for our application) when using an APD. The experimental data are given in section 5.4 .

Silicon avalanche detectors are commercially available with gainbandwidth products up to $100 \mathrm{GHz}$. For an avalanche gain of 100, the attainable signal bandwidth is thus $1 \mathrm{GHz}$. It can be seen that photodiodes are not the limiting factor in achieving large bandwidth in a fiber-optic system. The upper usable erequency in our system appeared to be limited by the carrier lifetime of the LED. Heterodyne conversions employing an rf local oscillator inside the active dipole could perhaps be used to achieve higher effective signal frequencies; however, an experimental investigation of this approach was not pursued.

Measurements were made of the frequency response of 17 LED's and 1 laser diode operated as an incoherent LED. These were all different types from various manufacturers. A pulsed laser was used to evaluate the response time of 8 regular photodiodes, 6 PIN photodiodes and 4 avalanche photodiodes. The emitter/detector pair chosen for the NBS fiber-optic system is a spectrally matched IED/APD pair optimized by the manufacturer for a wavelength of 800 to $900 \mathrm{~nm}$.

The type of fiber bundle chosen consists of $19 \mathrm{glass}$ filaments packaged in a plastic jacket with a connector at each end, similar in appearance to a coaxial cable. The outer diameter of each coated filament is $135 \mathrm{\mu m}$, with a core diameter of $85 \mu \mathrm{m}$. The numerical aperture of the guide is approximately 0.14 , which means that the maximum acceptance angle is $\pm 8^{\circ}$ to the fiber axis. 
One problem in fiber-optics is the high attenuation of the optoelectronic portion of the system. Also, the risetime of all LED's tested was $>10 \mathrm{~ns}$, which limits the $-3 \mathrm{~dB}$ bandwidth to $35 \mathrm{MHz}$. Thus, considerable frequency compensation was required in the rf amplifier in order to achieve a system response up to $200 \mathrm{MHz}$. Considerable difficulty was also experienced in capturing the limited power radiated by the LED's. Using typical published values for GaAs LED's and silicon photodiodes, the theoretical minimum coupling loss between an LED and an APD is $40 \mathrm{~dB}$. For example, assume an LED efficiency of $1 \mathrm{~mW} / 50 \mathrm{~mA}$ current and a photodiode responsivity of $0.5 \mathrm{~mA} / \mathrm{mW}$. The maximum current transfer ratio for the LED/APD pair is

$$
I_{\text {out }} / I_{\text {in }}=\text { LED efficiency } \times \text { APD responsivity }=0.01 \text {, or }-40 \mathrm{~dB} \text {. }
$$

We were not able to achieve the above overall efficiency in practice. With both butt-joints between the LED and APD touching, or when using lenses on $X-Y-Z$ micrometers to focus the LED output on the APD, we experienced typical losses of 70 to $75 \mathrm{~dB}$. An optical power meter was assembled and calibrated at NBS in order to measure the power output coefficients during this development work.

Time-domain evaluations were made of several promising types of Si avalanche photodiodes. The first type of APD tested produced a small-signal avalanche gain of $16 \mathrm{~dB}$ with 330 volts of reverse bias. Its measured 10-908 risetime was $2.5 \mathrm{~ns}$, compared with a specified risetime of $2 \mathrm{~ns}$. This corresponds to a $-3 \mathrm{~dB}$ bandwidth of $140 \mathrm{MHz}$. It was found that infrared APD's are sensitive to stray radiation and must be kept shielded from ambient light during measurements on an optical bench.

The second type of APD evaluated was tested for photocurrent gain and internal random noise as a function of bias voltage and temperature, from $+10^{\circ} \mathrm{C}$ to $+50^{\circ} \mathrm{C}$. Figure 6 is a plot of the measured results at an ambient temperature of $28^{\circ} \mathrm{C}$. The gain and noise are both strongly dependent on temperature. With a regulated-voltage APD bias of 160 volts, the photocurrent gain (also called avalanche multiplication) ranged from $42 \mathrm{~dB}$ at $+10^{\circ} \mathrm{C}$ to $30 \mathrm{~dB}$ at $+50^{\circ} \mathrm{C}$. The optimum operating point for this particular APD (at room temperature) was at 160 volts. As shown in figure 6 , the output signal-to-noise ratio $(\mathrm{S} / \mathrm{N})$ for this condition is about $45 \mathrm{~dB}$.

\subsection{Measurements of Two Infrared Optoelectronic Links}

\subsubsection{Performance of a Radiated System}

An experimental infrared broadband transmission link was assembled and tested. Figure 7 is a block diagram of the system. The arrangement is similar to that of the final system, except that this first test did not use a fiber guide. The modulator for the LED is a low-current drain (10 mA) rf 
amplifier. The bandwidth of this first design was $60 \mathrm{MHz}$. The IR output from the LED was focused by lenses onto the photodiode. The detected signal was amplified by two wideband amplifiers and applied to the input terminal of a spectrum analyzer used as a sensitive rf voltmeter.

Figure 8 shows the input/output performance characteristics of the IR link for a signal frequency of $25 \mathrm{MHz}$. With a $100 \mathrm{~Hz}$ bandwidth the spectrum analyzer noise level was $-110 \mathrm{dBm}(0.7 \mu \mathrm{V})$ for a $10 \mathrm{~dB}(\mathrm{~S}+\mathrm{N}) / \mathrm{N}$ ratio. The upper limit for linear operation was about $-35 \mathrm{dBm}$ input. The overall attenuation of the rf signal in the IR link was $7 \mathrm{~dB}$ in this test. As seen in figure 8, the dynamic range achieved in this first test was $55 \mathrm{~dB}$, which was greater than anticipated. It should be noted, however, that a typical EMI receiver has a larger bandwidth than the $100 \mathrm{~Hz}$ used in this test. A bandwidth would reduce both the sensitivity and the dynamic range.

\subsubsection{Performance of a Fiber-Optic System}

The optimum wavelength to use for a fiber-optic system must be chosen on the basis of three considerations: (a) high source radiation, (b) low fiber absorption, and (c) high photodetector efficiency. The near IR portion of the electromagnetic spectrum ( 800 to $900 \mathrm{~nm}$ ) is a good choice for transmission in glass fibers. GaAs LED's have a peak output near $900 \mathrm{~nm}$ so this wavelength was chosen for our system.

The fiber waveguide chosen consists of a bundle of 19 filaments. The specified maximum attenuation in the guide is $0.03 \mathrm{~dB} / \mathrm{m}$, at a wavelength of $820 \mathrm{~nm}$. However, this low value of attenuation was not achieved in practice. Initial measurement of the bundle attenuation was $3.3 \mathrm{~dB}$ for a guide $10 \mathrm{~m}$ long, using a focused He-Ne laser beam. However, when using an LED the measured system loss was $28 \mathrm{~dB}$, for either an (LED/fiber) butt joint or with a set of focusing lenses. These measurements were made using an optical power meter. It should be emphasized that the major loss was not the attenuation within the fibers but was due to the difficulty of injecting the LED radiation into the fiber.

When passing an rf signal through an (LED/fiber/APD) link, the additional loss due to the waveguide was typically 45 to $50 \mathrm{~dB}$. The apparent discrepancy between the rf attenuation and the optical power measurements (28 dB above) is caused by the linear optical-power to electrical-current conversion by the APD. If the modulation current (rf signal) is passed through a load resistor, the power delivered to the load is proportional to the current squared. Thus a given $d B$ infrared power loss causes an output $r f$ signal power loss of double that number of $\mathrm{dB}$. 
The instrumentation used to measure the rf signal loss in a fiber-optic system is given in figure 9. The LED driver circuit was an emitter follower in series with a matching network. As shown in the simplified schematic, the matching network was a $40 \Omega$ resistor in parallel with a variable capacitor, which was tuned for maximum output. The maximum usable modulation frequency for an LED depends partially on the driver circuit's ability to supply charging current to the LED's capacitance. The input capacitance of highfrequency LED's is typically 100 to $1000 \mathrm{pF}$. Also, this capacitance is shunted by a low dynamic resistance of only a few ohms. One method to drive such a source would be by brute force, using a high-current, lowimpedance rf source. Another approach, a constant-current LED driver, was used in our system because it avoids the large dI/dt requirement for high frequency modulation.

Figure 10 gives the measured values of overall rf signal attenuation as a function of frequency. The minimum insertion loss, at low frequencies, was about $60 \mathrm{~dB}$ for the APD temperature and voltage used. As seen, the insertion loss increased rapidly for signal frequencies above $100 \mathrm{MHz}$. Accurate measurements above this frequency could not be made (in this system) because of signal leakage between the rf source and receiver.

\section{FIELD STRENGTH AND ANTENNA CALIBRATIONS}

\subsection{Discussion of Field Strength Meters}

A receiver used as a frequency-selective voltmeter is the keystone of any system for measuring field strength and interference. Figure ll is a block diagram of a typical FIM. It consists basically of a superheterodyne communications receiver with certain added features. The model EMC-25 receiver ${ }^{2}$ used for this project is a solid-state "interference analyzer" covering $14 \mathrm{kHz}$ to $1 \mathrm{GHz}$ in 15 tuning bands. There are three intermediate frequencies, depending on the tuning band in use. A multistage detection system with logarithmic response is incorporated in the IF amplifier section. This is done to achieve a readout scale which is Iinearly proportional to $\mathrm{dB}$ above $1 \mu \mathrm{V}$. The detector function used for sine-wave signals

\footnotetext{
${ }^{2}$ The overall fiber-optic antenna system described in this report was designed to be compatible with an EMC-25 type of field intensity meter. This type of receiver was chosen because it is a typical FIM and because it was available both at NBS and at the sponsoring agency. The use and identification of the receiver type number does not imply recommendation or endorsement by the National Bureau of standards, nor does it imply that the equipment identified is necessarily the best available for the purpose. Identification of the FIM type will, however, enable another experimenter to reproduce the equipment and results described in this report.
} 
has a nominal time constant of $600 \mathrm{~ms}$ for both. charge and discharge. A summary of the characteristics of the receiver for signal frequencies up to $200 \mathrm{MHz}$ is given in table 6 . The term "tangential sensitivity" used here is defined as the input signal level required to increase the meter reading by $3 \mathrm{~dB}$ above the receiver internal noise. Table 7 gives data on the measured values of receiver bandwidth.

As mentioned previously, a short dipole antenna acts as a voltage generator of high (capacitive) impedance having a pickup which is essentially independent of signal frequency. By contrast, the induced voltage of a self-resonant dipole is inversely proportional to frequency. ' In order to measure absolute field strength with a receiver (rf voltmeter), it is necessary to apply a multiplying factor to the dial indication. This conversion factor between the antenna pickup (volts) and the electric field strength (volts/meter) is known as the "antenna factor." Figure 12 shows the theoretically-anticipated value of antenna factor vs. frequency for a passive $\lambda / 2$ dipole. The factor for an active dipole must be determined experimentally by immersing it in a known (standard) field [27 and 28].

\subsection{Auxiliary Calibration of the Receiver as a}

Tunable rf Voltmeter

The first phase in calibrating a receiver to measure field strength is to adjust the gain control setting, at the frequency of interest, in terms of a known sine-wave voltage. This is comonly referred to as "calibration" of the FIM as a tunable or frequency-selective rf voltmeter. Figure 13 is a block diagram of the instrumentation used for this project. The technique shown employs a special I-pad with 50 ohms input resistance and a very low output resistance. This attenuator pad has 57 dB insertion loss and consists of a selected $49.95 \Omega$ series resistor and a $0.071 \Omega$ annular-ring resistor in shunt with the output terminal. It is housed in a coaxial chamber I inch long, with $50 \Omega$ characteristic impedance, and has a type $N$ connector at each end. For each voltage calibration the output level of the signal generator is adjusted to obtain a power meter reading (accuracy of $\pm 1 \%$ ) of $100 \mu \mathrm{W}$. This produces a $100 \mu \mathrm{V}$ signal at the receiver input.

The $0.071 \Omega$ resistor in figure 13 supplies a known voltage to the receiver which is essentially independent of variations in receiver input impedance. For example, assume the use of a receiver with nominal $50 \Omega$ input but having an actual input VSWR of 2:1. The maximum possible variation of receiver input voltage under these conditions would be 0.017 dB or $0.2 \%$. By comparison, the receiver input voltage could be in error by as much as $3.52 \mathrm{~dB}$, or $50 \%$, if a $50 \Omega$ generator is used directly as the receiver "voltage" source. 
Figure 14 is a graph showing the measured non-linearity of the particular receiver we used. It can be seen that the dial indication has a variation from true voltage level which exceeds $2 \mathrm{~dB}$ at some points. These corrections to the indicated values must be made manually in order to obtain more accurate measurements of $\mathrm{CW}$ voltage and field strength.

\subsection{Standard Field Setup Used to Calibrate the Active Antenna}

Initial tests of the $31 \mathrm{~cm}$ active dipole were made at a frequency of $25 \mathrm{MHz}$. Figure 15 shows the instrumentation used to establish a known electric field for calibrating the active dipole. The antenna factor and system sensitivity for the antenna under test were determined by immersing the dipole in the standard field of a transverse electromagnetic (TEM) cell [29]. This cell consists of a large "coaxial" $50 \Omega$ transmission line in which the center conductor is a flat metal strip and the outer (grounded) conductor has a rectangular cross section. The TEM line we used (see figure 16) is about $3 \mathrm{~m}$ long and has a square $1.2 \mathrm{~m} \times 1.2 \mathrm{~m}$ cross section. At frequencies sufficiently low so that only the principal wave (TEM mode) will propagate through the cell, a fairly uniform and calculable E field can be established. The electric field at these frequencies, at the location shown in figure 15, is given by:

$$
E=\frac{\text { Voltage }}{\text { Distance }}=\frac{\sqrt{50 \mathrm{P}}}{\mathrm{D}}
$$

where: $E=$ Field strength, volts/meter

50 = Characteristic impedance of the cell

50 = Resistance of the cell termination, ohms

$\mathrm{P}=$ Measured power through the cell, watts

$\mathrm{D}=$ Distance between the center conductor and top of the cell, meters.

The $1.2 \mathrm{~m} \times 1.2 \mathrm{~m}$ TEM cell exhibited cavity-mode resonances at frequencies above $140 \mathrm{MHz}$. This is similar to the well-known resonances occurring in shielded rooms. In order to calibrate the active dipole at frequencies above $140 \mathrm{MHz}$ it was necessary to measure the field strength inside the cell with a small (10 cm) transfer probe, which in turn had been calibrated previously in a smaller TEM cell. The signal frequency vs. cell power required to produce a field level of $0.1 \mathrm{~V} / \mathrm{m}$ was measured for a larger test probe having the same dimensions as the $31 \mathrm{~cm}$ active dipole. Corrections were thus made for field perturbations caused by the larger probe. The high $Q$ of the TEM cell for higher order modes was reduced by placing several pieces of $r f$ absorber in the bottom half of the cell. All subsequent 
tests of the active dipole sensitivity were made in this improved test chamber. It is felt that standard fields for calibrating the 31 cm active dipole were produced with an uncertainty less than $\pm 1 \mathrm{~dB}$ at any Irequency up to $100 \mathrm{MHz}$ and $\pm 2 \mathrm{~dB}$ from 100 to $200 \mathrm{MHz}$.

\section{DESIGN OF A SINGLE-DIPOLE FIBER-OPTIC ACTIVE ANTENNA}

\subsection{Description of the Dipole Unit and APD Circuit}

Physically each dipole antenna consists of two identical brass tubes $15.25 \mathrm{~cm}$ ( 6 inches) long and $3.5 \mathrm{~cm}$ in diameter, with a $0.5 \mathrm{~cm}$ gap at the center of the dipole. The overall dipole length is thus $31 \mathrm{~cm}$. The rf amplifier, LED, fiber waveguide connector and battery all fit within one of the brass tubes. The second tube serves as the opposing half of the dipole antenna. The amplifier construction features microstrip and ground plane techniques to achieve wideband response in the rf amplifier and LED driver circuitry.

The rf amplifier and FET-input stage, as originally designed, had one major problem. The unit was small enough, but the circuit required 15 volts at $60 \mathrm{~mA}$, an excessive battery consumption. The antenna circuit was then redesigned and now requires $30 \mathrm{~mA}$ at 9 volts, supplied by a Nicd rechargeable battery. Figure 17 gives a schematic diagram of the final circuit. The rf amplifier features a diode-protected MOS FET front end, Q 1. The input impedance presented to the antenna is 10 megohms resistance shunted by $3 \mathrm{pF}$ capacitance. The amplifier has a $-3 \mathrm{~dB}$ bandwidth of $170 \mathrm{MHz}$ and nominal gain of $60 \mathrm{~dB}$.

Figure 18 shows an equivalent circuit of the active dipole antenna. It is similar to that discussed in section 2, but includes an effective noise generator at the amplifier input. At frequencies below $200 \mathrm{MHz}$ the source impedance $\mathrm{z}_{\mathrm{a}}$ is given approximately by the reactance of a $3 \mathrm{pF}$ capacitor. I'his capacitance value was determined experimentally by mounting half of the dipole unit as a monopole above an extended ground plane. The measured capacitance was $5.4 \mathrm{pF}$, corresponding to a dipole source capacitance of half this value, or $2.7 \mathrm{pF}$. The nominal $3 \mathrm{pF}$ value was also verified approximately by several theoretical calculations of dipole input imepedance. The shunt capacitance $\mathrm{C}_{\mathrm{s}}$ of about $3 \mathrm{pF}$ was determined by adding capacitance at the antenna gap until the pickup voltage in an rf field was reduced by a factor of two.

The APD required specially designed auxiliary circuits and power supply. Figure 19 gives a simplified schematic diagram. The circuitry provides temperature compensation of the APD avalanche voltage, which helps stabilize the APD gain. As shown in the figure, the temperature reference diode is 
thermally connected to the APD by physically mounting the two components on a common heat sink. The APD bias voltage (and hence its avalanche gain) are adjustable. A crowbar circuit is included in the power supply to protect the APD, since if too much light is applied to the APD and/or the bias voltage is too high, the APD current will exceed its maximum permissible value. The APD current is sensed across the $1 \mathrm{k} \Omega$ output resistor and applied to the 741 operational amplifier (op. amp.) connected as a voltage comparator. If the current exceeds a preset value, the crow-bar transistor Q 3 turns off the high voltage bias supply. The circuit automatically resets when the overload is removed.

\subsection{Preliminary Tests of the Active Dipole System}

Figure 20 gives a block diagram of the prototype antenna system including the active dipole circuitry, LED, fiber guide and APD. An oscilloscope was used to observe the step response and operation of the system. The test signal (CW or step) was applied across a $50 \Omega$ termination at the dipole gap. Table 8 lists the system gain and signal-to-noise (S/N) ratio for several frequencies as measured with a spectrum analyzer.

The $31 \mathrm{~cm}$ active dipole antenna was then used to pick up rf fields in the laboratory. Figure 21 shows the spectrum from dc to $200 \mathrm{MHz}$ as received by the active antenna system. The lower white band is the system noise. The antenna system has also been demonstrated to receive TV signals from broadcast stations, as shown by the photographs of a TV screen in figure 22.

\subsection{Effects of Noise and Receiver Bandwidth on Sensitivity [30 and 31]}

Adequate performance of the infrared (LED/fiber guide/APD) system requires a combination of high sensitivity, low noise, and large antenna bandwidth. One of the most important requirements of any active antenna system is that the $S / N$ ratio should not be degraded excessively between the rf pickup and the FIM. The FET input stage, rf amplifier and the process of converting to IR and back to rf should all maintain a high $\mathrm{S} / \mathrm{N}$ ratio. In other words, the sensitivity and reception characteristics depend on the noise figure of the overall system. The $S / N$ ratio must also be considered as a major criterion when determining the FIM receiver bandwidth that can be used. This is due to the fact that the random noise power received by an FIM is proportional to the receiver bandwidth.

The measured value of sensitivity for any receiving system depends on the definition or criterion used. One common term for receiver sensitivity is "minimum discernible signal" level (MDS), generally defined as the signal required to produce a receiver indication $0.5 \mathrm{~dB}$ above the background noise. 
In this contract we chose to use a more conservative and more precisely measurable criterion known as "tangential sensitivity." It is defined as the field intensity required to increase the receiver indication 3 dB above the background noise level, or $(S+N) / N=3 \mathrm{~dB}$.

In general, noise is defined as any unwanted disturbance which is superimposed on the desired signal. In this report the term noise is used for voltages which vary randomly in amplitude and phase, and which are present over a wider frequency band than the resolution bandwidth of the receiver. Therefore, the response of a receiver (or spectrum analyzer) depends on the resolution bandwidth used. Doubling the measurenent bandwidth doubles the noise power accepted, which increases the receiver voltage indication by a factor of $\sqrt{2}$.

The maximum attainable sensitivity of any receiving system for narrowband signals is controlled by the signal-to-noise ratio. Since the noise contribution of an (LED/fiber guide/APD) system is greater than that of the rf amplifier, our approach was to minimize the noise in the optoelectronics and use the lowest possible receiver bandwidth. The noise problem in a fiber-optic antenna system is severe compared with a conventional antenna and receiver. The pickup antenna is intentionally broadband, to avoid tuning or adjustment, and has a large mismatch to the rf amplifier. This produces both a large noise pickup and a low signal level. In addition, the optoelectronic link causes a large attenuation (requiring further rf amplification) and a major addition to the random noise. Since the overall sensitivity is ultimately limited by noise, no amount of receiver gain can improve the sensitivity.

One method to obtain additional receiver selectivity at signal frequencies above $25 \mathrm{MHz}$, and thus higher tangential sersitivity, would be to use the "Q-fiver" technique familiar to radio amateurs. This involves loose coupling of the If output of the conventional receiver to the antenna input terminal of another receiver with low intermediate frequency and narrow bandwidth. This technique of using narrow bandwidth to achieve high receiver sensitivity causes tuning inconvenience and does not apply to the measurement of broadband signals. For example, the impulse response voltage of a receiver as measured with a peak detector is directly proportional to the receiver bandwidth. Thus high sensitivity for impulsive signals (and ease of tuning for $\mathrm{CW}$ signals) is achieved by using a wide receiver bandwidth. The EMC-25 receiver is furnished with two selectable bandwidths labeled on the front panel as "narrow" and "wide." The former may be used for measuring $C W$ signals and the latter for measuring noise and interference. 


\subsection{Measurements of the System Sensitivity}

\subsubsection{Sensitivity of the Active Dipole}

Table 9 gives a summary of the measured sensitivity for the (dipole/ receiver) system at $25 \mathrm{MHz}$. It can be seen that $\mathrm{CW}$ sensitivity is a function of receiver bandwidth, dipole gap width, level of APD current, and the criterion used to define the term "sensitivity." On the basis of tangential sensitivity, using the EMC-25 receiver on narrowband selectivity, the active dipole developed at NBS meets the desired MIL-STD-461 specifications at $25 \mathrm{MHz}$ if the receiver is on Band 10. The measured tangential sensitivity for a $0.5 \mathrm{~cm}$ dipole gap was $9 \mu \mathrm{V} / \mathrm{m}$ and the required sensitivity is $10 \mu \mathrm{V} / \mathrm{m}$. However, if the receiver is tuned to $25 \mathrm{MHz}$ on Band 11 instead of Band 10, the tangential sensitivity is $23 \mu \mathrm{V} / \mathrm{m}$ which fails to meet the specification by $7 \mathrm{~dB}$.

It appears from the data of table 9 that $50 \mu \mathrm{A}$ is about the optimum value of APD current when using the $2 \mathrm{~m}$ fiber guide. Also, it can be seen by comparing the last of two conditions in table 9 that it is not necessary (or helpful) to use an extra rf amplifier between the APD and the FIM. As noted previously, the MDS level could not be measured as precisely as the other three criteria and was therefore not used. The last column of table 9 gives data on the measured threshold noise level of the receiver. It shows the increase in noise floor caused by the fiber-optic system.

All of the sensitivity measurements in the remainder of this report are for a dipole gap width of $0.5 \mathrm{~cm}$. Also, the remainder of the data were taken with the receiver switched to the narrowband position.

A series of measurements was made with the $31 \mathrm{~cm}$ active dipole to determine the system sensitivity as a function of signal frequency. Several criteria of sensitivity were used, varying from the MDS level to a signal $20 \mathrm{~dB}$ above the noise level. A summary of the data is shown in figure 23. For comparison purposes, similar measurements of system sensitivity were taken using a photomultiplier tube (PMT) instead of the APD. Figure 24 is a graph of the data (PMT vs. APD) for the case of tangential sensitivity.

The electronic circuitry of the rf amplifier in the antenna was optimized in an attempt to increase the sensitivity at frequencies above $25 \mathrm{MHz}$, while maintaining good performance at frequencies below $25 \mathrm{MHz}$. The circuit design includes frequency compensation to overcome some of the amplitude rolloff at frequencies above $100 \mathrm{MHz}$. This rolloff is caused mainly by frequency limitations of the LED. Figure 25 is a graph summarizing the measured sensitivity of the system after optimizing the rf amplifier. As can be seen, the sensitivity was improved significantly at frequencies between 25 and $150 \mathrm{MHz}$. The abrupt changes in sensitivity at signal frequencies of $2.3 \mathrm{MHz}$ and $25 \mathrm{MHz}$ are readily apparent; they are due to step changes in the receiver bandwidth. 
In the remainder of this report the only criterion used for system sensitivity is "tangential sensitivity," the E field required to produce a receiver indication $3 \mathrm{~dB}$ above the noise. Using this criterion, the antenna system developed at NBS (with an EMC-25 receiver) meets the specifications of MIL-STD-461 for all frequencies from $20 \mathrm{kHz}$ up to $25 \mathrm{MHz}$. As seen in figure 25, the sensitivity is slightly low at frequencies between $25^{\circ}$ and $50 \mathrm{MHz}$ and at frequencies above $100 \mathrm{MHz}$.

The antenna data in the remainder of this report are for an improved type of fiber guide 10 meters long, whereas a $2 \mathrm{~m}$ guide of less expensive material was used for all of the previous data. The loss of optical energy in the longer guide changed the antenna factor and caused a slight deterioration in the system tangential sensitivity. The relative loss was greater at the lower signal frequencies. Before taking quantitative data, the connectors at both ends of the fiber guides were adjusted until maximum IR transmission was achieved. This condition of maximum transmission is easily determined experimentally because it corresponds with maximum indication of APD current on the panel meter.

\subsubsection{Effect of Using an Antenna Resonating Inductor}

Antenna resonance can be used to produce a significant improvement in the system sensitivity at frequencies near resonance. A broadly resonant dipole can be obtained by connecting a low-Q coil across the center gap of the dipole. Theory indicated that a parallel inductor would boost the sensitivity over a frequency band of about one octave. No inductor would be used at frequencies below $25 \mathrm{MHz}$, or whenever the added sensitivity is not required. The following sketch shows the equivalent circuit for an electricallyshort dipole with an inductor connected across the center gap.

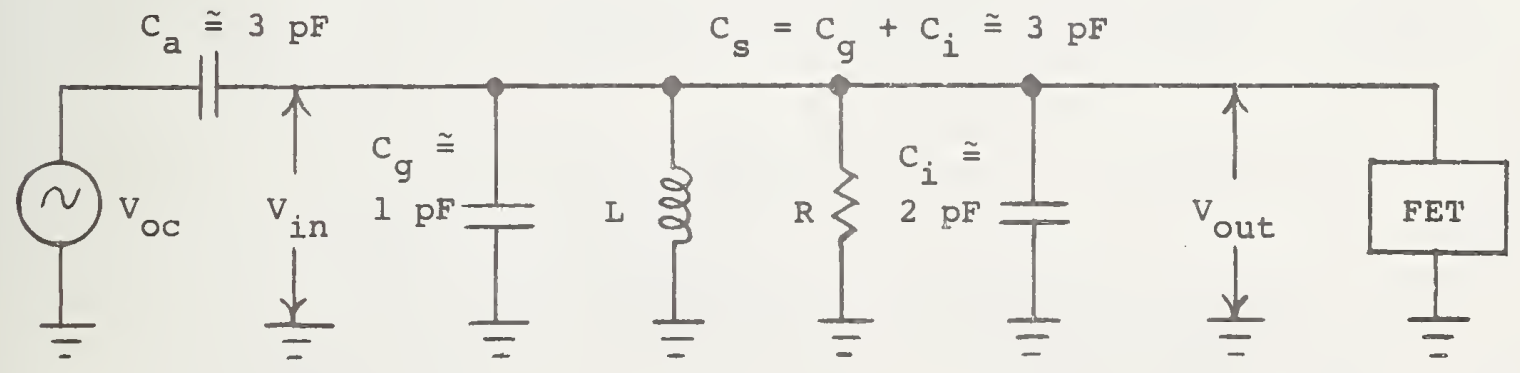


Equations for calculating the insertion loss due to the parallel coil are given by:

$$
\begin{aligned}
& \text { Insertion loss, } \mathrm{aB}=20 \log \left(\frac{\mathrm{V}_{\text {oC }}}{\mathrm{V}_{\text {out }}}\right)-6 \\
& \frac{\mathrm{V}_{\text {OC }}}{\mathrm{V}_{\text {out }}}=\sqrt{\left(2-\frac{\mathrm{x}_{\mathrm{C}}}{\mathrm{x}_{\mathrm{I}}}\right)^{2}+\left(\frac{\mathrm{x}}{\mathrm{R}}\right)^{2}}
\end{aligned}
$$

where: $\quad c \equiv c_{a}=c_{s} \cong 3 \mathrm{pF}$ (see eq. 2)

$L=$ Inductor connected across the antenna gap

$\mathrm{R}=$ Resistor connected across the antenna gap.

Figure 26 is a plot of the calculated gain for a $7 \mu H$ coil, for four values of coil Q. Figure 27 gives actual measurements of system sensitivity vs. frequency for the three inductors chosen. As can be seen, the 23 turn toroid produces sufficient improvement near $25 \mathrm{MHz}$ so that MIL-STD-46I is essentially satisfied from 25 to $100 \mathrm{MHz}$. In like manner, the 6 turn coil produces the required sensitivity in the frequency range of 75 to $150 \mathrm{MHz}$. The 4 turn coil can be used for improved sensitivity between 100 and $200 \mathrm{MHz}$, but we were not able to achieve sufficient improvement at frequencies above $150 \mathrm{MHz}$. At these higher frequencies it might be advantageous to use a series inductor, but this approach was not explored. A description of the 3 types of coils used in the final design is given in table 10. The coils were wound on ferrite toroid cores having a diameter of $0.64 \mathrm{~cm}$ and a thickness of $0.19 \mathrm{~cm}$.

\subsubsection{Effect of Non-coherence in the Fiber Bundle}

The type of waveguide generally used for fiber-optic communications consists of a bundle of several glass filaments. Multifilament bundles are used to achieve flexibility of the guide together with a large numerical aperture. In a "coherent" bundle the relative positions of the fibers are maintained the same at both ends of the guide. This type of bunde must be used for imaging through a guide but is not required simply for transmission of energy. All of the "low loss" guides we tested use incoherent bundes. However, an LED chip is much smaller in area than the end of a fiber guide, so only a few of the filament ends are illuminated. This causes random spreading of the light beam along the length of the guide, so that only a fraction of the incident beam is captured by the small APD chip at the far end of the line. The longer the guide, the greater is the incoherence of the filaments in the emergent beam. As a result, the total transmission loss was found to be greater than that expected on the basis of path-length attenuation alone. 
Tangential Sensitivity, Linearity, Dynamic Range and Antenna Factor

The design of the active dipole and fiber-optic link was optimized on the basis of three considerations, namely: (1) high overall sensitivity, (2) large dynamic range so as to receive weak signals, but keep spurious responses caused by strong signals to an acceptable level, and (3) wide bandwidth of the antenna so only one (isotropic) antenna unit is required over the total frequency range of $15 \mathrm{kHz}$ to $200 \mathrm{MHz}$.

In the NBS antenna system (active dipole/fiber-optic link/FIM receiver) the dynamic range is controlled by, and defined as, the difference between the weakest measurable signal and the signal level strong enough to drive the system into non-linear operation [32]. More precisely, the dynamic range was defined as the difference between the tangential sensitivity $[(\mathrm{S}+\mathrm{N} / \mathrm{N}=3 \mathrm{~dB}]$ and the point of $3 \mathrm{~dB}$ compression in gain. The latter point is where the receiver response falls $3 \mathrm{~dB}$ below a linear extrapolation of the characteristic curve plotted to give receiver response vs. field intensity. The overall design goal was to achieve high sensitivity and good linearity over a wide range of field intensity.

Tables 11 and 12 give a summary of the measured performance characteristics of the fiber-optic antenna system. Figure 28 is a graph of the raw data at four different receiver frequencies. On this graph an ideal curve is a straight line with a slope of $45^{\circ}$. The bottom (left) end of each line is a measure of the antenna system sensitivity. In fact, the bottom point is a plot of the tangential sensitivity. The curve becomes non-linear at the upper end of the line and tends toward a horizontal slope. This is where the rf amplifier or LED becomes overloaded. The length of the straight line portion is a measure of the system dynamic range.

The "antenna factor" is defined as the difference between the E field level $(\mathrm{dB} \mu \mathrm{V} / \mathrm{m})$ and the receiver indication $(\mathrm{dB} \mu \mathrm{V})$. The lateral position of the characteristic curve is thus a measure of the antenna factor. An unknown field strength may be measured with the calibrated active antenna by using the expression:

$$
E=M+K
$$

where: $E=$ field strength, $\mathrm{dB}$ above $1 \mu \mathrm{V} / \mathrm{m}$

$M=$ meter indication of the receiver, $\mathrm{dB}$ above $1 \mu \mathrm{V}$, on narrowband selecfivity, after calibration as a tunable voltmeter

$k$ = antenna factor, $d B$. 
Figure 29 is a graph of the tangential sensitivity vs. frequency for the fiber-optic antenna system, from $15 \mathrm{kHz}$ to $200 \mathrm{MHz}$. The figure includes the measured sensitivity when a parallel resonating coil is plugged into the antenna across the dipole center gap. Figure 30 is a graph of the dynamic range as a function of frequency. It also shows the calibrated value of antenna factor to be used when measuring field intensity.

The dynamic range of the fiber-optic antenna system generally decreases as the frequency increases. The measured dynamic range is about $70 \mathrm{~dB}$ at low frequencies, between $25 \mathrm{kHz}$ and $2 \mathrm{MHz}$. It is about $65 \mathrm{~dB}$ for frequencies between 2 and $25 \mathrm{MHz}$, and 45 to $55 \mathrm{~dB}$ at higher frequencies up to $200 \mathrm{MHz}$. The use of a parallel antenna coil increases the sensitivity but appears to have little effect on the dynamic range. The dynamic range is fairly constant as a function of frequency when compared with either the tangential sensitivity or the overload level.

\subsection{Overloading of the Active Antenna System by a Strong Interfering Signal}

The (active-antenna/fiber-optic) system has a limitation regarding the measurement of absolute field strength. The antenna becomes desensitized by any strong signal within its total frequency range of $15 \mathrm{kHz}$ to $200 \mathrm{MHz}$. A strong out-of-band signal may thus cause an error in the measured field strength at another frequency, or it may produce cross modulation products at various frequencies. This is a common limitation when using active antennas. In this case the same signal may be picked up at more than one receiver frequency. For example, a local FM station near $100 \mathrm{MHz}$ could also be heard when the receiver was tuned near $200 \mathrm{MHz}$. This was due to second harmonic generation, either in the rf amplifier of the active dipole or in the optoelectronic portion of the system. It is, therefore, advisable to check that the signals being measured are true signals and not spurious responses of the receiver system.

The use of fiber optics, with its large signal loss, demands a large amount of rf amplification. If a strong signal voltage is present, this leads to the possibility of overloading in the latter stages of the amplifier. A switchable attenuator could be incorporated in the front end of the active dipole to test for antenna overloading. Alternatively, a plug-in capacitor producing $20 \mathrm{~dB}$ attenuation could be fabricated to connect across each dipole gap, similar to the "outboard" resonating inductors. A design trend in broadband communications receivers for operation in strong signal environments is to eliminate the rf amplifier stage and make up the 
gain in the IF amplifier. However, our active antenna system is intentionally designed for high gain and broadband, untuned operation. One apparent alternative is to use a tunable, tracking preselector, which would be a major design problem for a three-dipole isolated antenna.

As mentioned previously, the upper end of the dynamic range was defined as the point of $3 \mathrm{~dB}$ compression in gain. This type of non-linearity leads to desensitization by any strong signal [33]. Therefore, tests were made to determine the error introduced when a weak signal at frequency Fl must be measured in the presence of a strong signal at frequency F2. Figure 31 is a block diagram of the instrumentation used for the test and table 13 gives a summary of the data. The level of the "interfering" field at $100 \mathrm{MHz}$ was adjusted in steps from 0 to $31.6 \mathrm{mV} / \mathrm{m}$. Measurements of the "desired" signal at $75 \mathrm{MHz}$ were then made to determine the effect on indicated field level, overall linearity, etc. It can be seen from the experimental data of table 13 that the tangential sensitivity and dynamic range for the weak signal at $75 \mathrm{MHz}$ were not altered by the interfering signal at $100 \mathrm{MHz}$ unless the interference level was greater than $10 \mathrm{mV} / \mathrm{m}$. However, the antenna factor was changed when the interfering field was greater than $1 \mathrm{mV} / \mathrm{m}$. When the out-of-band signal at $100 \mathrm{MHz}$ was large, the receiver indication was less, causing error when using the antenna system to measure an unknown field strength.

6. DESIGN AND FABRICATION OF THE COMPLETE ISOTROPIC ANTENNA AND CONTROL UNIT

\subsection{Description of the system}

The three active dipoles and associated fiber-optic circuitry have been assembled and tested. Figure 32 is a photograph showing how the dipoles are mounted orthogonally with essentially a common center. The total frequency range of each induced field component is amplified and used to modulate a high-speed LED. The isotropic antenna unit is connected to three glass fiber waveguides, each 10 meters long. The auxiliary circuitry for the avalanche photodiodes, time sequencing switches, and the analog "computer" required for the RSS processing of the three dipole signals have also been designed and tested. The latter circuitry is mounted on a separate "control unit" chassis.

Figure 33 is a block diagram of the antenna control unit. Figure 34 is an interior (rear) view of the chassis showing the circuit cards and power supply. The control unit performs two major functions, namely, to (1) demodulate the rf signal from the optical carrier, and (2) caiculate and display a voltage proportional to the Hermitian magnitude of the electric field. The 
first function is performed by three avalanche photodiodes (APD's) that receive the infrared signals from the three antennas via glass fiber waveguides. The outputs from the three APD's are sequentially switched into the antenna input of an FIM receiver.

Figure 35 is a view of the entire field strength measuring system. It shows the isotropic antenna on a tripod, the control unit placed on top of the conventional FIM, and the three fiber guides used to convey the infrared signal between the antenna unit and the rear of the control unit.

A dc voltage from the FIM proportional to the signal-strength meter indication is returned to the antenna control unit. This voltage is processed by an analog computer to give the RSS magnitude $\left|\bar{v}_{\text {in }}\right|$, where

$$
\left|\bar{v}_{i n}\right|=\left[v_{i n}^{2}(X)+v_{i n}^{2}(Y)+v_{i n}^{2}(Z)\right]^{1 / 2}
$$

$V_{\text {in }}(X, Y, o r ~ Z)$ is the rf voltage present at the FIM antenna input port when either the $X, Y$, or $Z$ APD and hence $X, Y$, or $Z$ dipole is selected. The resulting voltage magnitude is displayed on a panel meter identical to the FIM panel meter, but located on the control unit chassis.

A front-panel switch is provided to select and display the output from any individual $X, Y$, or $Z$ channel or the RSS magnitude. Other controls include separate photocurrent meters, gain controls, and overload indicators for each APD. Also on the front panel is an rf calibrator output supplying a $-20 \mathrm{dBm}, 5 \mathrm{MHz}$ square wave signal. All interconnections are made on the back panel of the instrument. These include the three APD optical fiber inputs, the rf signal output, the FIM interface cable, three battery charger outputs, DVM outputs, and an IR source calibrator.

The following sections discuss the separate blocks in more detail.

\subsection{Avalanche Photodiode Circuitry}

The modulated IR signal from each LED is received and detected by a silicon APD. The circuits for the APD and bias voltage regulators are shown in figures 36 and 37 , which are similar to the simplified schematic of figure 19. The APD is reverse-biased close to its breakdown voltage, specified by the manufacturer to lie between 140 and 200 volts. The APD is capable of providing internal photocurrent gain in excess of $40 \mathrm{~dB}$. The gain is adjusted by varying the bias voltage. The demodulated rf signal from the APD is coupled directly to the FIM $50 \Omega$ antenna input through the dc blocking capacitors at the output terminal of figure 36 . 
The APD bias regulator, figure 37, consists of three major subsections, (1) a 200 volt pre-reguiator, (2) adjustable APD bias, and (3) excess photocurrent clamp. The pre-regulator drops the raw dc (280 V nominal) from the high voltage rectifier card to a regulated $+200 \mathrm{~V}$. The $200 \mathrm{~V}$ zener diode D2 provides a reference voltage to the Darlington pair emitter follower, Q1-Q2 .

The adjustable APD bias current supply in figure 37 consists of transistors $\mathrm{Q} 4$ through $\mathrm{Q} 9$ and their associated components. All of the transistors are connected in Darlington pairs, thus functioning as very high beta transistors. Q4-Q5 and Q6-Q7 are connected as a "long tailed," emitter coupled differential amplifier. The $43 \mathrm{k} \Omega$ "long tail" resistor functions as a $3 \mathrm{~mA}$ current source. The $150 \mathrm{~V}$ Zener diode (D1 of figure 36) provides a $150 \mathrm{~V}$ reference voltage which is dropped by the $20 \mathrm{k} \Omega$ resistor (figure 37 ) to provide a stable $+130 \mathrm{~V}$ to the plus input ( 44 base) of the differential amplifier. The APD bias voltage is applied to the minus input (Q7 base) through the adjustable voltage divider labeled "APD bias adjust." $08-09$ is a low output-impedance, emitter-follower with its base (Q8) connected to the output (Q6-Q7 collector) of the differential amplifier. The APD breakdown voltage, and hence its current gain at a fixed bias, is temperature sensitive. To compensate for this the APD bias is adjusted automatically. The temperature reference diode $D 1$ is selected to have a breaikdown voltage and temperature coefficient similar to the APD. DI and the APD are mounted on the same thermal heat sink.

The remaining components are for the APD excess photocurrent protection circuit. The photocurrent is sensed by developing a small voltage across the $1 \mathrm{k} \Omega$ current-sensing resistor of figure 36. This voltage is applied to a 741 op. amp. (figure 37) operated open loop as a comparator circuit. The other input to the 741 is fixed at $300 \mathrm{mV}$. When the photocurrent exceeds $300 \mu \mathrm{A}$, the voltage across the $1 \mathrm{k} \Omega$ sensing resistor exceeds $300 \mathrm{mV}$ and the 741 output goes positive, saturating near $+15 \mathrm{~V}$. This in turn causes Ql0, Q11, and $\mathrm{Q} 3$ to conduct. When $\mathrm{Q} 3$ conducts it drops the pre-regulator voltage to $+35 \mathrm{~V}$. If the photocurrent then drops below $300 \mu \mathrm{A}$ again, $Q 3$ shuts off automatically, allowing the pre-regulator to reset to $+200 \mathrm{~V}$. An LED is provided on the front panel to indicate when an overload condition exists.

\section{3 rf/IR Calibrator Circuit}

As an aid in the initial setup and adjustment of the isotropic antenna system, a calibrator is provided with an rf output and also a modulated IR output for checking the APD's. The rf output is a $5 \mathrm{MHz}$ square wave with strong harmonic content. The output impedance is 50 ohms. The output level across a $50 \mathrm{ohm}$ load is a nominal $-20 \mathrm{dBm}$ at $5 \mathrm{MHz}$. The IR calibrator is a 
high-speed LED identical to those used in the active antennas. It is biased and also modulated with a $5 \mathrm{MHz}$ square wave. The average LED current is approximately $16 \mathrm{~mA}$, the same as the LED current in the final active antenna unit.

Figure 38 is a schenatic diagram of the calibrator circuit. Q1 is a $10 \mathrm{MHz}$ crystal-controlled oscillator. Q2 is a buffer and Q3 is a TTL logic driver. A $7474 \mathrm{flip-flop}$ is used to obtain a $50 \%$ duty cycle, $5 \mathrm{MHz}$ square wave. Q4-Q5 from the discrete emitter-coupled-logic, high-speed output stage. Q6 is the LED modulator.

\subsection{Interface with the EMC-25 Receiver}

Figure 39 shows the interface card used to mate the antenna control unit to the receiver. The rf signals from the APD's are sequentially switched into the single antenna input terminal of the receiver. Each signal is applied to the FIM one second. The complete measurement cycle takes 3.3 seconds. Switching is done by small reed relays $\mathrm{K} 3, \mathrm{~K} 4$, and $\mathrm{K} 5$.

The EMC-25 provides a dc output voltage $V_{0}$ across a $1.5 \mathrm{k} \Omega$, 18 resistor in the inter-tie cable that is proportional to the signal strength meter indication ( 1.5 volts full scale). A separate cable is used to connect this "output meter" voltage and the EMC-25 "dump" control signal to the isotropic antenna control unit. The meter dial indication is in terms of rf microvolts at the FIM antenna input calle. A second meter scale is linear in $\mathrm{dB}$ above $1 \mu \mathrm{V}$.

The basic measurement cycle time of one second for each field component $(X, Y$, or $Z$ ) is fixed by the slow response time of the EMC-25 receiver. Figure 40 shows examples of the FIM response, $V_{0}$, to various-length rf pulses for, respectively, the "carrier," "quasi-peak," and "peak" modes of detection. In the carrier mode the $0 \%-98 \%$ rise time is $0.6 \mathrm{~s}$ while the 100\%-2\% fall time is $1 \mathrm{~s}$. For quasi-peak detection the risetime is $6 \mathrm{~ms}$ while the fall time remains at $1 \mathrm{~s}$. For peak detection the risetime is only a few microseconds. The discharge characteristics are determined by the DUMP control. With the DUMP control fully ccw and into the switch detent the circuit is in a hold mode with a fall time in excess of $10 \mathrm{~s}$. With the DUMP control $\mathrm{CCW}$ the meter reading is held for a dump delay of $300 \mathrm{~ms}$ and is then discharged rapidly. The minimum dump delay is $20 \mathrm{~ms}$ when the control is $\mathrm{CW}$.

The two op. amps. of figure 39 are used as a peak detector to hold the maximum meter deflection $\mathrm{V}_{\mathrm{O}}$ during each measurement time interval (X, $\mathrm{Y}$, or Z). The peak detector is reset to zero at the end of each measurement interval by relay $\mathrm{Kl}$. At the same time relay $\mathrm{K} 2$ provides a contact opening to "dump" the EMC-25 output meter circuit when the FIM is operated in the PEAK mode. 


\subsection{Vector Magnitude Analog Computer}

The vector magnitude of the $X, Y$, and $Z$ inputs to the FIM is determined by an analog computer that consists of three circuit boards, figures 41,42 , and 43. Operational amplifiers, an antilog integrated circuit (IC), sample and hold circuits, an analog multiplier IC, and a logarithmic amplifier IC are used to calculate a voltage according to eq. (12). The following discussion presents in detail the various mathematical operations performed. The FIM output meter voltage $V_{0}$ follows the equation

$$
\mathrm{V}_{0}=1.05+0.45 \log _{10}\left[\mathrm{~V}_{\text {in }}(\mu \mathrm{V}) / 1 \mu \mathrm{V}\right] \text { volts. }
$$

Thus for $\mathrm{V}_{\text {in }}=10 \mu \mathrm{V}, \mathrm{V}_{0}=1.5 \mathrm{~V}$; for $\mathrm{V}_{\text {in }}=1 \mu \mathrm{V}, \mathrm{V}_{0}=1.05 \mathrm{~V}$; for $\mathrm{V}_{\text {in }}=$ $0.1 \mu \mathrm{V}, \mathrm{V}_{0}=0.6 \mathrm{~V}$; and for $\mathrm{V}_{\text {in }}=0.01 \mu \mathrm{V}, \mathrm{V}_{0}=0.15 \mathrm{~V}$. The maximum meter voltage during each sample time is detected and held in the. EMC-25 interface, where

$$
v_{o m}=v_{0}(\operatorname{maz})
$$

The first op. amp. of figure 41 , IC-1, is simply a high input impedance buffer such that

$$
\mathrm{v}_{1}=\mathrm{v}_{\mathrm{om}}
$$

IC-2 of figure 41 provides signal inversion, amplification and level shifting to obtain

$$
\begin{aligned}
v_{2} & =-2.22 v_{1}+3.33 \\
& =1-\log _{10}\left[v_{i n}(\mu V) / 1 \mu V\right] \text { volts. }
\end{aligned}
$$

IC-3 is an antilog IC that is used to extract a voltage proportional to the FIM input voltage (in $\mu \mathrm{V}$ ) squared. That is,

$$
v_{3}=v_{\text {ref }} 10^{-\left(V_{2} / K\right)}
$$

The circuit constants are chosen to give

$$
\begin{aligned}
V_{\text {ref }} & =10 \mathrm{~V}, \\
K & =0.5
\end{aligned}
$$

thus producing a voltage $v_{3}$ given by

$$
\mathrm{v}_{3}=\frac{1}{10}\left[\mathrm{v}_{\mathrm{in}}(\mu \mathrm{V}) / 1 \mu \mathrm{V}\right]^{2} \text { volts. }
$$

Thus at this point we effectively have $v_{\text {in }}^{2}$ 
The next step is to obtain the summation of $\mathrm{V}_{\text {in }}^{2}(\mathrm{X}), \mathrm{V}_{\text {in }}^{2}(\mathrm{Y})$, and $\mathrm{V}_{\text {in }}^{2}(\mathrm{Z})$. This is accomplished by first storing $V_{3}(X), V_{3}(Y)$, and $V_{3}(Z)$ in three separate sample-and-hold circuits, IC-4, 5, 6 in figure 41 . The output voltages are

$$
\begin{aligned}
& \mathrm{V}_{4}=\mathrm{V}_{3}(\mathrm{X}) \propto \mathrm{V}_{\text {in }}^{2}(\mathrm{X}) \\
& \mathrm{V}_{5}=\mathrm{V}_{3}(\mathrm{Y}) \propto \mathrm{V}_{\text {in }}^{2}(\mathrm{Y}) \text { and } \\
& \mathrm{V}_{6}=\mathrm{v}_{3}(\mathrm{z}) \propto \mathrm{V}_{\text {in }}^{2}(\mathrm{z}) .
\end{aligned}
$$

These voltages are algebraically added in the op. amp. adder IC-7 of figure 42 to obtain $v_{7}$, given by

$$
\begin{aligned}
\mathrm{V}_{7} & =-\frac{1}{3}\left(\mathrm{~V}_{4}+\mathrm{V}_{5}+\mathrm{V}_{6}\right) \\
& =\left(\frac{-1}{30}\right)\left(\left(\frac{\mathrm{V}_{\text {in }}(\mathrm{X})}{1 \mu \mathrm{V}}\right)^{2}+\left(\frac{\mathrm{V}_{\text {in }}(\mathrm{Y})}{1 \mu \mathrm{V}}\right)^{2}+\left(\frac{\mathrm{V}_{\text {in }}(\mathrm{Z})}{1 \mu \mathrm{V}}\right)^{2}\right) .
\end{aligned}
$$

IC-8 is simply an inverter, so

$$
\mathrm{v}_{8}=-\mathrm{v}_{7}
$$

IC-9 is an analog multiplier connected to perform the square root operation,

$$
\begin{aligned}
V_{9} & =-\sqrt{10 V_{8}} \\
& =-\sqrt{\frac{1}{3}}\left(\left(\frac{V_{\text {in }}(X)}{1 \mu V}\right)^{2}+\left(\frac{V_{\text {in }}(Y)}{1 \mu V}\right)^{2}+\left(\frac{V_{\text {in }}(Z)}{1 \mu V}\right)^{2}\right)^{1 / 2} .
\end{aligned}
$$

IC-10 is an inverter, so

$$
\mathrm{v}_{10}=-\mathrm{v}_{9}
$$

$\mathrm{V}_{10}$ is sampled by $\mathrm{K} 4$ each second and held by the $0.1 \mu \mathrm{F}$ capacitor and $\mathrm{IC}-11$. That is

$$
\mathrm{v}_{11}=\mathrm{v}_{10}(\text { sampled })
$$

$\mathrm{V}_{11}$ is the desired answer and is linearly proportional to $\left|\overline{\mathrm{V}}_{\text {in }}(\mu \mathrm{V})\right|$ in equivalent microvolts. The EMC-25 meter scale is linear in $\mathrm{dB} \mu \mathrm{V}$, thus $\mathrm{V}_{11}$ must be processed by a log circuit, IC-12 of figure 43, before driving the meter. Thus

$$
\mathrm{v}_{12}=-\log _{10}\left(\mathrm{v}_{11} / 5.77 \mathrm{~V}\right)
$$


The meter on the control unit panel is driven by IC-13 according to the equation

$$
I(\text { meter })=-0.3 \mathrm{v}_{12} \text { (volts) }+1 \mathrm{~mA} \text {. }
$$

In addition to the front panel meter shown in figure 43, two outputs are available on the back panel for connecting an external digital voltmeter (DVM). IC-14 provides an output proportional to dBHV while IC-15's output is proportional to $\mu \mathrm{V}$. These voltages are given by

$$
\begin{aligned}
& v_{14}=-2 v_{12}+2, \\
& v_{15}=0.173 \mathrm{v}_{11} .
\end{aligned}
$$

Table 14 lists the voltages throughout the analog computer for various rf input voltages. As can be seen from the table, for antenna input voltage below $0.1 \mu \mathrm{V}$, the squaring process yields values for $v_{7}$ in the microvolt region. Due to noise, drifts, offsets, etc., in the analog computer these low level signals are useless. To obtain accurate field strength measurements, the rf signals should be greater than $I \mu V$.

\section{$6.6 \quad X-Y-Z$ Measurement Seguencer}

The measurement sequencer board, figure 44, provides the timing and control signals for the interface circuits and the analog computer. As discussed previously, the 3.43 s measurement cycle time is fixed by the slow response time of the FIM. Figure 45 shows the important control signals and their timing relationship. Figure 46 shows the internal signals within the measurement sequencer. cMos integrated digital logic is used.

An internal clock is provided which consists of a 555 timer, IC-1, and two flip-flops, IC-2 and 3. The 555 timer produces a pulse train at $28 \mathrm{~Hz}$. The flip-flops produce square waves at $14 \mathrm{~Hz}$ and $7 \mathrm{~Hz}$.

The X, Y, Z pulses are the antenna channel selectors. Each pulse is of I s duration. These pulses are generated by three 8-bit shift registers, IC-6, 7 and 8. A measurement cycle is started by a LOAD pulse which loads the data words $X=11111110, Y=00000000$, and $Z=00000000$ into the shift registers. The $7 \mathrm{~Hz}$ square wave, CLK, then sequentially shifts these words out of the shift registers. As CLK repeats, a "O" on the serial input to IC -6 is shifted in until the first register is full of all "0"s. The output of the first register, $x$, is the serial input to the second register, IC-7. Thus 8 CLK pulses later in time the $X$ word appears as the $Y$ pulse. The same thing occurs for the last register, I -8 , to generate the $z$ pulse. 
With the particular data word selected for $X$, a dead time of one CLK period ( $1 / 7$ second) is provided between the $X, Y$, and $Z$ pulses. During this time interval the peak detectors on the interface board of figure 39, and in the EMC-25 receiver, are discharged. This is accomplished through the DUMP pulse. A NOR gate IC-18 determines when X, Y, and $\mathrm{Z}$ are all "O"s. In the middle of the DUMP pulse a SAMPLE (IS) pulse is produced to activate the sample and hold relay in the analog computer, $\mathrm{K} 4$ in figure 42 . This is a $1 / 28$ second pulse selected by the NOR gate IC-17 when $\overline{\text { DUMP, }}$ CLK, and $\overline{\text { CLKX2 }}$ are all "O"s. The DUMP and SAMPLE (1S) pulses occur three times during each measurement cycle.

At the end of the measurement cycle the shift registers must be reloaded. Figure 46 shows the various signals required to generate a LOAD pulse. The negative-going transition of $\mathrm{z}$ is inverted by IC-9 of figure 44 and used to clock the D type flip-flop IC-4. The D input was a "1," thus the flip-flop $\bar{Q}_{1}$ is toggled to a "0." This "0" applied to the NOR gate IC-14 allowed it to pass a $1 / 28$ second pulse when flip-flop $\overline{\mathbf{Q}}_{1}, \mathrm{CLK}$, and $\overline{\text { CLKX2 }}$ are all "O"s. This pulse is labeled SAMPLE (3S) and is used to set the next flip-flop IC-5. SAMPLE (3S) can be used to control the analog computer sample-and-hold if a new meter reading is desired only every $3-1 / 2$ seconds. When flip-flop $Q_{2}$ is set, this enables the NOR gate IC-15 to generate a $1 / 28$ second LOAD pulse when flip-flop $\bar{Q}_{2}, \overline{C L K}$, and $\overline{C L K X 2}$ are all "O"s. The positive-going transition of $\overline{L O A D}$ is used to clock a "O" into the flip-flop $\mathrm{Q}_{2}(I C-5)$, thus resetting it.

The above discussion describes all sequences in a normal measurement cycle. However, at power turnon time it is possible for either or both of the flip-flops, IC-4 and IC-5, to latch up in the wrong state. If this occurs, a LOAD pulse would not be generated, thus resulting in $X, Y$, and $Z$ all remaining at "0." To alleviate this problem a train of several LOAD pulses is generated for one second after the power is turned on. This is accomplished by interrupting the connection of flip-flop IC-5 into the LOAD NOR gate IC-15 with an alternate gating pulse, START. An RC delay circuit ( $1 \mathrm{M} \Omega, 1 \mu \mathrm{F}$ ) is connected to the $+5 \mathrm{~V}$ line. This RC circuit delays applying a "l" to the input of inverter IC-Il for approximately one second. Thus the output of the inverter is the 1 second START pulse. The NOR gate IC-16 is used to route either the START pulse or the $\Omega_{2}$ output of IC-5 into the LOAD NOR gate, thus always assuring several LOAD pulses at turn-on time.

\subsection{Auxiliary Eguipment}

Figure 47 is a schematic diagram of the battery charger for recharging the $9.6 \mathrm{~V}$ Ni-Cd batteries in the active antennas. The circuit consists of three $15 \mathrm{~mA}$ constant-current sources with over-voltage protection provided by the $13 \mathrm{~V}$ Zener diode. The three diodes at the charger output terminals are 
used to prevent the batteries from discharging back into the charger when the ac power is turned off.

The high voltage $(280 \mathrm{~V})$ supply for the APD bias regulator is shown in figure 48. The $\pm 15 \mathrm{~V}$ supply is shown in figure 49. It is an ordinary regulated power supply. The only special requirement is that the voltages must be precisely set to $+15.00 \mathrm{~V}$ and $-15.00 \mathrm{~V}$ because they are used as reference voltages in the analog computer. Deviations in these voltages will affect the computer accuracy.

Figure 50 is a diagram showing the interconnecting cables between the antenna control unit, the rf/IR calibrator, and a conventional EMC-25 receiver.

A complete parts list and detailed instructions for proper alignment of the electronic circuitry in the control unit have been furnished to ECOM in a separate manual.

\section{SUMMARY AND CONCLUSIONS}

A broadband isotropic antenna system was developed for measuring rf emanations in a screen room environment. It uses a fiber-optic link between the electrically-isolated antenna unit and a conventional EMI receiver. The frequency range of interest is $15 \mathrm{kHz}$ to $200 \mathrm{MHz}$. Above this frequency the optoelectronic link suffers severe rolloff in response. However, at these higher frequencies it is possible to use "hooded" antenna techniques and anechoic chambers. The NBS active antenna consists of 3 mutually orthogonal dipoles and responds to arbitrary polarization, which decreases some of the difficulty encountered in screen room measurements. Each of the dipoles is $31 \mathrm{~cm}$ long $\times 3.5 \mathrm{~cm}$ diameter and contains an rf amplifier, electroluminescent diode (LED), and a battery. The dipole is electrically short at all frequencies, thus achieving a sensor with wide bandwidth. The antenna has high sensitivity (up to $10 \mu \mathrm{V} / \mathrm{m}$ ) and does not require tuning.

The signal picked up by each dipole is applied to a FET-input rf amplifier which modulates the infrared (IR) intensity of a solid-state LED. The IR radiation, which is injected into the end of a glass fiber waveguide, is thus modulated with all signal frequencies within the system bandwidth. The far end of each guide is optically coupled to an avalanche photodiode (APD) in the "control" unit, which recovers the rf modulation from the IR carrier. Each of the 3 fiber guides is $10 \mathrm{~m}$ long, thus isolating the antenna electrically from the equipment under test and the enclosure walls. The 3 recovered rf signals are applied to the EM receiver through a time sequencing switch, sample-and-hold circuitry, and RSS processing. The one indication on the field strength readout meter is proportional to the Hermitian magnitude of the electric field. 
The present antenna system uses an incoherent LED for the IR source, a silicon APD for the photodetector, and a multimode glass fiber bundle for the transmission line. Compared with lasers, LED's are slow (5 to 10 ns risetime), have relatively large spectral width (30 to $40 \mathrm{~nm}$ ) and large beam divergence (about $30^{\circ}$ ). The slow response time limits the analog bandwidth in the antenna to about $150 \mathrm{MHz}$. The large beam divergence makes it difficult to couple the LED output into the end of the fiber, causing coupling losses of 20 to $25 \mathrm{~dB}$. The APD used has a gain-bandwidth product of $100 \mathrm{GHz}$, so it is not the limiting factor for high signal frequencies. The rolloff in sensitivity at frequencies above $150 \mathrm{MHz}$ is quite steep and is due mainly to limitations of the LED source. An attempt was made to use current state-cfthe-art technology for the fiber-optic link and antenna system. The overall system was designed to be compatible with an ECM-25 type of FIM.

New technologies employing laser diodes, single-mode fibers, and integrated-circuit optical components may eventually provide the answer to the search for an EMI antenna with huge bandwidth and high sensitivity. However, the only battery-operated source available for our project, which was compatible with fiber optics, was the incoherent IED. It is small, light, rugged, reliable, inexpensive, and (most important) is easy to modulate with an rf signal. It can be battery operated with low voltage and low current. The data presented in this report are believed to represent the optimum performance for a non-lasing diode at the time of this project.

The initial tests for choosing the optimum components and improving the circuit design were made by both time-domain and frequency-domain techniques. In general, the testing of optoelectronic components was done by observing pulses on a sampling oscilloscope. The preliminary design of the circuitry was optimized by observing swept-frequency results on a spectrum analyzer. Later refinements were then accomplished at discrete frequencies by immersing the active dipole in a known field and checking the performance characteristics The rf open-circuit pickup of a $31 \mathrm{~cm}$ dipole is quite low and the signal is further reduced by the impedance mismatch between the short antenna and the rf amplifier. The sensitivity of the antenna system developed at NBS is adequate for signal frequencies below $25 \mathrm{MHz}$. At higher frequencies the bandwidth of the receiver used is larger $(50 \mathrm{kHz})$ and the sensitivity is generally below that required for making MIL-STD-461 measurements. The circuitry of the rf amplifier incorporates frequency compensation to accentuate the signals above $50 \mathrm{MHz}$, thus compensating for some of the LED rolloff at these higher frequencies. Also, small toroid inductors were designed to be connected across the center gap of each dipole. The resulting antenna resonance increased the sensitivity enough to meet the specifications up to a frequency of $150 \mathrm{MHz}$. 
The antenna factor vs. frequency for the fiber-optic antenna was determined by calibrating the individual dipoles in the known field of a TEM transmission line. For our project the antenna sensitivity was defined as the field intensity required to increase the receiver indication $3 \mathrm{~dB}$ above the system noise level; that is, the tangential sensitivity. The ultimate sensitivity of any measurement system is set by the noise accompanying the signal, and therefore by the system bandwidth. Using an EMC-25 receiver, the fiberoptic antenna system essentially satisfied the sensitivity requirements for measuring narrowband fields according to MIL-STD-461 up to a frequency of $150 \mathrm{MHz}$. The linear dynamic range of the antenna system was defined as the difference between the tangential sensitivity and the field level causing 3 dB compression. The dynamic range of the fiber-optic antenna system varied from $70 \mathrm{~dB}$ at a signal frequency of $20 \mathrm{kHz}$ to about $50 \mathrm{~dB}$ at a frequency of $150 \mathrm{MHz}$.

Acceptable performance of an infrared (LED/fiber guide/APD) antenna system requires a combination of high sensitivity, low noise, large bandwidth so no antenna tuning is required, and large dynamic range so the distortion is low. Engineering tradeoffs were made in an attempt to achieve optimum overall performance. The high-sensitivity system developed at NBS is somewhat restricted by the low dynamic range of the system. The antenna is thus most suitable for measurement of weak signals. When measuring a strong field it is advisable to insert an attenuator in the rf amplifier. Also, the present active antenna becomes desensitized by any one strong signal in the total frequency range; this may cause error in the measured field strength of a weak signal in the presence of a strong out-of-band signal.

It was not possible to demonstrate experimentally the degree to which the antenna response pattern is truly isotropic. NBS does not have an anechoic chamber for measuring antenna patterns below $1 \mathrm{GHz}$, and calibration at an outdoor field site was hampered by large ambient signals from local AM and FM stations. However, from past experience in evaluating the response vs. orientation angle for microwave hazard probes, which also employ 3 orthogonal dipoles in the rf sensor, it is known that an isotropic response is achieved if the dipoles have separate responses which are equal and if accurate signal processing is used to obtain the Hermitian magnitude. The three dipoles in the engineering prototype antenna delivered to ECOM were adjusted for equal response at a frequency of $25 \mathrm{MHz}$ and a field level of $100 \mu \mathrm{V} / \mathrm{m}$. The required alignment procedure for the antenna, a parts list, and a set of schematic diagrams were furnished to ECOM in a separate instruction manual. 
It is not possible to measure a single transient pulse of interference with the time sequencing approach used here because the metering unit does not sample the output of all 3 dipoles simultaneously. The reception and measurement of impulse interference caused by repetitive pulses can be accomplished, however, even when time sequencing the $X-Y-Z$ field components. One procedure to insure pickup of an isolated pulse of unknown polarization would be to use three separate EMI receievers, although this is not an economical approach.

In conclusion, we have developed a sensitive, isotropic, electricallyisolated antenna, using commercially-available fiber-optic technology. The antenna can be used to measure weak steady-state emanations in a shieldedroom environment. It was found that an infrared system employing LED sources, multimode glass fiber transmission lines, and avalanche photodiode. detectors can offer certain improvements over a more conventional antenna. Some of the problems relating to fiber-optic technology have not yet been solved, and should receive further development work. However, the basic concept of an isotropic EMI antenna has been verified. Newer and better components and techniques, such as integrated optics and solid-state laser diodes, could lead to significant improvements in performance.

\section{RECOMMENDATIONS AND FUTURE PLANS}

The results achieved in this NBS/ECOM program have been very encouraging in nearly all aspects. The concept of measuring field strength with an active isotropic antenna using a fiber-optic link to the EMI receiver has been demonstrated. In view of certain advantages gained by this type of isolated probe, it would be highly desirable to continue this research effort, evaluating additional opto-electronic components and hardware for improving the measurement system. Also, it might be possible to simplify some of the circuitry, alignment procedure, and technique for measuring absolute field strength; these now require a fairly high degree of skill. It would then be possible to fabricate a general purpose EMI antenna with a more repeatable antenna factor and a greater dynamic range.

In particular, it is suggested that a more thorough evaluation be made of a new type of "high speed" LED which became available recently [34 and 35]. One of these LED's was checked briefly at signal frequencies from 25 to $200 \mathrm{MHz}$. The overall performance (tangential sensitivity, linearity and dynamic range) was no better than the LED used in our project. In fact, at the upper frequency end of the spectrum (150 to $200 \mathrm{MHz}$ ) the sensitivity was worse by about $2 \mathrm{~dB}$. This type of LED has a specified frequency rolloff of only $3 \mathrm{~dB}$ at $200 \mathrm{MHz}$. Our measured rolloff was much greater. However, the new LED was tested for only one value of bias current (16 mA) which may have been too low to achieve the expected high frequency improvement. 
NBS thus recommends a follow-on program in which the existing isotropic antenna and control unit are more thoroughly evaluated in order to establish the optimum procedure for measuring absolute field strength. Additional development work could then be initiated if that is considered advisable. Another possible investigation would be to evaluate the new GaAlAs laser diodes which have just become available. These are solid-state replacements for bulkier and less efficient gas lasers. They have a specified risetime of only $0.1 \mathrm{~ns}$, beam spread of only $5^{\circ}$ and spectral width of only $2.5 \mathrm{~nm}$, with peak emission at $850 \mathrm{~nm}$. However, the specified minimum forward current is about $150 \mathrm{~mA}$, so they would require frequent battery replacement or other means of supplying power to the isolated antenna.

\section{ACKNOWLEDGMENTS}

This work was sponsored by the U.S. Army Electronics Command, Fort Monmouth, New Jersey, under Contract No. 74-93095. Appreciation is expressed to all those who have contributed time, interest, and suggestions for the success of this project, especially to the project monitor at ECOM, Mr. Paul Major.

Several employees in the Electromagnetics Division of NBS have helped and encouraged us in various aspects of this project. Recognition of the contributions of some of these people can be listed as follows:

Dr. Ramon Baird -- Helpful advice as Chief of the Antennas and Fields Section at NBS,

Stanley Kilgore -- Preliminary testing and field strength calibrations, William Jessen -- Assembly of the isotropic antenna unit and performance testing of the field strength measurement system,

John Adams and Richard FitzGerrell -- Useful suggestions and technical readers for this report,

Sharon Foote -- Efficient typing of the instruction manual and final report, and

Dr. James Wittke of RCA -- Conversations regarding the latest developments in high speed LED's.

\section{REFERENCES}

[1] W.R. Free (Georgia Inst. of Tech.), "Radiated EMI Measurements in Shielded Enclosures," IEEE EMC Symposium Record, Washington, D.C., pp. 43-53 (July 1967).

[2] W.C. Dolle and G.N. Vansteenberg (Southwest Research Inst.), "Effects of Shielaed Enclosure Resonances on Measurement Accuracy," IEEE Inter national Symposium on EMC, Anaheim, Calif., pp. 417-420 (July 1970). 
[3] C.W. Stuckey, "The Hooded Antenna -- An Approach to Meaningful Field Strength Measurements in Shielded Enclosures," IEEE Trans. on EMC, pp. 360-367 (December 1965).

[4] W.R. Free and C.W. Stuckey, "Electromagnetic Interference Measurement Methodology-Communication Equipment," Technical Report ECOM-0189F (October 1969).

[5] C.W. Stuckey, W.R. Free and D.W. Robertson, "Preliminary Interpretation of Near-Field Effects on Measurement Accuracy in Shielded Enclosures," IEEE EMC Symposium Record, Asbury Park, NJ, pp. 119-127 (June 1969).

[6] R.L. Mckenzie, "Advanced Measurement Techniques Within Shielded Enclosures," Research and Development Technical Report ECOM-4226, U.S. Army Electronics Command, Fort Monmouth, N.J. (June 1974).

[7] R.R. Bowman, E.B. Larsen and D.R. Belsher, "Electromagnetic Field Measuring Device," U.S. Patent No. 3,750,017 (July 31, 1973).

[8] F.M. Greene, G.R. Reeve, E.B. Larsen and W.E. Jessen, "Near-Zone E-M Field Measurement Studies," DASA Order No. HD-1102-3171-0001, NBS report (unpublished), Chapter 2 (June 20, 1963).

[9] J.C. Ross, Jr. and S. Jauregui, "A Wideband RF Application of Fiber Optics," (2 to $30 \mathrm{MHz}$ ), Naval Postgraduate School Thesis, Monterey, Calif. (June 1974).

[10] G.N. Vansteenberg, E.L. Bronaugh, O.L. Jouffray and W.C. Dolle, "Radiation Field Measurement Study," USAF Contract F 41609-69-C-0008, 40 pages (October 1969).

[11] G.N. Vansteenberg, E.L. Bronaugh, G.T. Darilek and W.C. Dolle (Southwest Research Inst.), "An Isolated Antenna System for Shielded Enclosure Measurements, 20-200 MHz," IEEE International Symposium Record, Philadelphia, Pa., pp. 198-202 (July 1971).

[12] MIL-STD-461A, "Electromagnetic Interference Characteristics, Requirements for Equipment," U.S. Department of Defense (August 1, 1968).

[13] MIL-STD-462, "Electromagnetic Interference Characteristics, Measurement of," U.S. Department of Defense (July 31, 1967).

[14] C.L. Andrews, "Microwave Probes for Electric Fields Near Metal Surfaces," IEEE Trans. A\&P, pp. 441-445 (July 1968).

[15] C.D. Taylor, S.M. Iin and H.V. Adams, "Scattering From Crossed Wires," IEEE Trans. A\&P, pp. 133-136 (January 1970).

[16] L.R. Bloom, "Optical Communications -- In the 70's and Beyond," Report to the National Science Foundation under Contract H-1221, Panel on Telecommunications Research, pp. 118-129 (June 1973).

[17] S.E. Miller, E.A.J. Marcatili and T. Li, "Research Toward Optical Fiber Transmission Systems. Part I: The Transmission Medium. Part II: Devices and Systems Considerations," Proc. IEEE, "Vol. 61, pp. 1703-1751 (December 1973). 
[18] R.L. Gallawa, "Optical Waveguide Technology for Modern Uxban Communications," IEEE Trans. Commun., No. 1, pp. 131-142 (January 1975).

[19] J.J. Pan, "High Frequency, Wideband Fiber-Optic Link," Digest of Technical Papers, Meeting on Optical Fiber Transmission, Williamsburg, VA (January 7-9, 1975).

[20] J.P. Wittke, "Designer's Guide to: Optical-Fiber Communications Systems," EDN, pp. 30-36 (May 20, 1975).

[21] F.M. Mims, III, "Light-Beam Communications," 160 pages (H.W. Sams \& Co., Inc., First Edition, 1975).

[22] R.L. Gallewa, "A User's Manual for optical Waveguide Communications," OT Report No. 76-83, U.S. Dept. of Commerce, Office of Telecommunications, 287 pages (March 1976).

[23] J.K. Galt, "Lasers and LED's for Optical Fiber Transmission," Digest of Technical Papers, Meeting on Optical Fiber Transmission, Williamsburg, VA (January 7-9, 1975).

[24] F.L. Thiel and W.B. Bielawski, "Optical Waveguides Look Brighter Than Ever," Electronics, pp. 89-96 (March 21, 1974).

[25] J.P. Wittke, "Dispersion-limited Modulation Bandwidths of Optical Fibers," RCA Review, Vol. 35, pp. 198-215 (June 1974).

[26] M. DiDomenico, Jr., "Wires of Glass," Industrial Research, pp. 50-54 (August 1974).

[27] F.M. Greene," NBS Field-Strength Standards and Measurements (30 Hz to $1000 \mathrm{MHz}$ )," Proc. IEEE, Vol. 55, pp. 970-981 (June 1967).

[28] H.E. Taggart and J.L. Workman, "Calibration Principles and Procedures for Field Strength Meters ( $30 \mathrm{~Hz}$ to $1 \mathrm{GHz}$ )," Nat. Bur. Stand. (U.S.), Tech. Note 370,151 pages (March 1969).

[29] M.L. Crawford, "Generation of Standard EM Fields Using TEM Transmission Cells," IEEE Trans. on EMC, Vol. EMC-16, No. 4, pp. 189-195 (November 1974).

[30] D.F. Wait, "Measurement of Amplifier Noise," Microwave Journal, Vol. 16, No. 1 (January 1973).

[31] M.G. Arthur, "The Measurement of Noise Performance Factors: A Metrology Guide," Nat. Bur. Stand (U.S.), Monog. 142, 188 pages (June 1974).

[32] W. Hayward, "Defining and Measuring Receiver Dynamic Range," QST, pp. 15-21 (July 1975).

[33] "Nonlinear System Modeling and Analysis with Applications to Communications Receivers," Rome Air Development Center Report No. RADC-TR-73-178, Edited by J.W. Graham, L. Ehrman Consulting Scientist, Signatron, Inc. (June 1973). 
[34] H. Kressel and M. Ettenberg, "A New Edge-Emitting (AlGa) As Heterojunction LED for Fiber-optic Communications," Proc. IEEE, Vol. 63, pp. 1360-1361 (September 1975).

[35] J.C. Blackburn, "A 120-MHz Bandwidth Linear Signal Transmission System Using Fiber Optics," IEEE Trans. Instr. \& Meas., Vol. IM-24, pp. 230-232 (September 1975). 


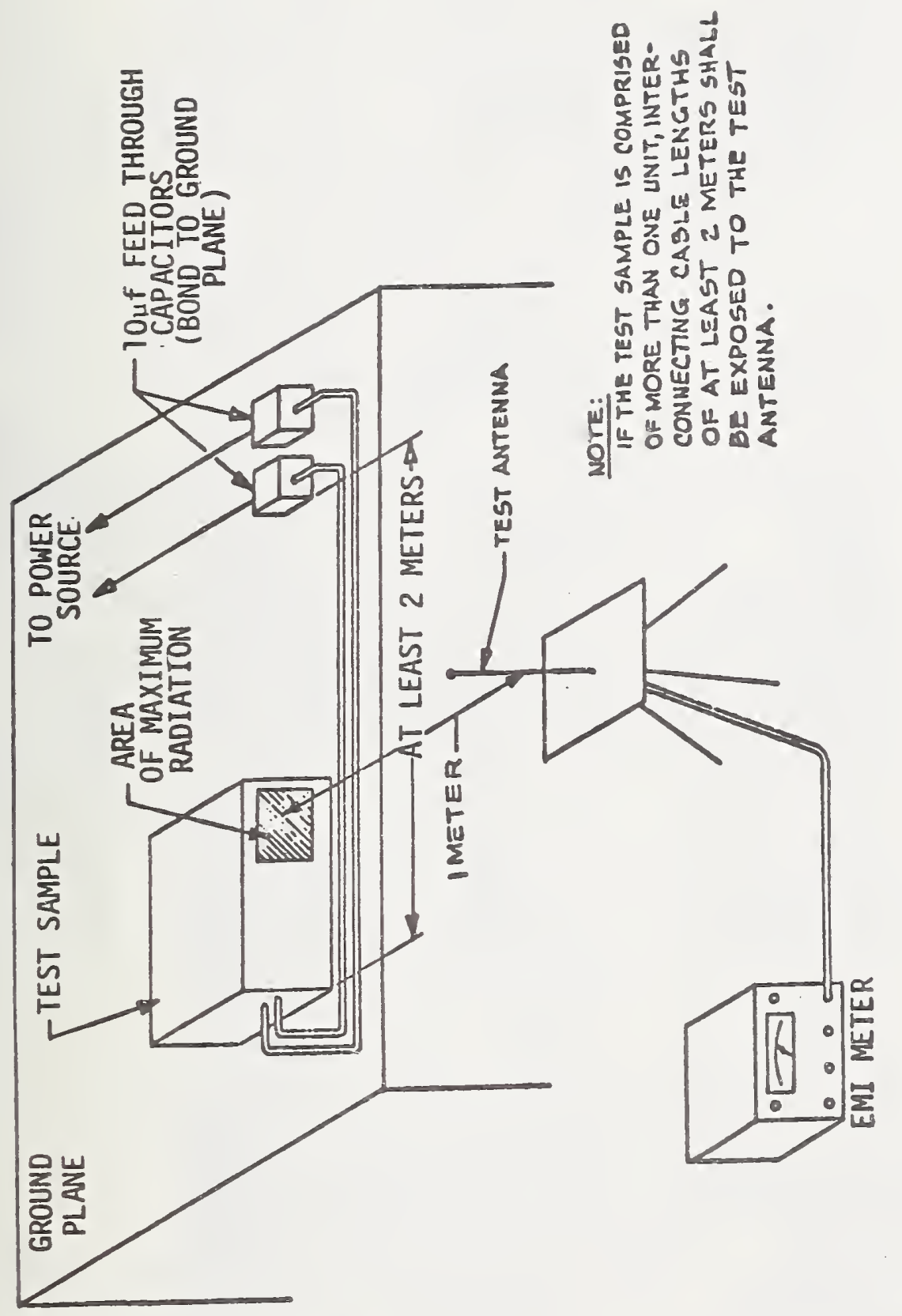

U

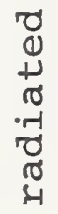

¿

넌

을

o

U

(1) 6

$+\pi$

ชค

0 U

०,

서늘

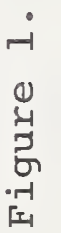




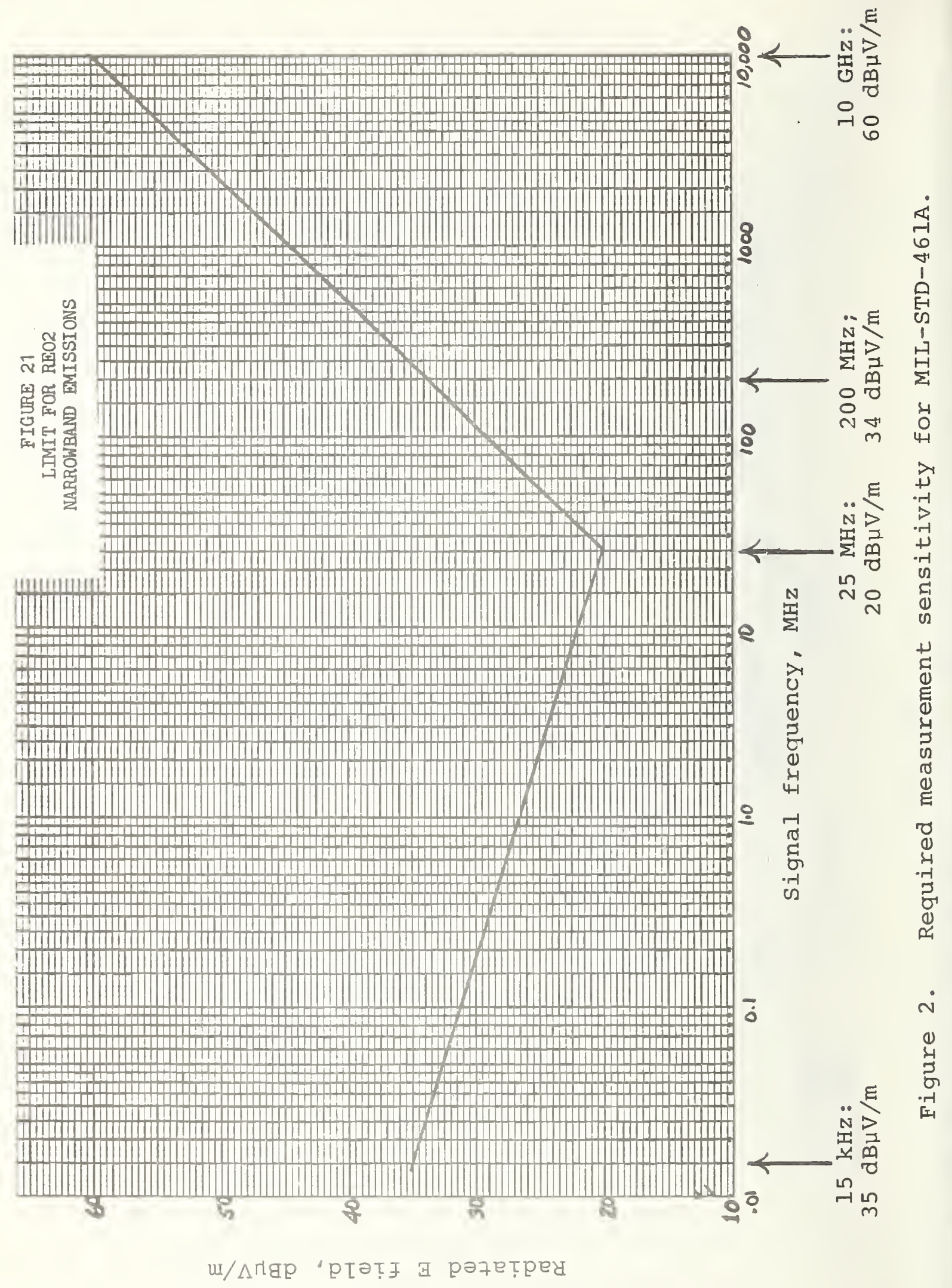




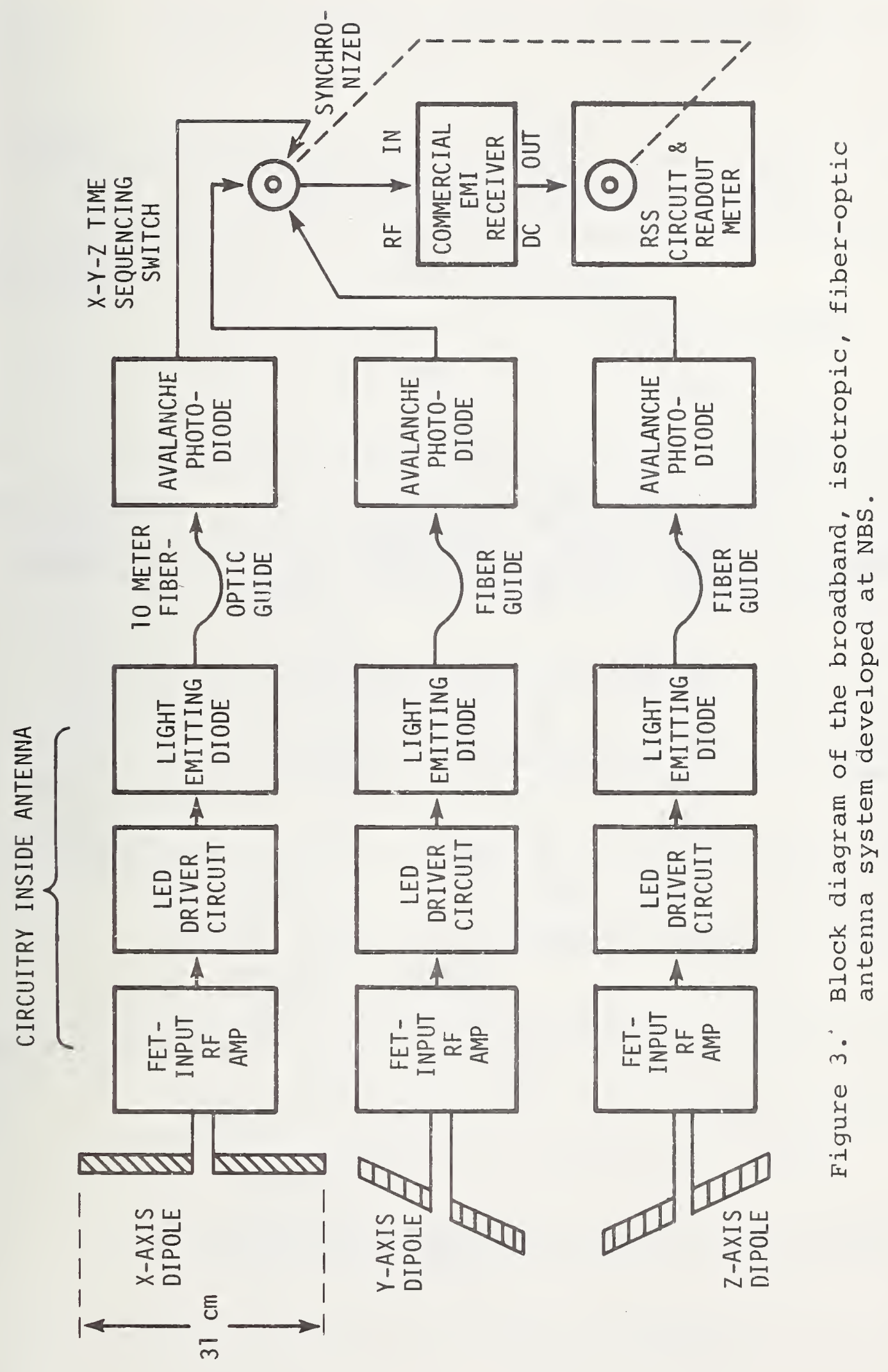


Table 1. Sensitivity requirements for measuring narrowband signals according to MIL-STD-461/462.

\begin{tabular}{|c|c|c|c|c|}
\hline \multirow{2}{*}{$\begin{array}{c}\text { Signal } \\
\text { Frequency } \\
\end{array}$} & \multicolumn{2}{|c|}{$\begin{array}{l}\text { MIL-STD- } 461 / 642 \\
\text { EField Limits }\end{array}$} & \multirow{2}{*}{$\begin{array}{l}\text { Open-Circuit } \\
\text { Pickup of a } 31 \mathrm{~cm} \\
\text { Dipole } \cong 0.15 \mathrm{E} \\
\end{array}$} & \multirow{2}{*}{$\begin{array}{c}\text { Approximate } \\
\text { Receiver } \\
\text { Input } \\
\end{array}$} \\
\hline & $\mathrm{dB} \mu \mathrm{V} / \mathrm{m}$ & $\mu \mathrm{V} / \mathrm{m}$ & & \\
\hline $15 \mathrm{kHz}$ & 35.0 & 56 & $8.4 \mu \mathrm{V}$ & $4.2 \mu \mathrm{V}$ \\
\hline $100 \mathrm{kHz}$ & 31.2 & 36 & 5.4 & 2.7 \\
\hline $1 \mathrm{MHz}$ & 26.5 & 21 & 3.2 & 1.6 \\
\hline $10 \mathrm{MHz}$ & 21.9 & 12 & 1.9 & 0.9 \\
\hline $25 \mathrm{MHz}$ & 20.0 & 10 & 1.5 & 0.8 \\
\hline $100 \mathrm{MHz}$ & 29.1 & 29 & 4.3 & 2.1 \\
\hline $200 \mathrm{MHz}$ & 33.7 & 48 & 7.3 & 3.6 \\
\hline $1 \mathrm{GHz}$ & 44.5 & 168 & -- & -- \\
\hline $10 \mathrm{GHz}$ & 60.0 & 1000 & -- & -- \\
\hline
\end{tabular}


Table 2. Characteristics of fiber-optic and radiated infrared communication links.

\section{Advantages:}

Large information bandwidth

High security, low cross-talk and pickup

Freedom from EMI, no $\mathrm{E}$ or $\mathrm{H}$ coupling

Electrical isolation, absence of ground loops

No short circuits, arcing or grounding problems

Components are small, lightweight, and low power

Transmission lines are light, flexible and low loss

For radiated links: large antenna gain, no license required

will eventually be cheaper than coax or radiated rf links.

Disadvantages: Shortage of off-the-shelf opto-electronic components

Glass fibers are difficult to splice and are not rugged to handle.

Proposed Uses: Outer space and aircraft applications (lightweight) Military airplanes and ships (high security)

Inter and inner city trunk lines (large bandwidth)

* Electrically $\frac{\text { isolated links for EMI antennas and }}{\text { rf hazard probes. }}$ 


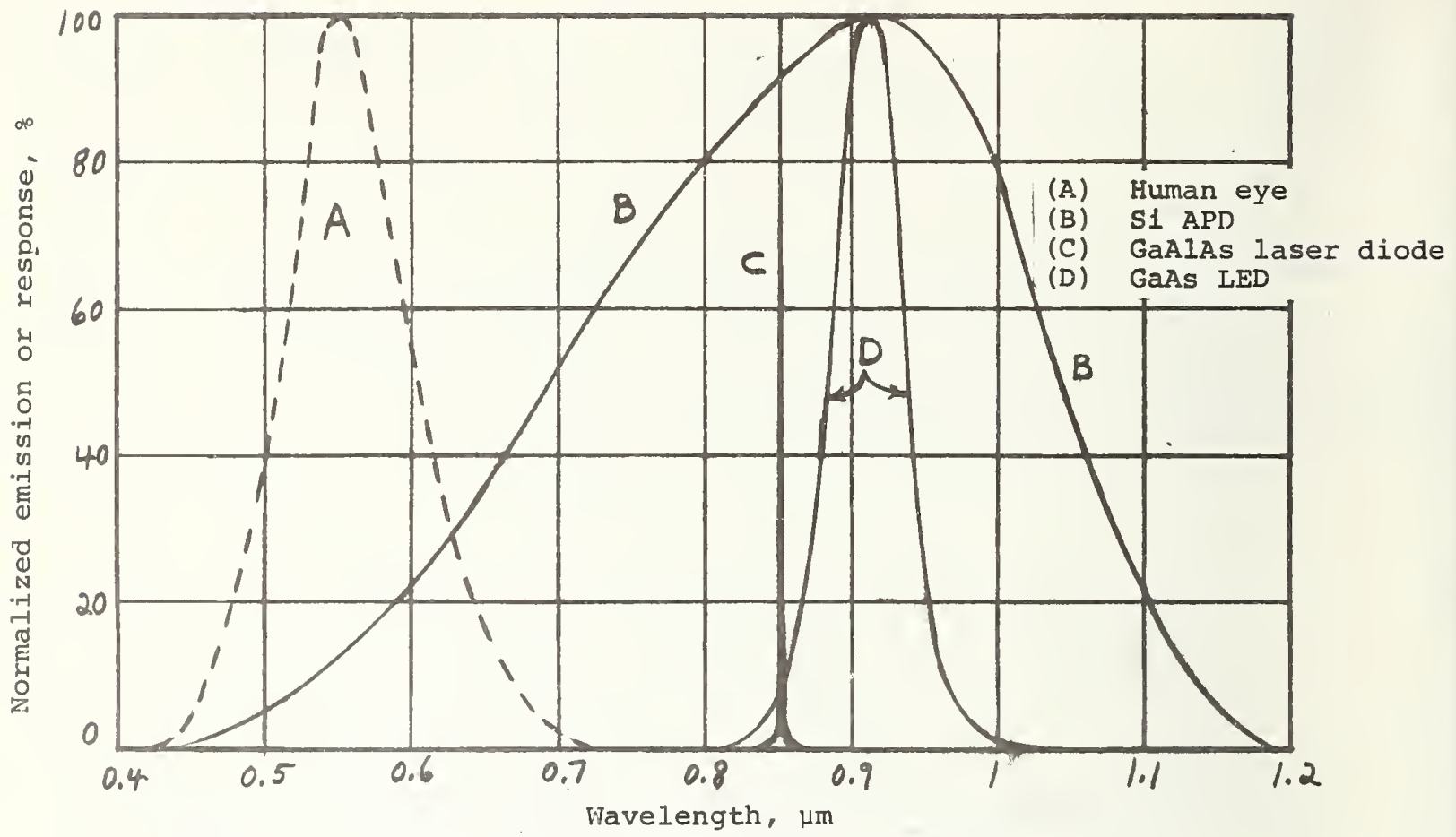

Figure 4. Typical emission spectra or response of various optical sources and detectors.

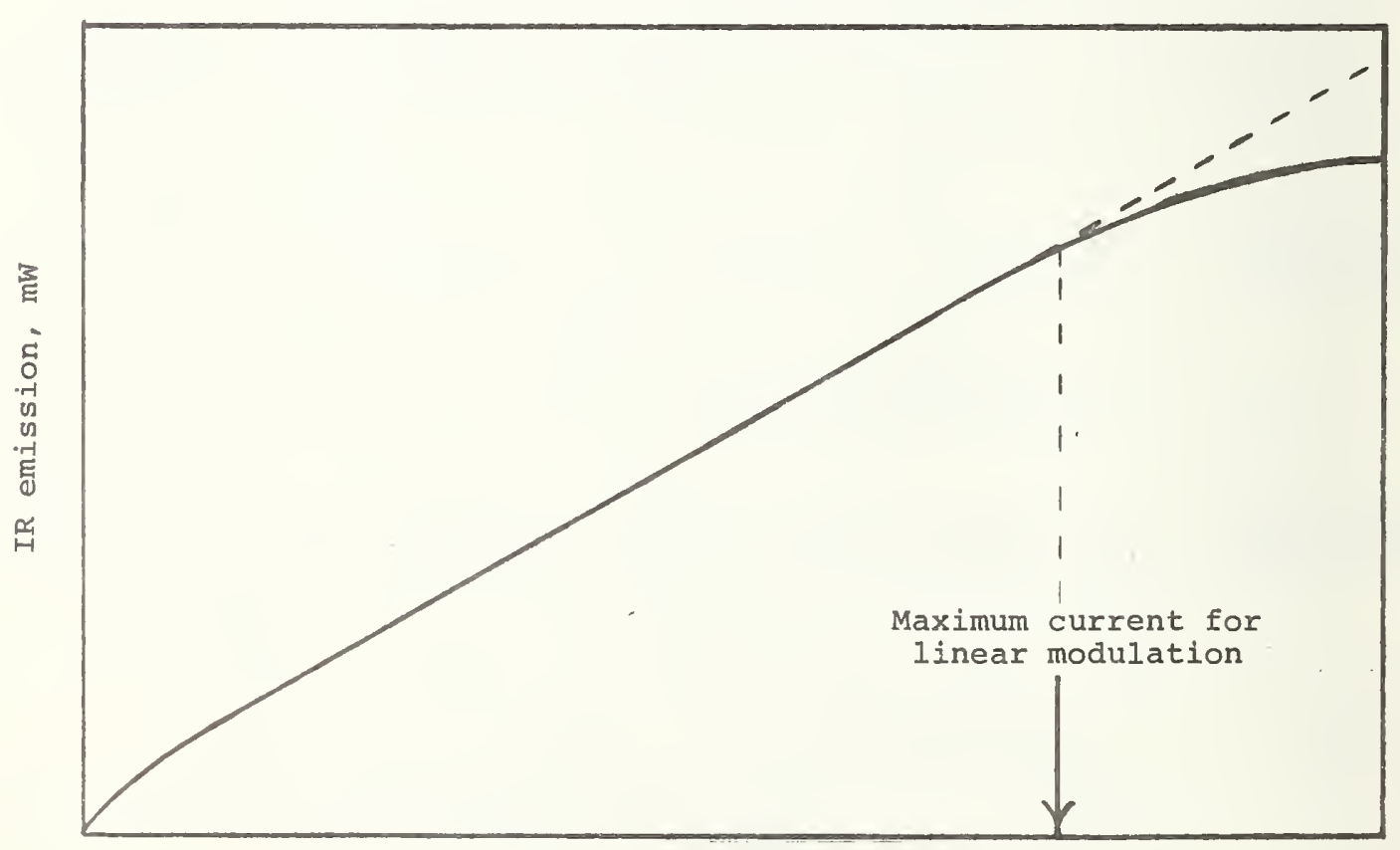

Forward current, mA

Figure 5. Intensity of radiation vs. forward current for a typical infrared LED. 
Table 3. Specified CW characteristics of some typical LED's.

\begin{tabular}{|l||r|r|r|r|r|r|r|}
\hline \multicolumn{1}{|c||}{ Type Number } & \multicolumn{1}{|c|}{471} & 31 & 3 & 930 & 4120 & 2430 & 6478 \\
\hline Forward bias current, mA & 150 & 100 & 50 & 100 & 100 & 150 & 3000 \\
Radiated power output, mW & 1 & 6 & 0.8 & 0.65 & 0.2 & 0.3 & 300 \\
$\begin{array}{l}\text { Peak emission wavelength, nm } \\
\text { Spectral bandwidth at 508 of } \\
\text { peak intensity, nm }\end{array}$ & 210 & 940 & 900 & 900 & 890 & 907 & 935 \\
$\begin{array}{l}\text { Beam spread at 50z of peak } \\
\text { intensity, degrees }\end{array}$ & 130 & 10 & 56 & 30 & 90 & 32 & 180 \\
$\begin{array}{l}\text { LED emitting diameter, mils } \\
\text { loz-908 risetime, ns }\end{array}$ & 18 & -- & -- & -- & 24 & -- & -- \\
& 15 & 600 & 1 & -- & 100 & 20 & 700 \\
\hline
\end{tabular}

Table 4. Specified characteristics of some typical photodetectors.

\begin{tabular}{|c|c|c|c|c|c|c|c|c|}
\hline Type Number & 30807 & 2 & 4220 & 3421 & 30817 & 59 & $\stackrel{*}{*}$ & $\begin{array}{l}7102 \\
\text { (Tube) }\end{array}$ \\
\hline Type of device & $\begin{array}{l}\text { Si PIN } \\
\text { diode }\end{array}$ & $\begin{array}{l}\text { Si PIN } \\
\text { diode }\end{array}$ & $\begin{array}{l}\text { Si PIN } \\
\text { diode }\end{array}$ & $\begin{array}{l}\text { Si PIN } \\
\text { diode }\end{array}$ & Si APD & Si APD & Si APD & $\begin{array}{l}\text { Photomul- } \\
\text { tiplier }\end{array}$ \\
\hline Responsivity, $\mu \mathrm{A} / \mu \mathrm{W}$ & 0.65 & 0.7 & 0.5 & 0.55 & 80 & 24 & -- & 400 \\
\hline $\begin{array}{l}\text { Peak spectral response, } \\
\text { nm }\end{array}$ & 900 & 900 & 770 & 890 & 900 & 770 & 850 & 800 \\
\hline $\begin{array}{l}\text { Spectral bandwidth at } \\
108 \text { points }\end{array}$ & $\begin{array}{l}400- \\
1100\end{array}$ & $\begin{array}{l}310- \\
1140\end{array}$ & $\begin{array}{l}400- \\
1040\end{array}$ & $\begin{array}{l}420- \\
1100\end{array}$ & $\begin{array}{l}420- \\
1100\end{array}$ & $\begin{array}{l}550- \\
960\end{array}$ & $\begin{array}{l}550- \\
1100\end{array}$ & -- \\
\hline $\begin{array}{l}\text { Active reception area, } \\
\mathrm{mm}^{2}\end{array}$ & 0.8 & 0.58 & 0.2 & 1.3 & 0.5 & 0.45 & 0.45 & 780 \\
\hline $\begin{array}{l}\text { Current amplification } \\
\text { factor }\end{array}$ & 1 & 1 & 1 & 1 & 120 & 120 & 200 & 150,000 \\
\hline $\begin{array}{l}\text { Noise equivalent power, } \\
\mathrm{pW} \sqrt{\mathrm{Hz}}\end{array}$ & 0.1 & -- & -- & -- & 0.01 & 0.2 & 0.2 & -- \\
\hline 10-908 risetime, ns & 3 & 0.5 & $<1$ & $<5$ & 2 & $<10$ & $<10$ & 25 \\
\hline
\end{tabular}




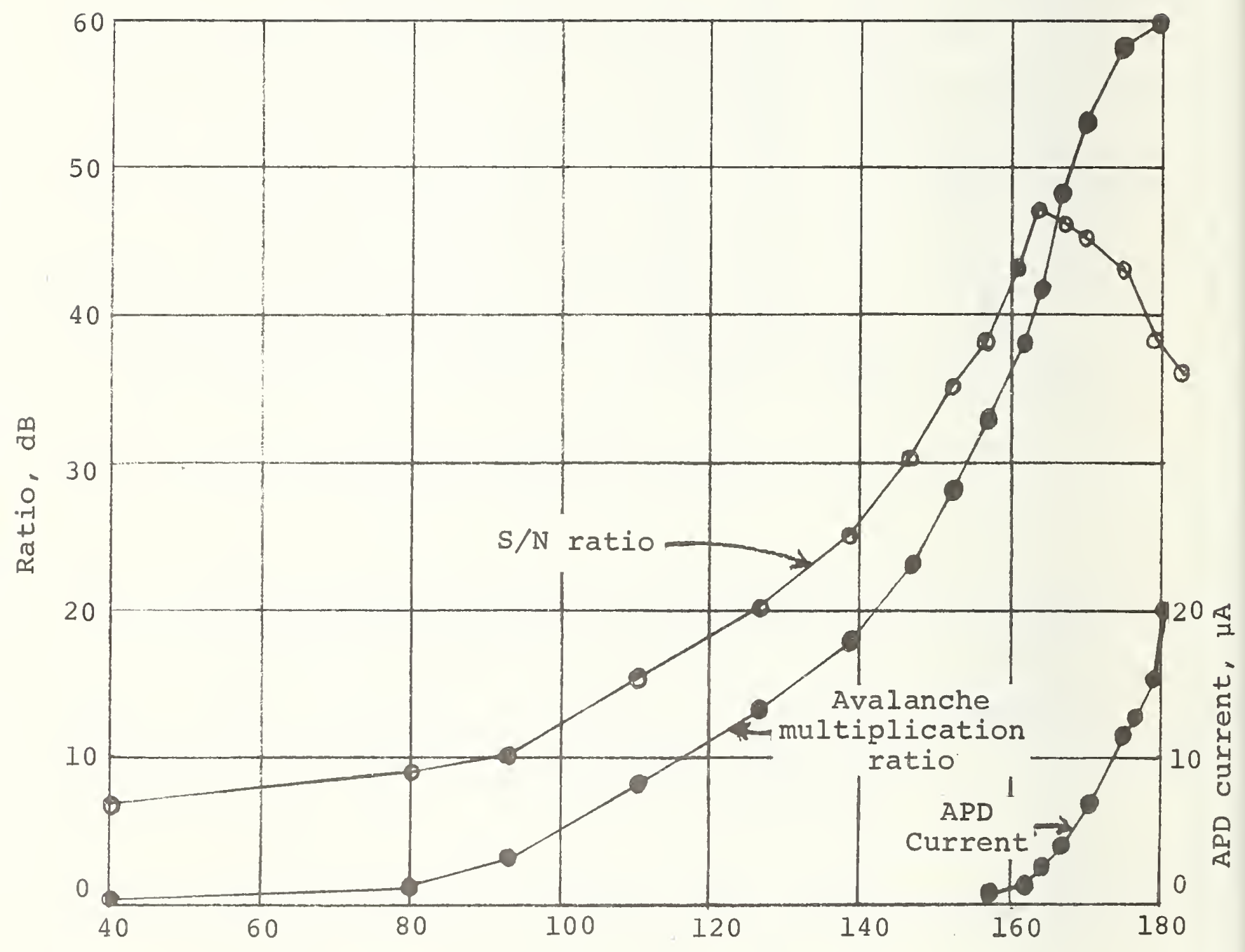

Reverse bias on $\mathrm{APD}$, volts

Figure 6. Measured performance of avalanche photodiode No. 2 at an ambient temperature of $28^{\circ} \mathrm{C}$. 


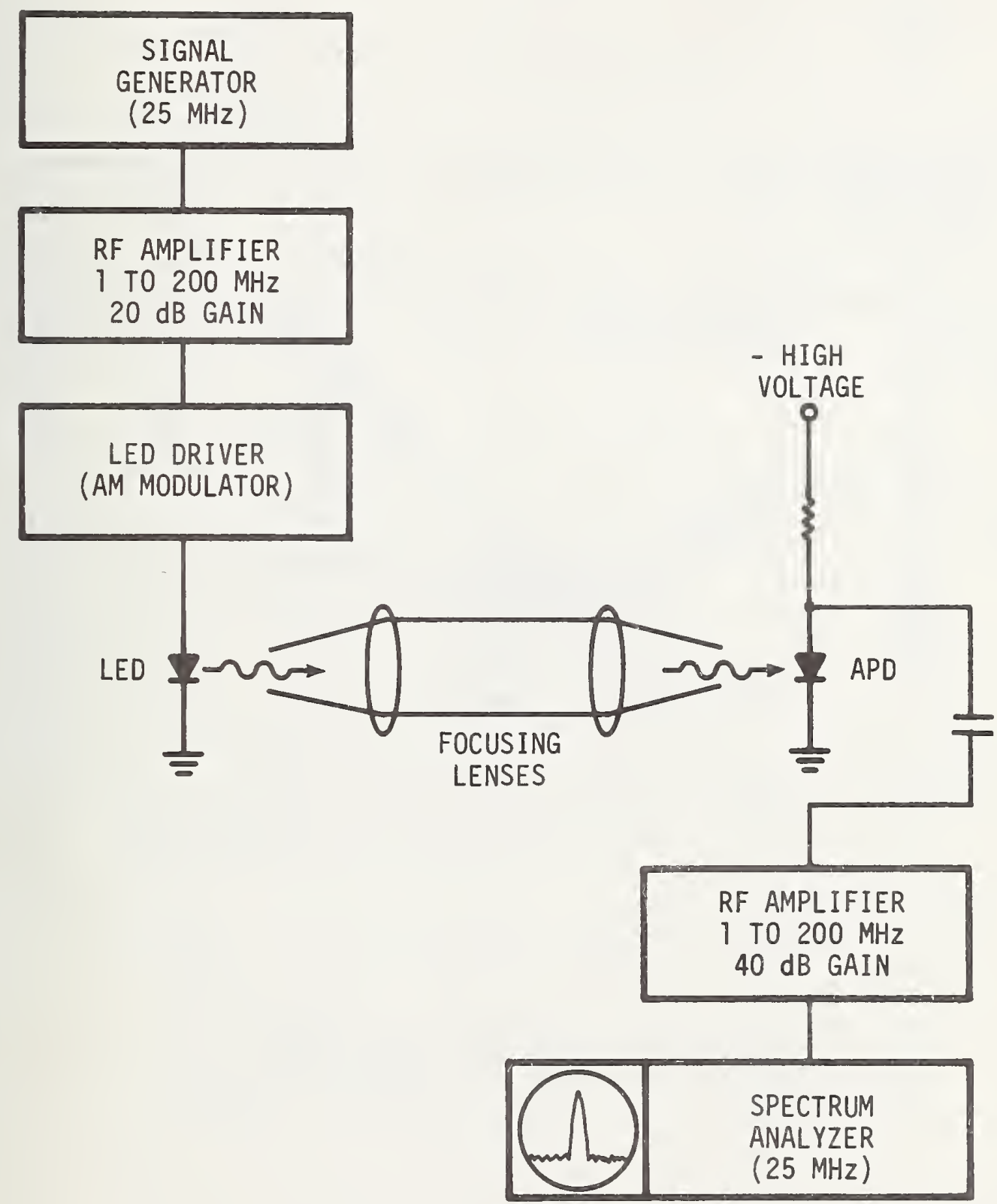

Figure 7. Instrumentation for an experimental radiated communications link. 


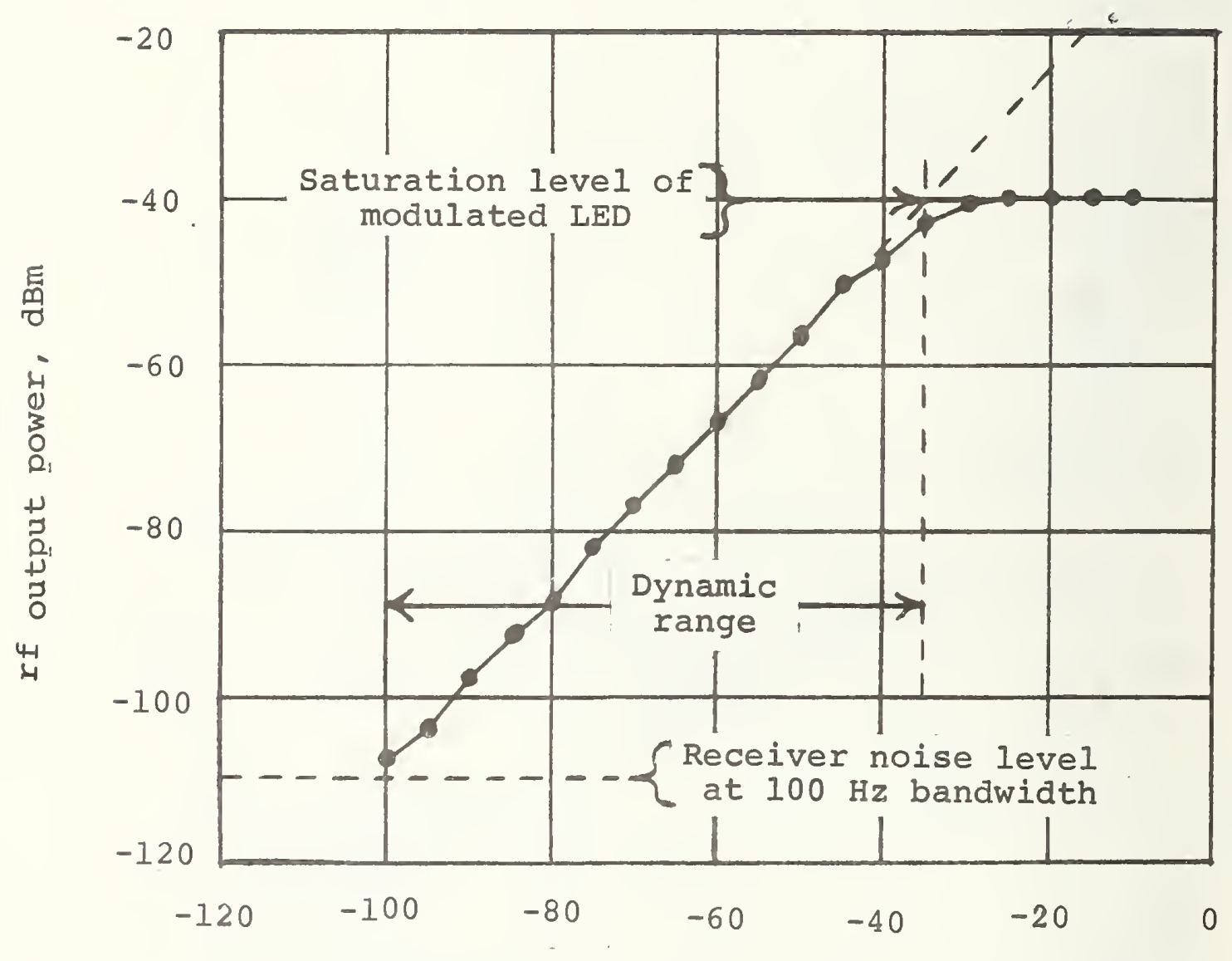

rf signal input power, dBm

Figure 8. Performance of the experimental radiated link at a signal frequency of $25 \mathrm{MHz}$. 


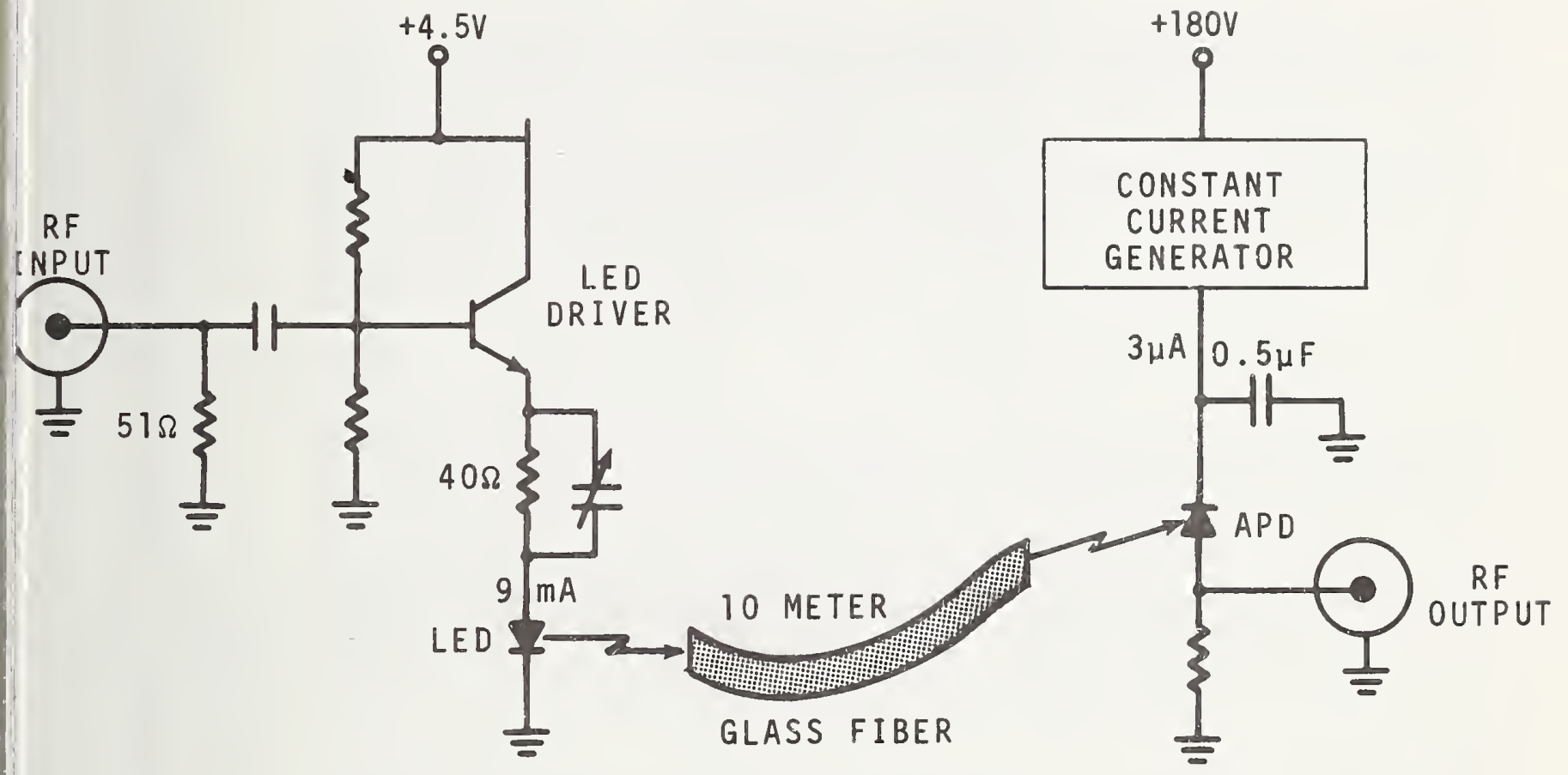

If signal attenuation at low frequencies:

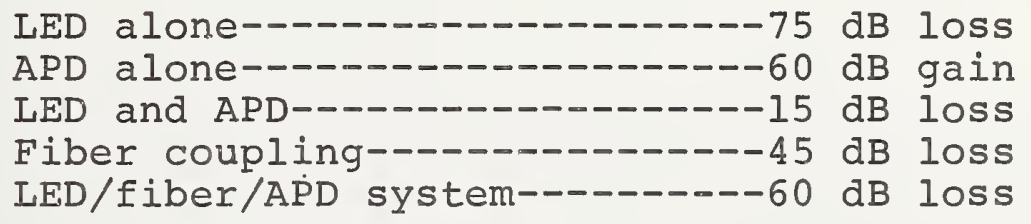

Figure 9. Simplified schematic of the instrumentation for measuring rf attenuation of the fiber-optic link. 


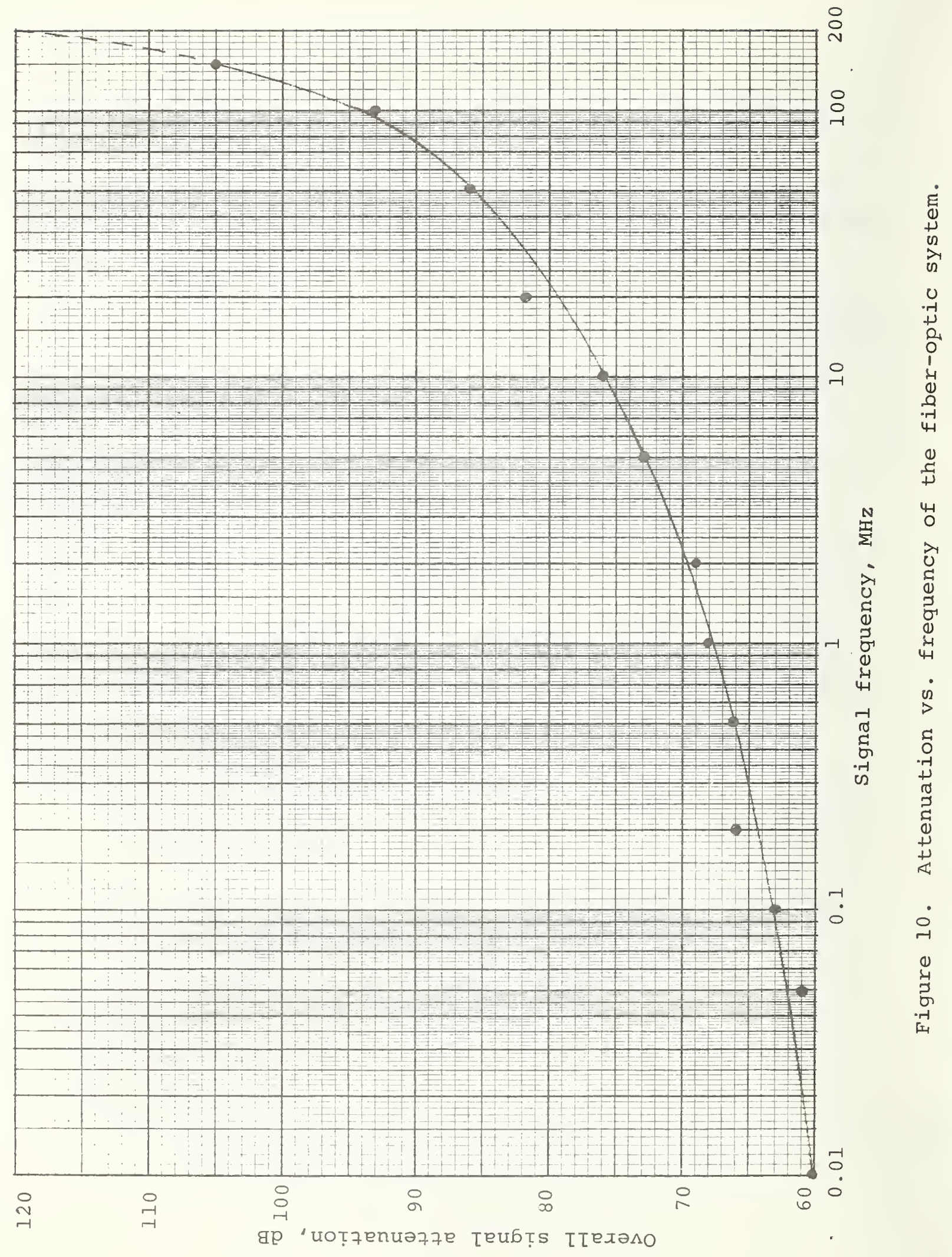




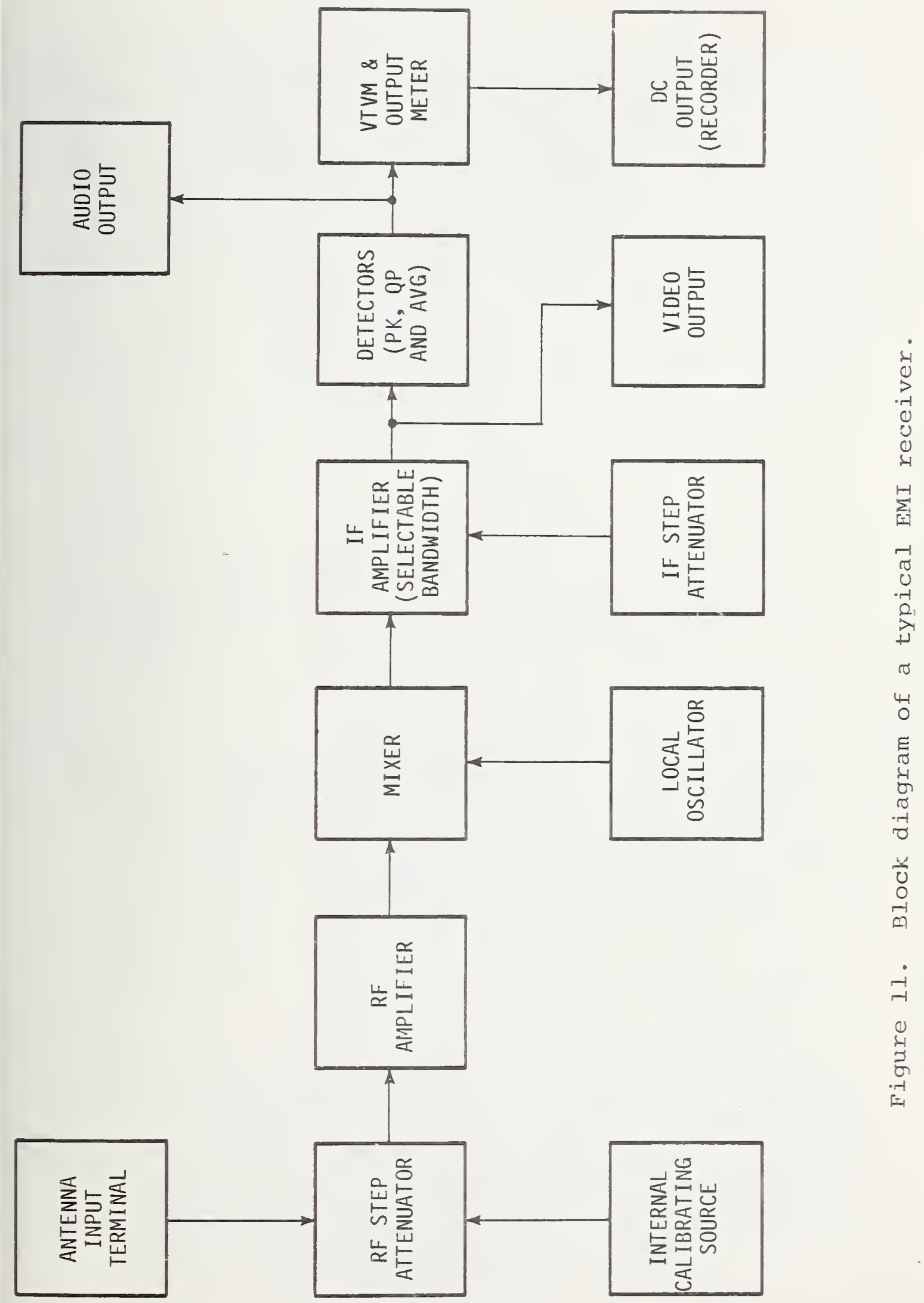




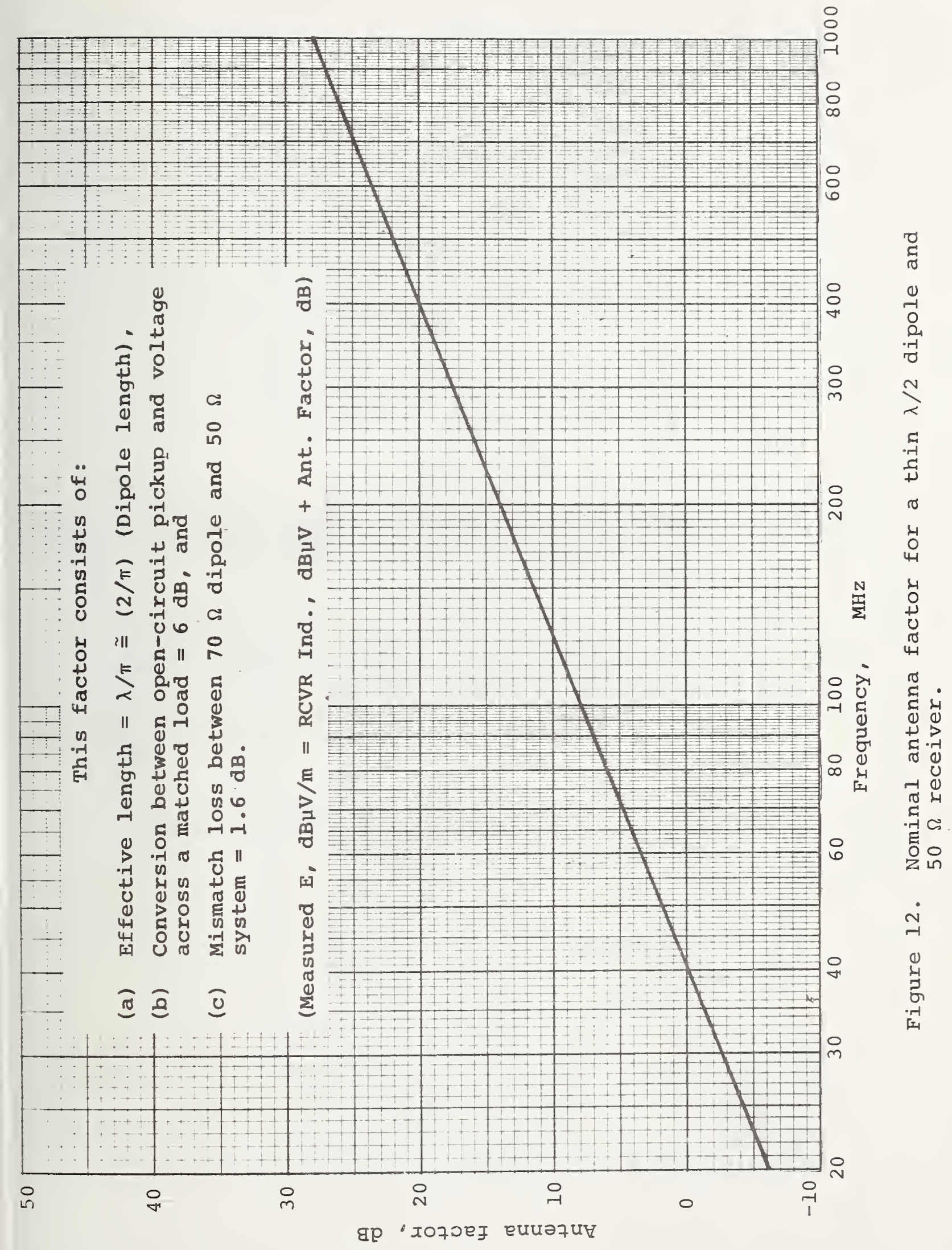




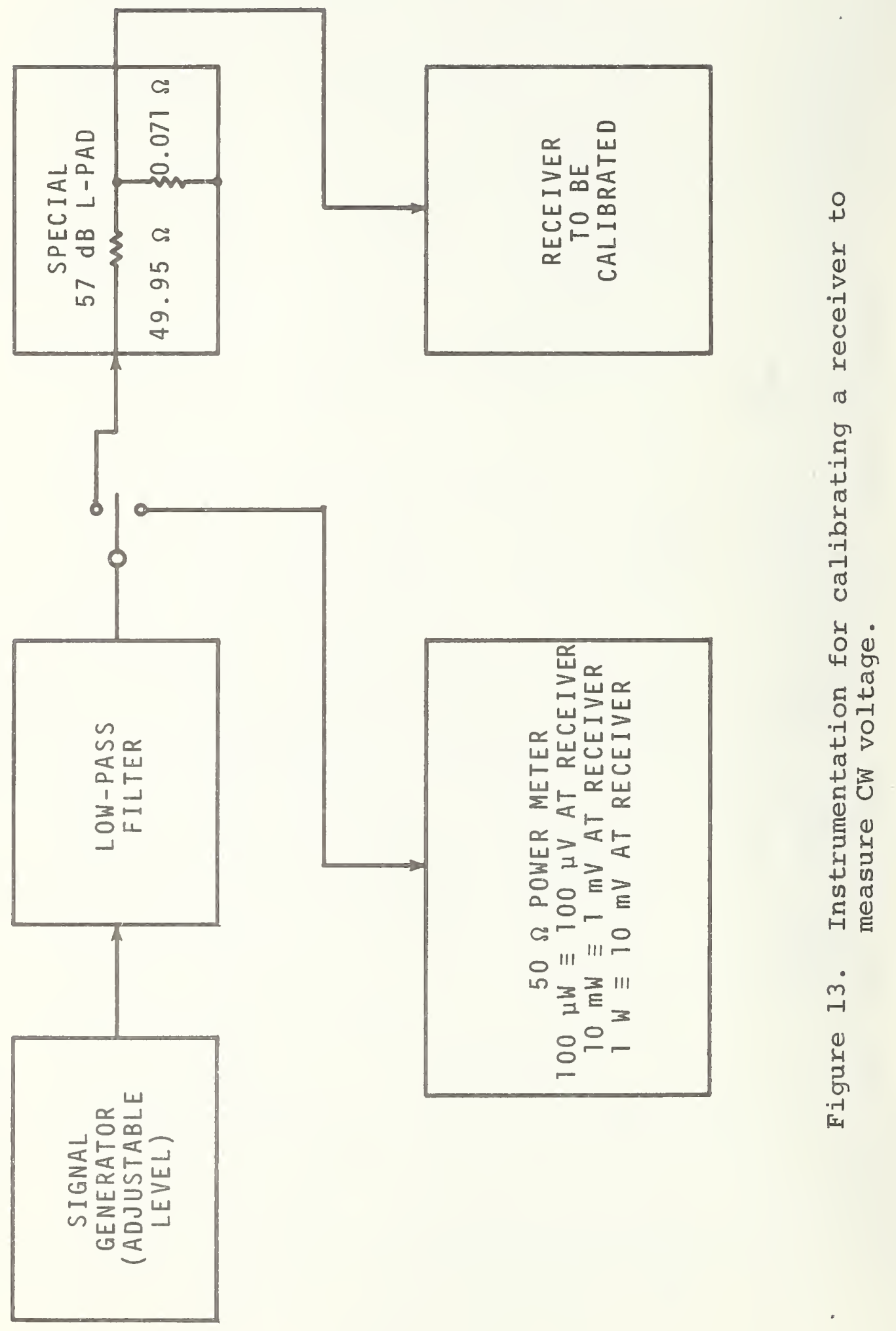




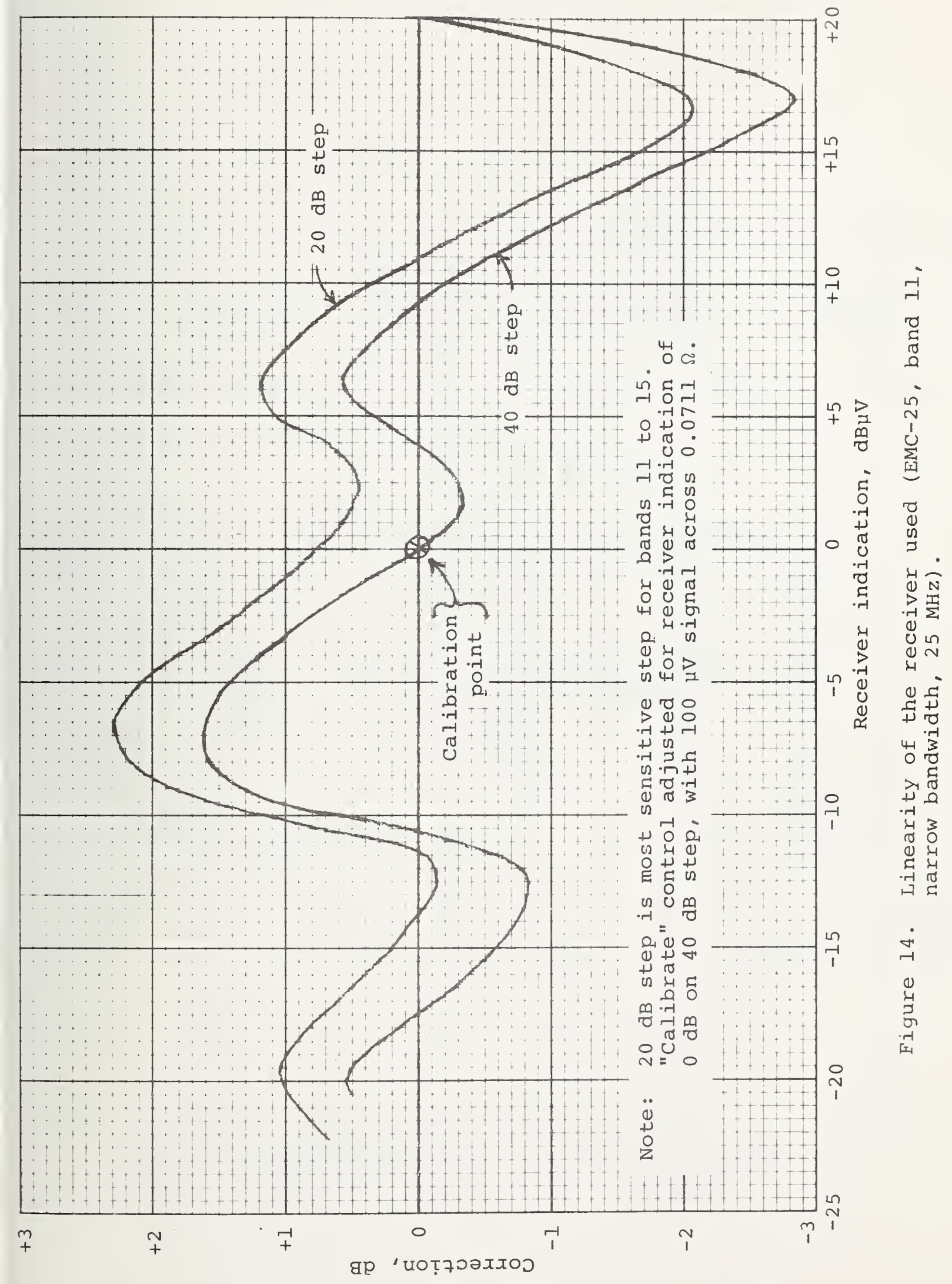



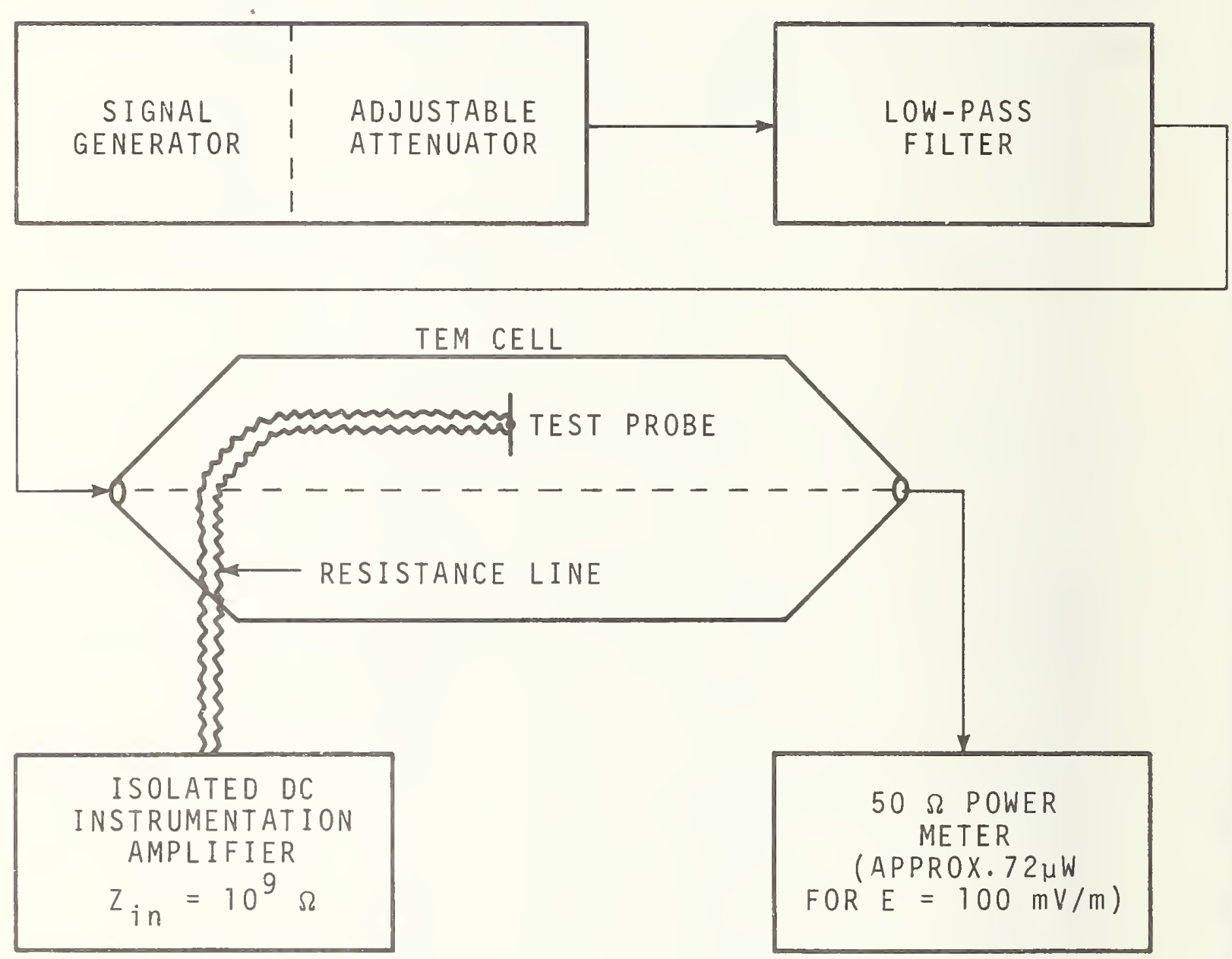

Figure 15. Instrumentation used to establish a known E field in the TEM cell for calibrating the active dipole. 


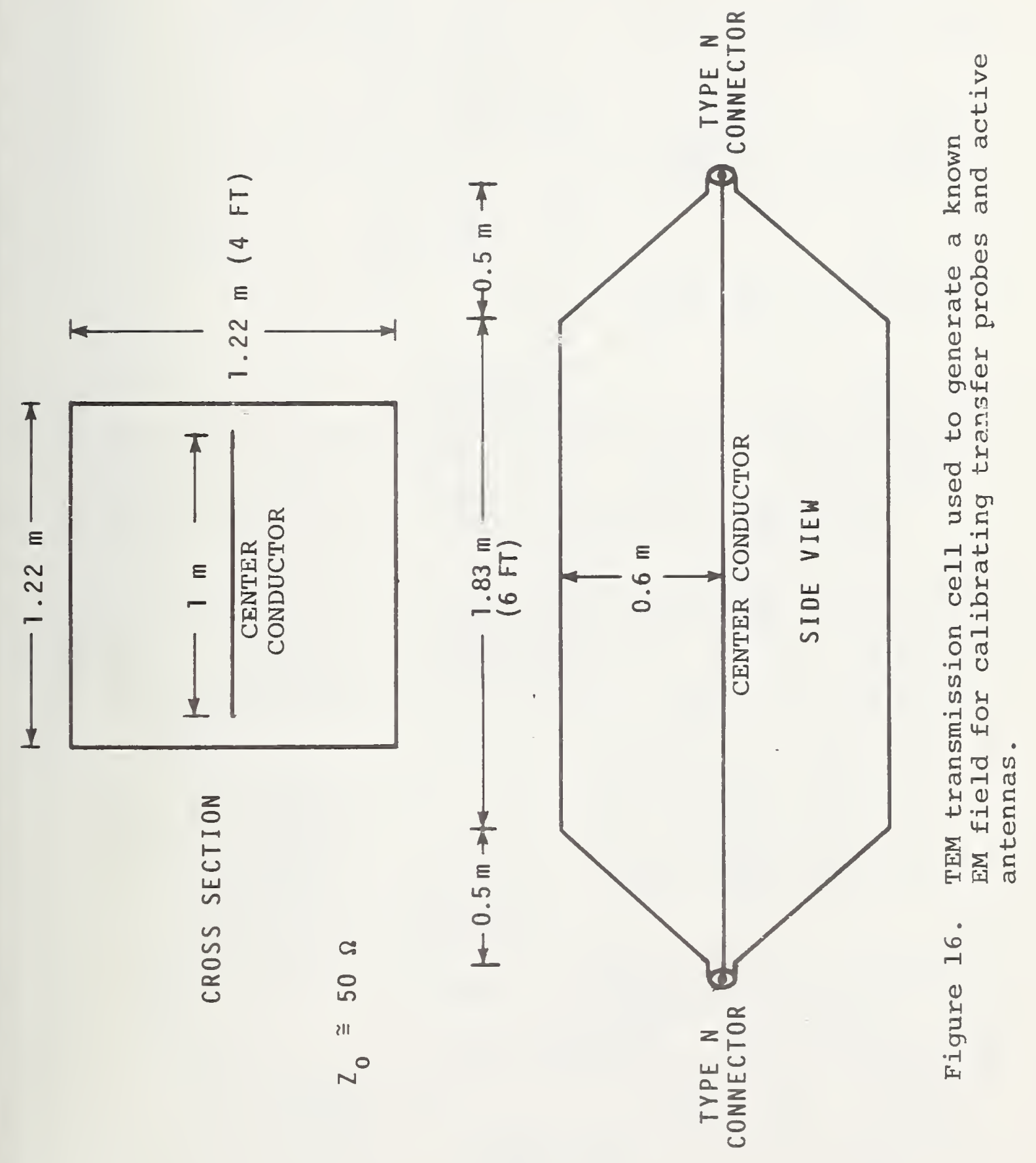




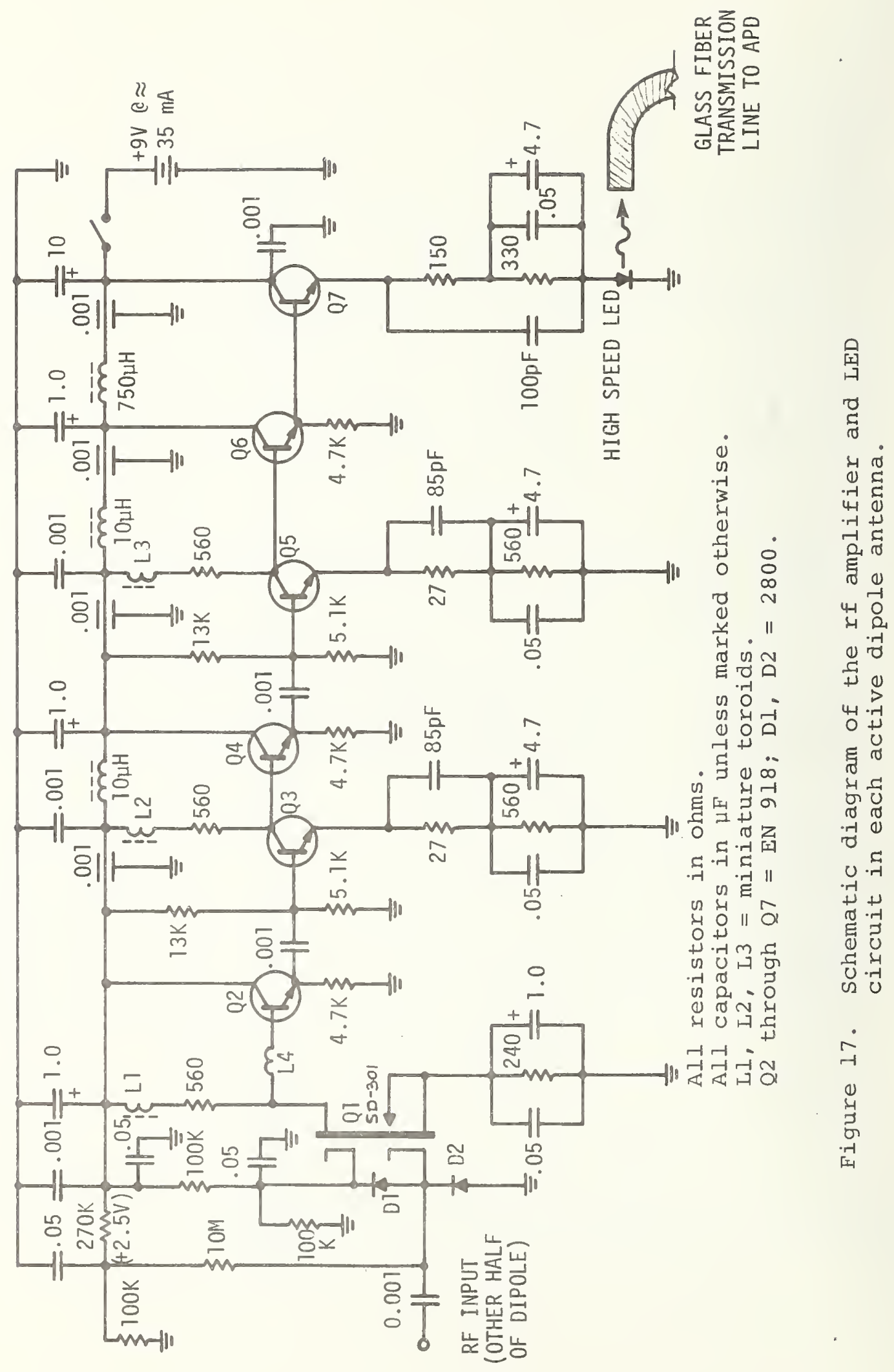




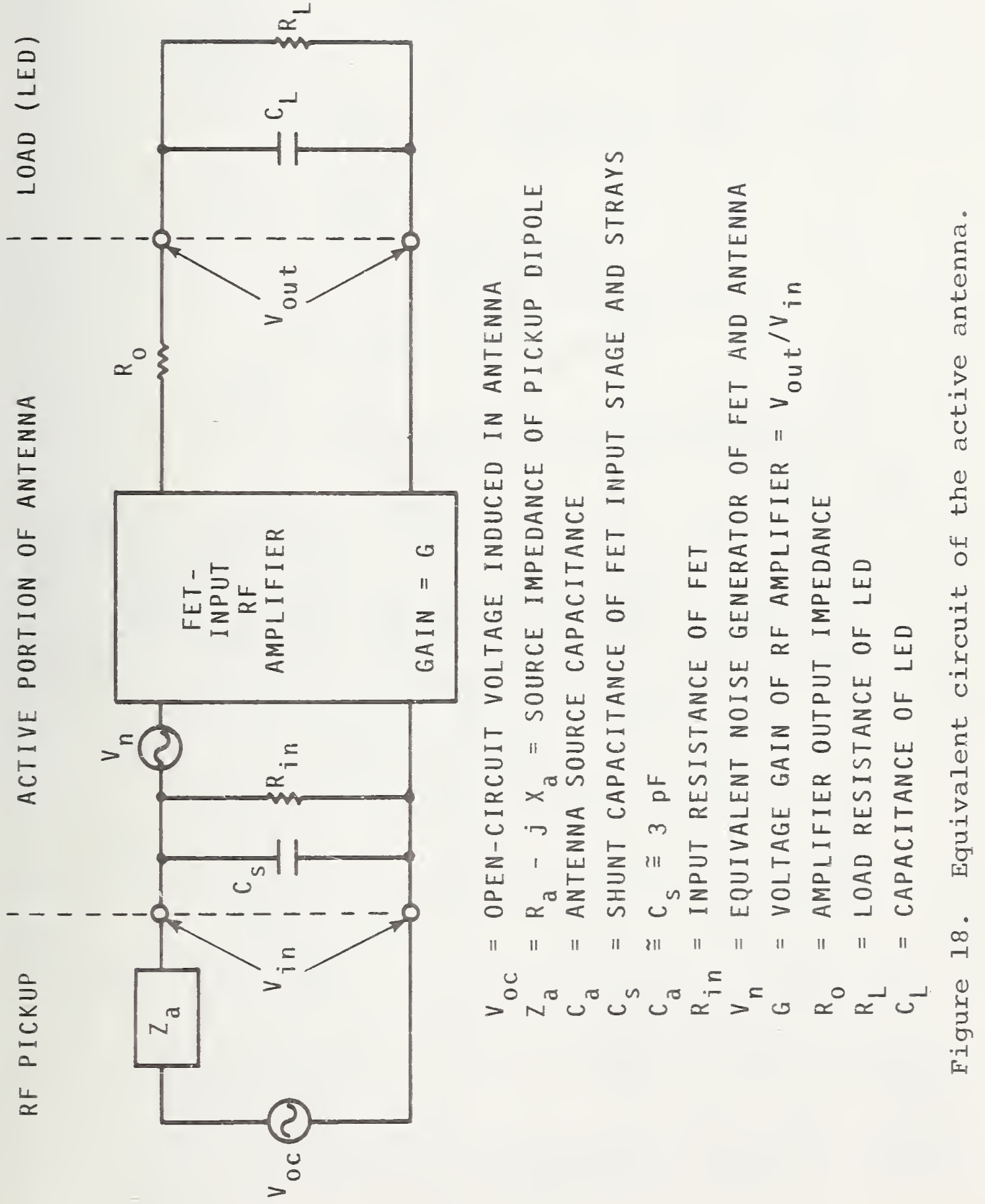




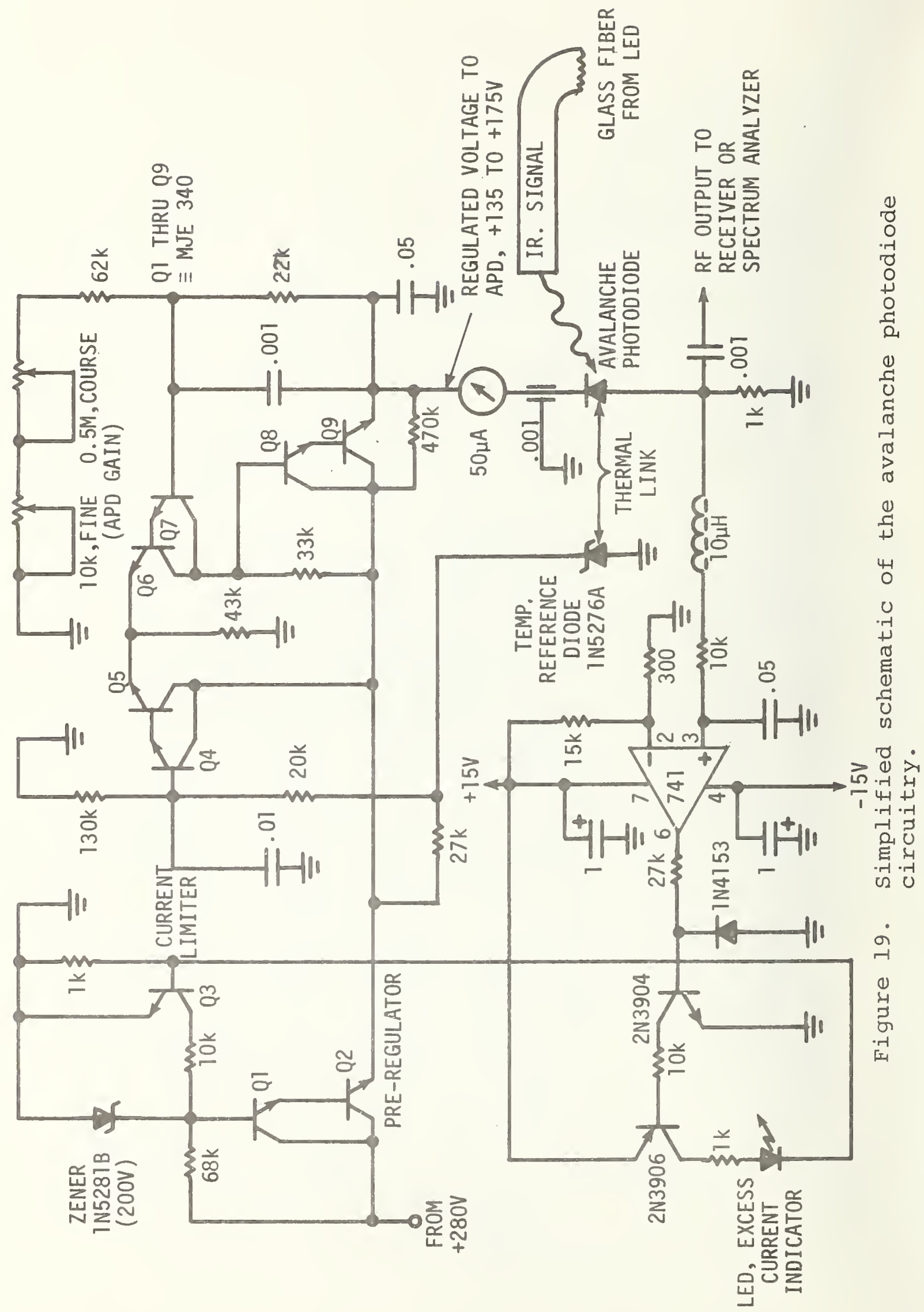




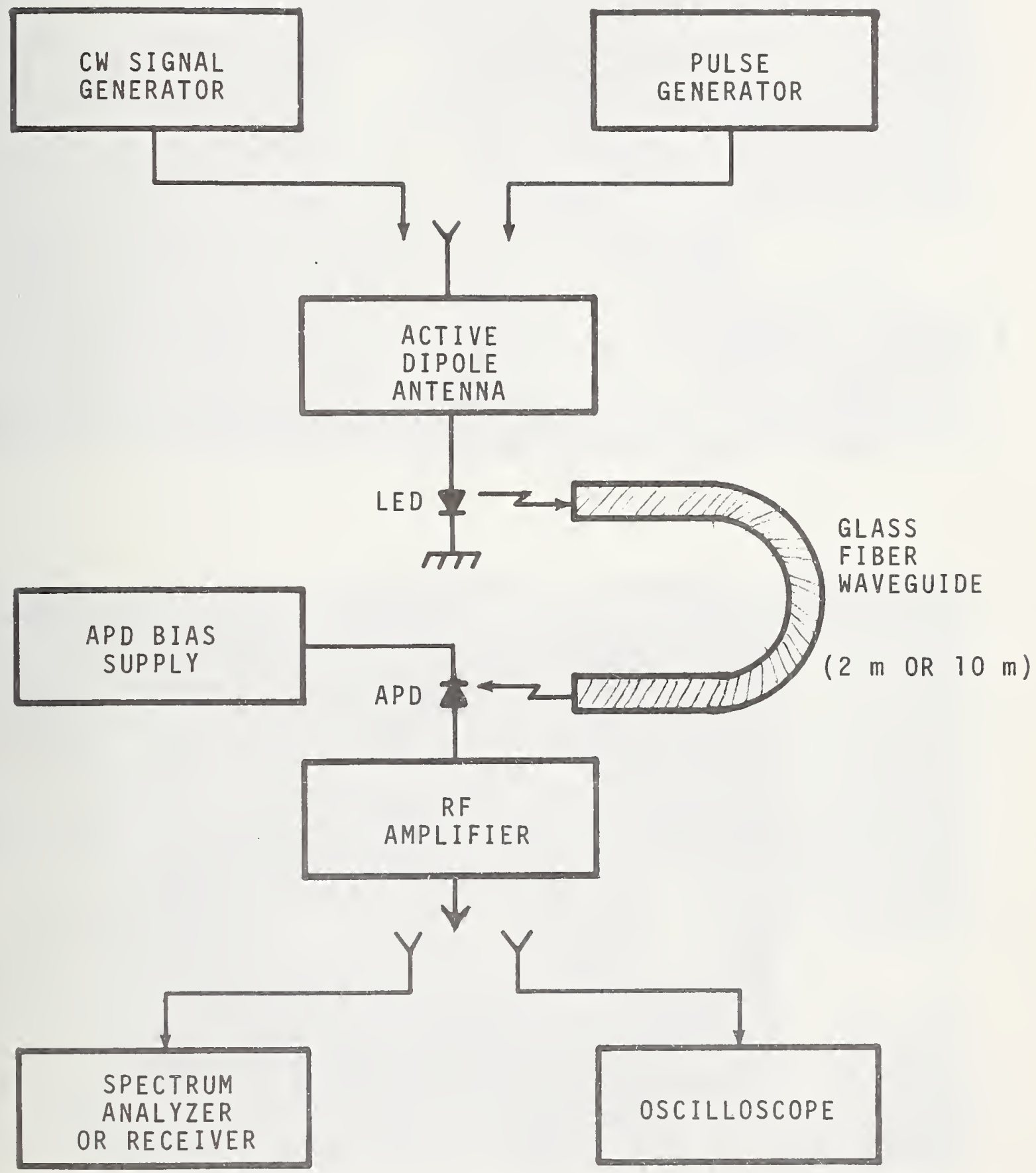

Figure 20. Test setup for observing the system gain, frequency response and step response. 
Table 7. Frequency response test of the prototype antenna system. (Input signal $=-80 \mathrm{dBm}$, Spectrum analyzer bandwidth $=3 \mathrm{kHz}$.)

\begin{tabular}{|c|c|c|}
\hline Frequency, MHz & Gain, $\mathrm{dB}$ & $(\mathrm{S}+\mathrm{N}) / \mathrm{N}$ ratio, $\mathrm{dB}$ \\
\hline 15 & 16 & 20 \\
25 & 16 & 20 \\
50 & 15 & 19 \\
75 & 6 & 18 \\
100 & 5 & 16 \\
125 & 0 & 12 \\
150 & -3 & 10 \\
175 & -4 & 8 \\
200 & -6 & 6 \\
& & \\
\hline
\end{tabular}

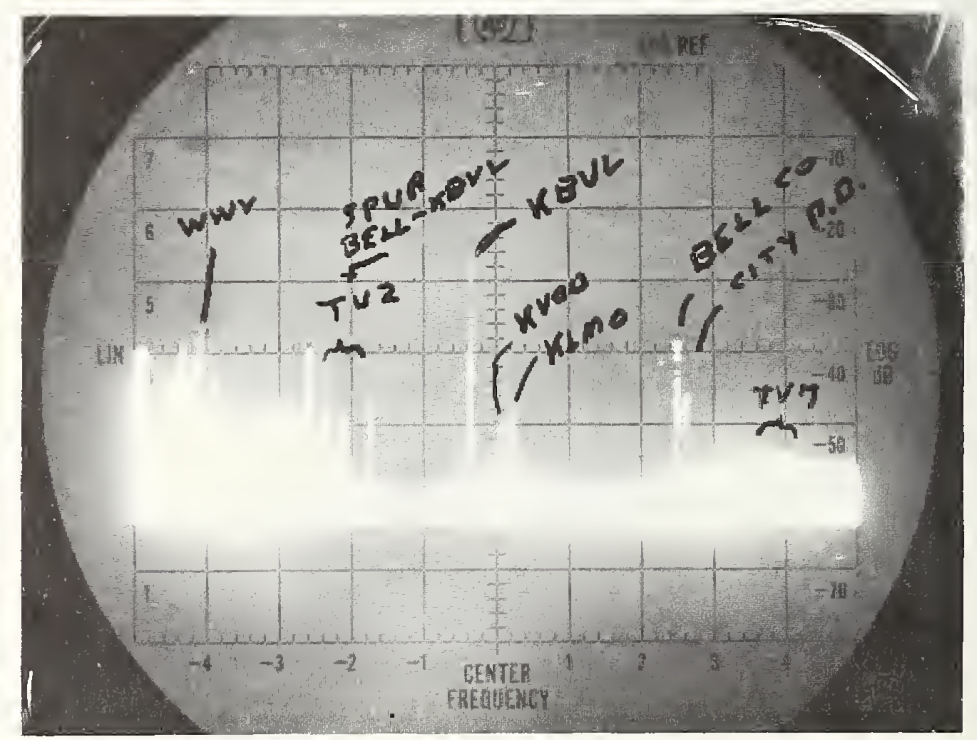

Figure 21. Signals received in the laboratory by a prototype active dipole. (Horizontal scan from DC to $200 \mathrm{MHz}$, spectrum analyzer bandwidth $=3 \mathrm{kHz}$.) 

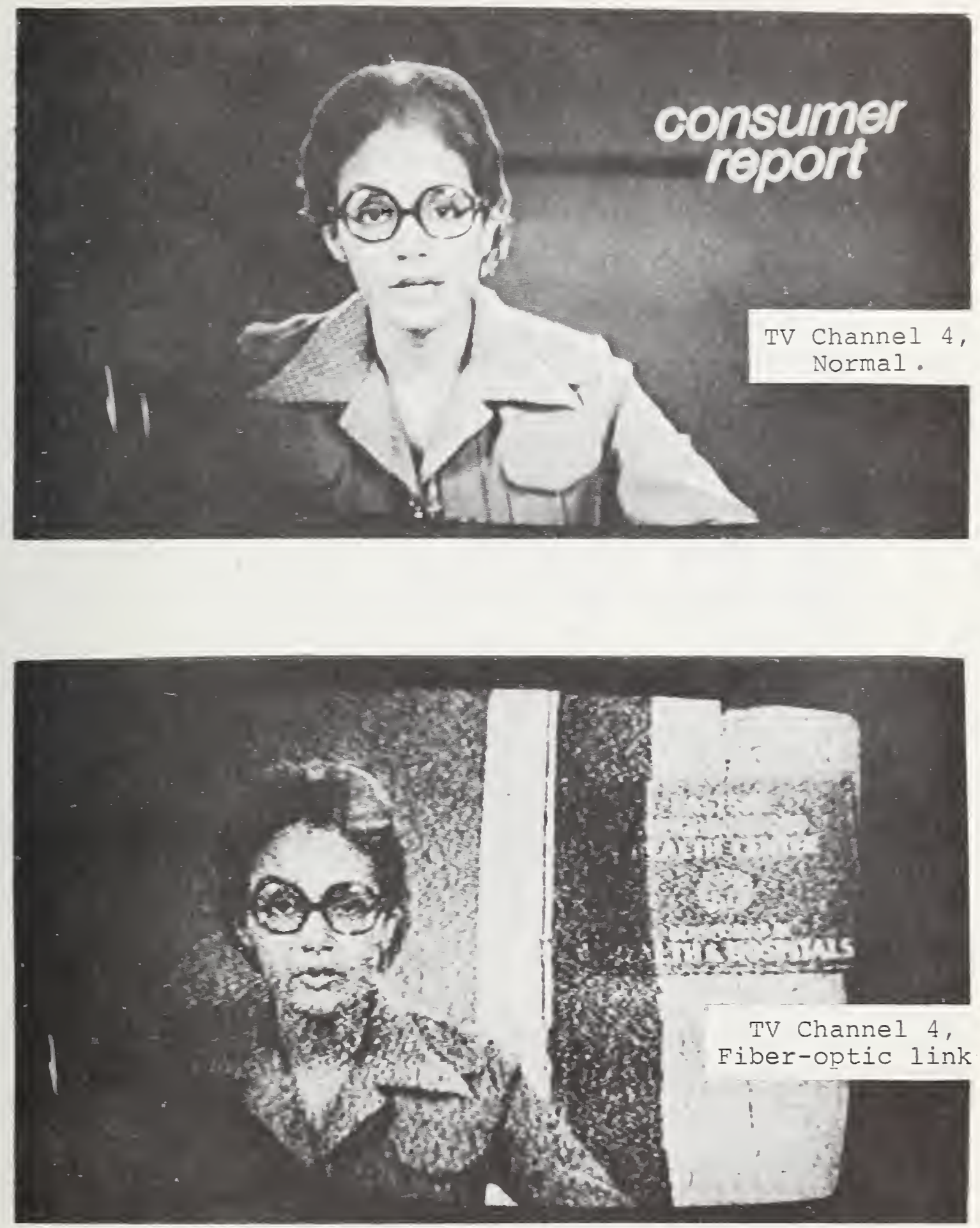

Figure 22. Degradation of TV picture caused by the fiber-optic link. 


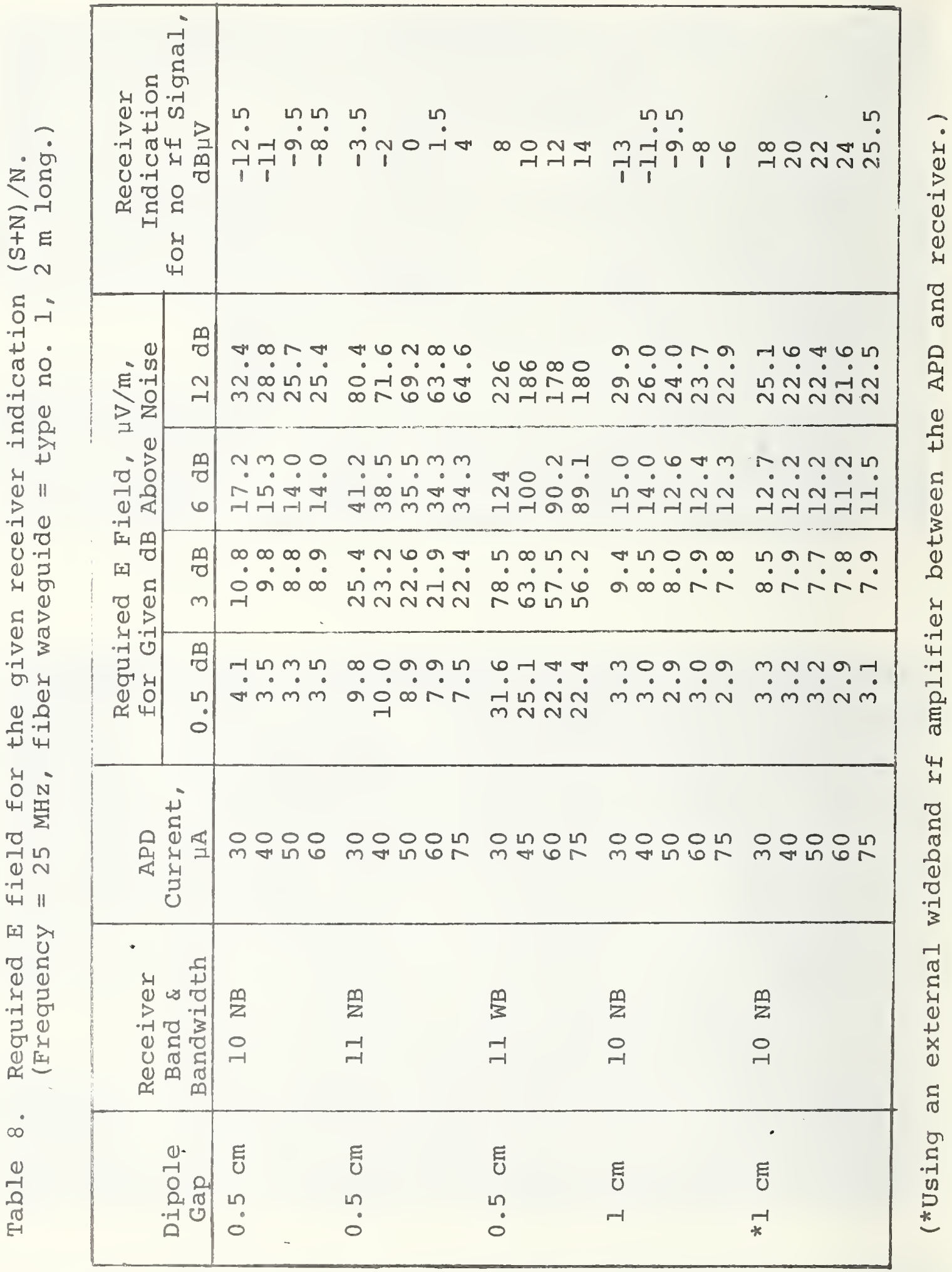




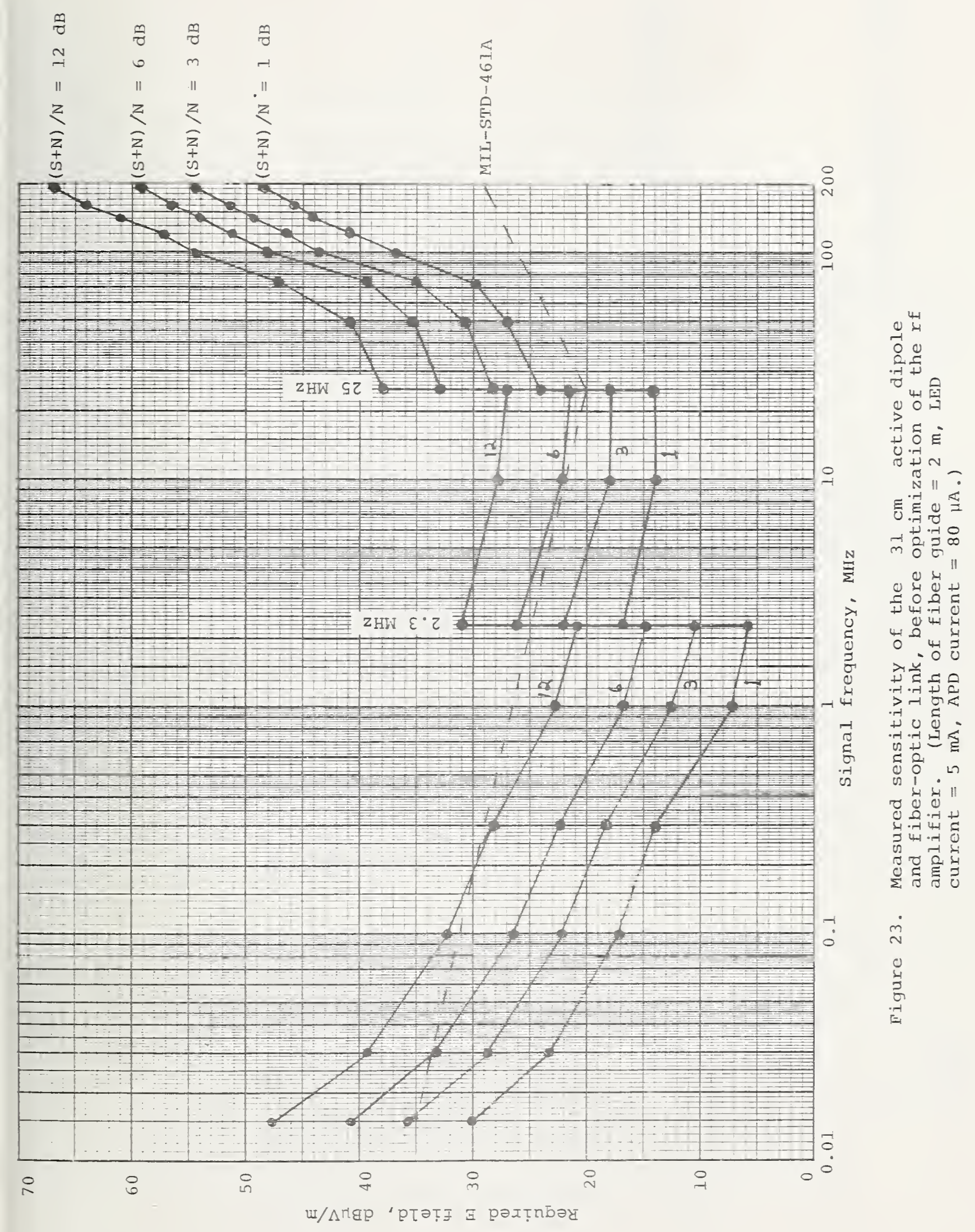




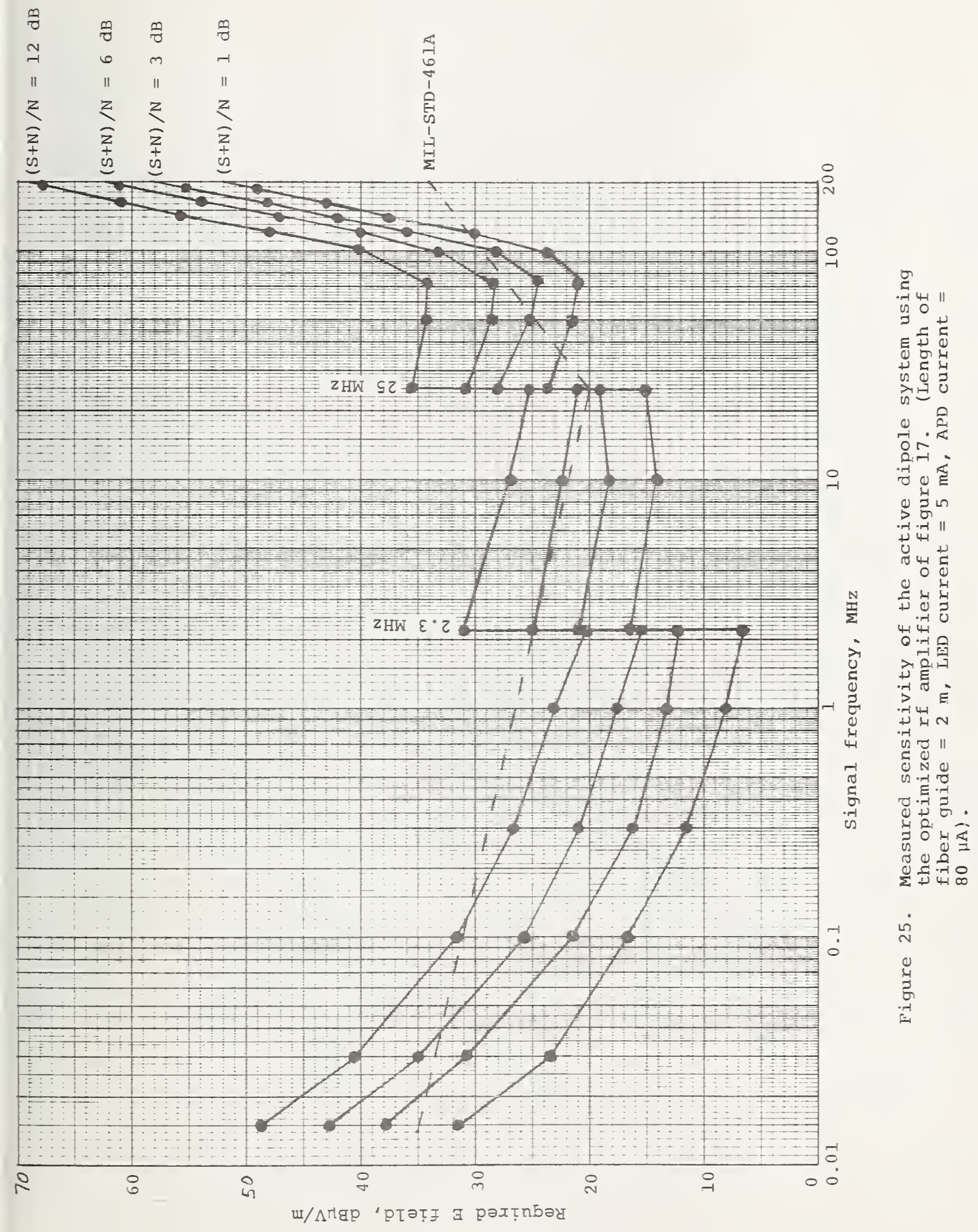




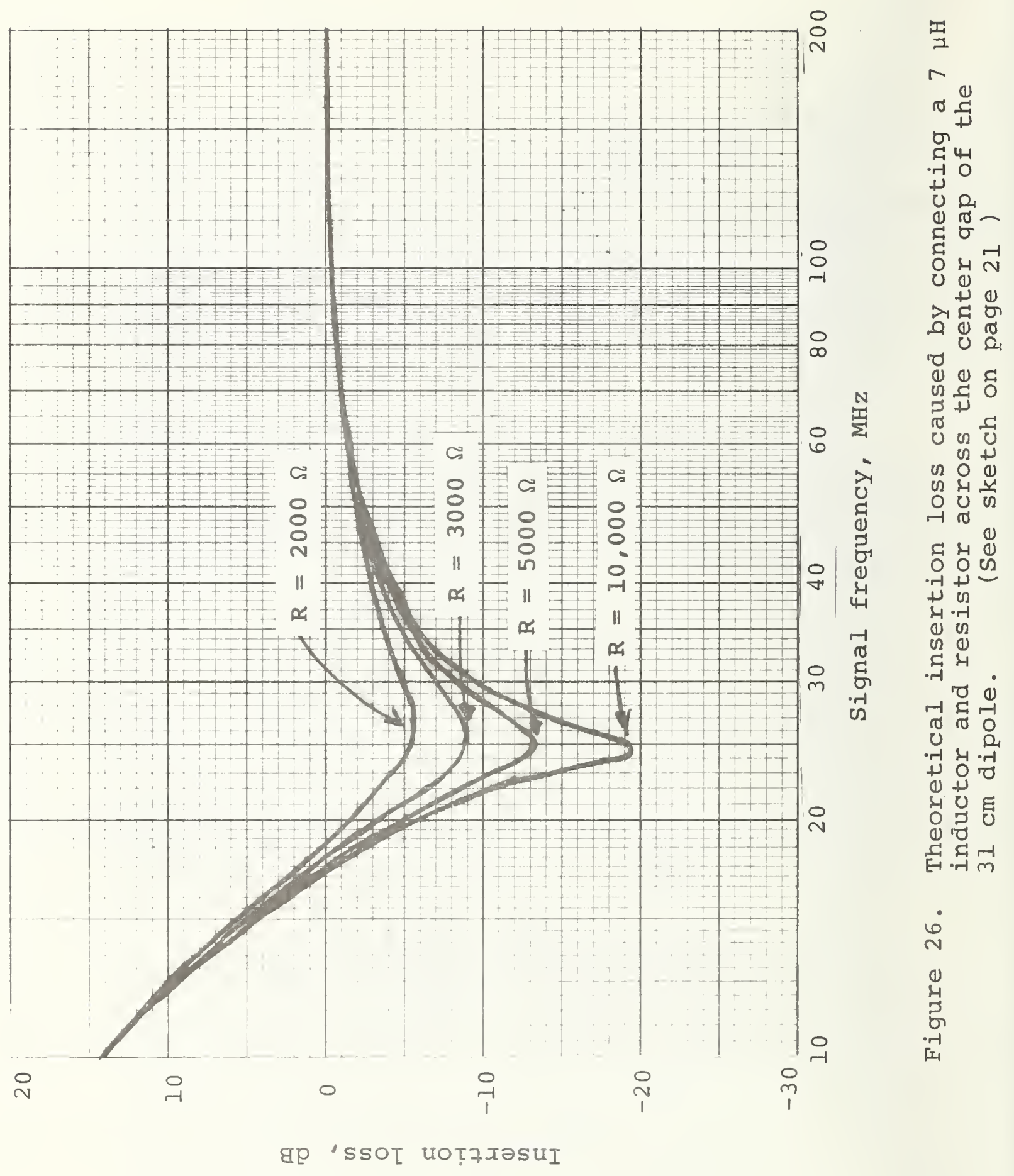




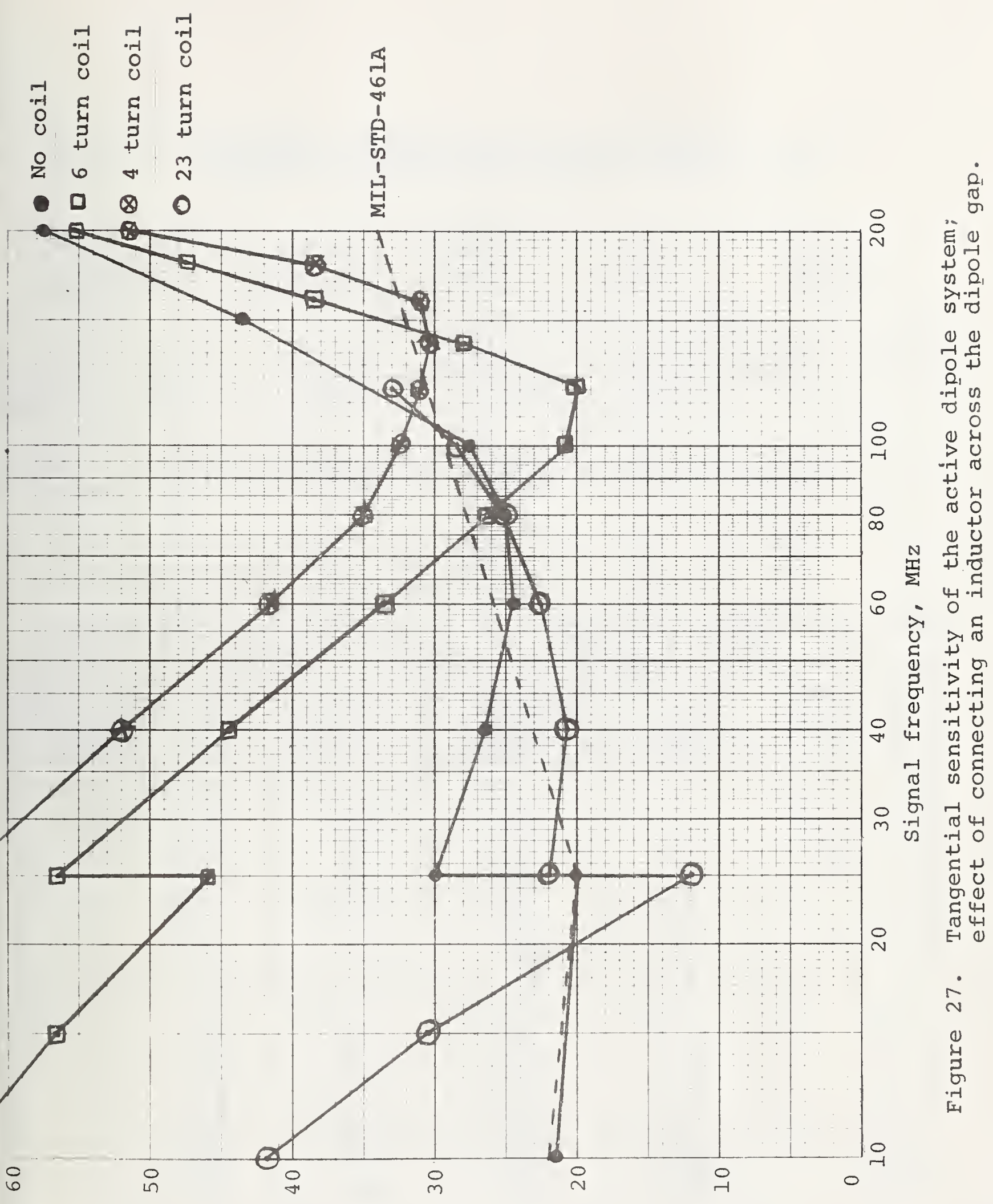

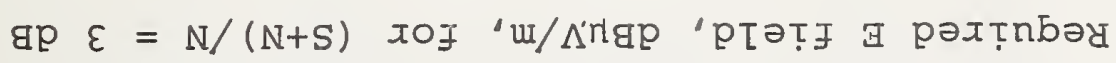


Table 9. Description of the parallel-resonating coils used with the final active antenna.

\begin{tabular}{|c|c|c|c|c|}
\hline $\begin{array}{c}\text { Coil } \\
\text { Number }\end{array}$ & $\begin{array}{c}\text { Type } \\
\text { of Core }\end{array}$ & $\begin{array}{c}\text { Wire } \\
\text { Size }\end{array}$ & $\begin{array}{c}\text { Number } \\
\text { of Turns }\end{array}$ & $\begin{array}{c}\text { Series } \\
\text { Resistor }\end{array}$ \\
\hline 1 & Two Q3 & $\# 36$ & 23 & $50 \Omega$ \\
2 & One Q3 & $\# 30$ & 6 & $10 \Omega$ \\
3 & One Q3 & $\# 30$ & 4 & None \\
\hline
\end{tabular}

Table 10. Measured performance of the fiber-optic antenna system.

\begin{tabular}{|c|c|c|c|c|c|}
\hline $\begin{array}{c}\text { Signal } \\
\text { Fuequency } \\
\text { MHz }\end{array}$ & $\begin{array}{c}\text { Receiver } \\
\text { Band } \\
\text { Number }\end{array}$ & $\begin{array}{c}\text { Tangential } \\
\text { sensitivity, } \\
\mathrm{dB} \mu \mathrm{V} / \mathrm{m}\end{array}$ & $\begin{array}{c}\text { Overload } \\
\text { Level, } \\
\mathrm{dB} \mu \mathrm{V} / \mathrm{m}\end{array}$ & $\begin{array}{c}\text { Dynamic } \\
\text { Range, } \\
\mathrm{dB}\end{array}$ & $\begin{array}{c}\text { Antenna } \\
\text { Factor, } \\
\text { dB }\end{array}$ \\
\hline 0.015 & 1 & 43.5 & 110.5 & 67 & 54.5 \\
0.025 & 1 & 37.5 & 110.5 & 73 & 47 \\
0.05 & 2 & 30 & 103 & 73 & 37.5 \\
0.1 & 3 & 25 & 99 & 74 & 33.5 \\
0.3 & 5 & 20 & 92 & 72 & 30.5 \\
1 & 6 & 20 & 93.5 & 73.5 & 32.5 \\
2.3 & 7 & 17 & 87 & 70 & 34.5 \\
2.3 & 8 & 25 & 92 & 67 & 32.5 \\
5 & 9 & 23 & 86.53 & 32.5 \\
10 & 9 & 21.5 & 91.5 & 70 & 37 \\
25 & 10 & 20 & 86 & 66 & 30.5 \\
25 & 11 & 30 & 85 & 55 & 30.5 \\
40 & 11 & 26.5 & 77.5 & 51 & 32.5 \\
60 & 12 & 24.5 & 66.5 & 42 & 20 \\
80 & 12 & 25 & 64 & 39 & 17 \\
100 & 13 & 27.5 & 73.5 & 46 & 27 \\
150 & 13 & 43.5 & 92 & 48.5 & 44.5 \\
200 & 13 & 58 & 102 & 44 & 60 \\
\hline
\end{tabular}


Table 11. Measured performance of the fiber-optic antenna system with an inductor across the dipole gap.

\begin{tabular}{|c|c|c|c|c|c|c|}
\hline $\begin{array}{l}\text { Type of } \\
\text { Parallel } \\
\text { Inductor }\end{array}$ & $\begin{array}{c}\text { Signal } \\
\text { Fequency, } \\
\mathrm{MHz}\end{array}$ & $\begin{array}{c}\text { Receiver } \\
\text { Band } \\
\text { Number } \\
\end{array}$ & $\begin{array}{r}\text { Tangential } \\
\text { Sensitivity, } \\
\mathrm{dB} \mu \mathrm{V} / \mathrm{m}\end{array}$ & $\begin{array}{l}\text { Overload } \\
\text { Level, } \\
\mathrm{dB} \mu \mathrm{V} / \mathrm{m} \\
\end{array}$ & $\begin{array}{c}\text { Dynamic } \\
\text { Range, } \\
\text { dB }\end{array}$ & $\begin{array}{c}\text { Antenna } \\
\text { Factor } \\
\text { aB }\end{array}$ \\
\hline $\begin{array}{l}23 \text { turn } \\
\text { toroid, } \\
50 \Omega \text { series } \\
\text { resistor }\end{array}$ & $\begin{array}{l}10 \\
15 \\
25 \\
25 \\
40 \\
60 \\
80 \\
100 \\
120\end{array}$ & $\begin{array}{l}9 \\
10 \\
10 \\
11 \\
11 \\
12 \\
12 \\
13 \\
13\end{array}$ & $\begin{array}{l}42 \\
30.5 \\
12 \\
22.5 \\
21 \\
23 \\
25 \\
28.5 \\
33\end{array}$ & $\begin{array}{l}110 \\
99.5 \\
81 \\
79.5 \\
72 \\
57 \\
66 \\
75.5 \\
78\end{array}$ & $\begin{array}{l}68 \\
69 \\
69 \\
57 \\
51 \\
34 \\
41 \\
47 \\
45\end{array}$ & $\begin{array}{l}55.1 \\
43.4 \\
23.7 \\
23.9 \\
17.7 \\
18.3 \\
18.2 \\
28.4 \\
34.1\end{array}$ \\
\hline $\begin{array}{l}6 \text { turn } \\
\text { toroid, } \\
10 \Omega \text { series } \\
\text { resistor }\end{array}$ & $\begin{array}{r}10 \\
15 \\
25 \\
25 \\
40 \\
60 \\
80 \\
100 \\
120 \\
140 \\
160 \\
180 \\
200\end{array}$ & $\begin{array}{l}9 \\
10 \\
10 \\
11 \\
11 \\
12 \\
12 \\
13 \\
13 \\
13 \\
13 \\
13 \\
13\end{array}$ & $\begin{array}{l}64 \\
57 \\
46 \\
56.5 \\
44.5 \\
33.5 \\
26 \\
20.5 \\
20 \\
28 \\
38.5 \\
47.5 \\
55.5\end{array}$ & $\begin{array}{l}123 \\
121 \\
110 \\
109.5 \\
94.3 \\
66.5 \\
62 \\
68.5 \\
66 \\
77 \\
86.5 \\
92.5 \\
100.5\end{array}$ & $\begin{array}{l}59 \\
64 \\
64 \\
53 \\
50 \\
33 \\
36 \\
48 \\
46 \\
49 \\
48 \\
45 \\
45\end{array}$ & $\begin{array}{l}76.5 \\
67.2 \\
55.9 \\
55.8 \\
39.7 \\
20.6 \\
14.2 \\
20.3 \\
19.9 \\
35.6 \\
41.6 \\
51.4 \\
58.2\end{array}$ \\
\hline $\begin{array}{l}4 \text { turn } \\
\text { toroid }\end{array}$ & $\begin{array}{r}25 \\
40 \\
60 \\
80 \\
100 \\
120 \\
140 \\
160 \\
180 \\
200\end{array}$ & $\begin{array}{l}11 \\
11 \\
12 \\
12 \\
13 \\
13 \\
13 \\
13 \\
13 \\
13\end{array}$ & $\begin{array}{l}63.5 \\
52 \\
41.5 \\
35 \\
32.5 \\
31 \\
30.5 \\
31 \\
38.5 \\
51.5\end{array}$ & $\begin{array}{l}116.5 \\
100 \\
74.5 \\
71 \\
78.5 \\
78 \\
83.5 \\
75.5 \\
85.5 \\
95.5\end{array}$ & $\begin{array}{l}53 \\
48 \\
33 \\
36 \\
46 \\
47 \\
53 \\
44.5 \\
47 \\
44\end{array}$ & $\begin{array}{l}63.2 \\
47.9 \\
27.3 \\
24.7 \\
33.5 \\
34 \\
36.8 \\
30 \\
40.3 \\
54.2\end{array}$ \\
\hline
\end{tabular}




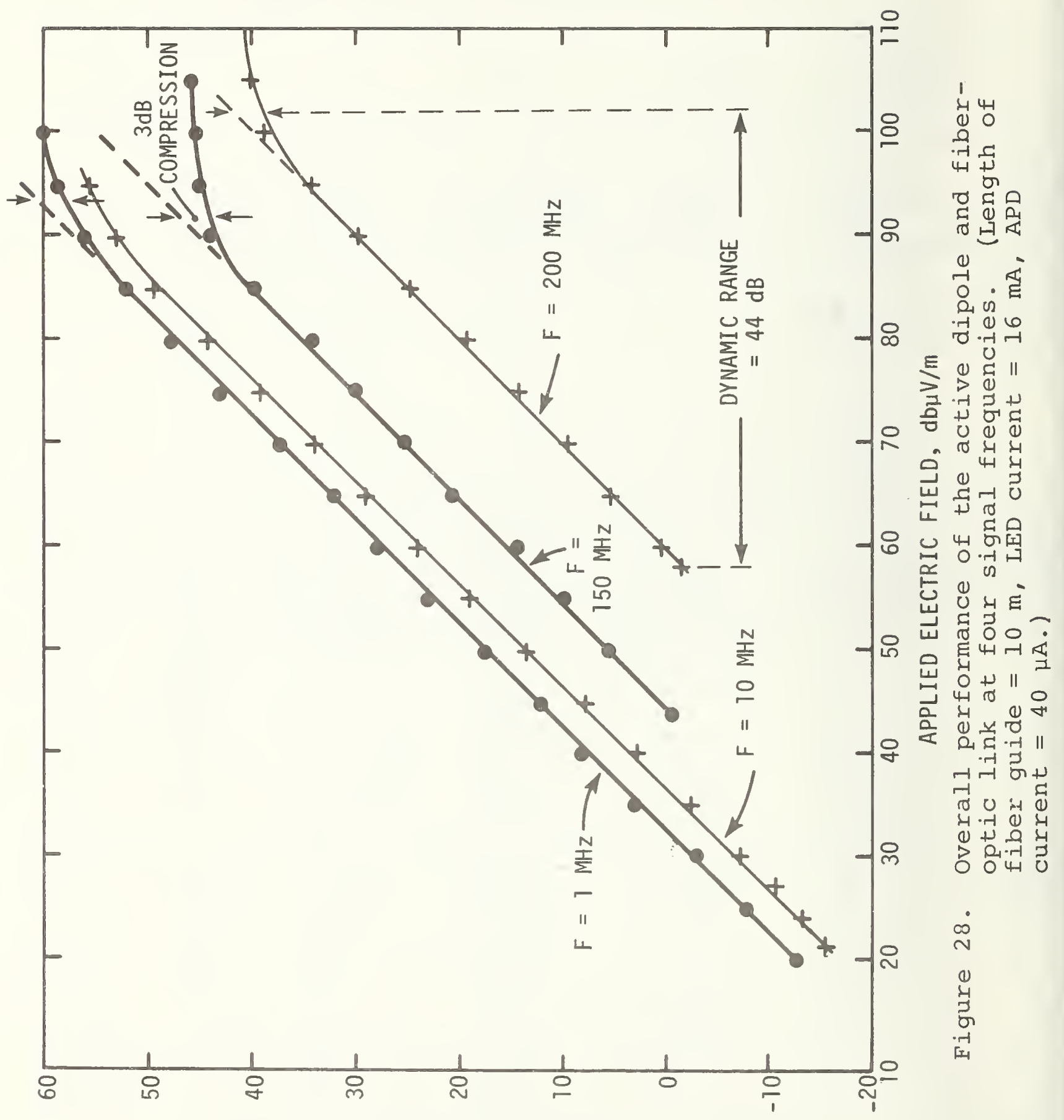

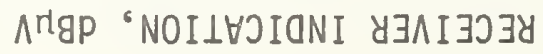




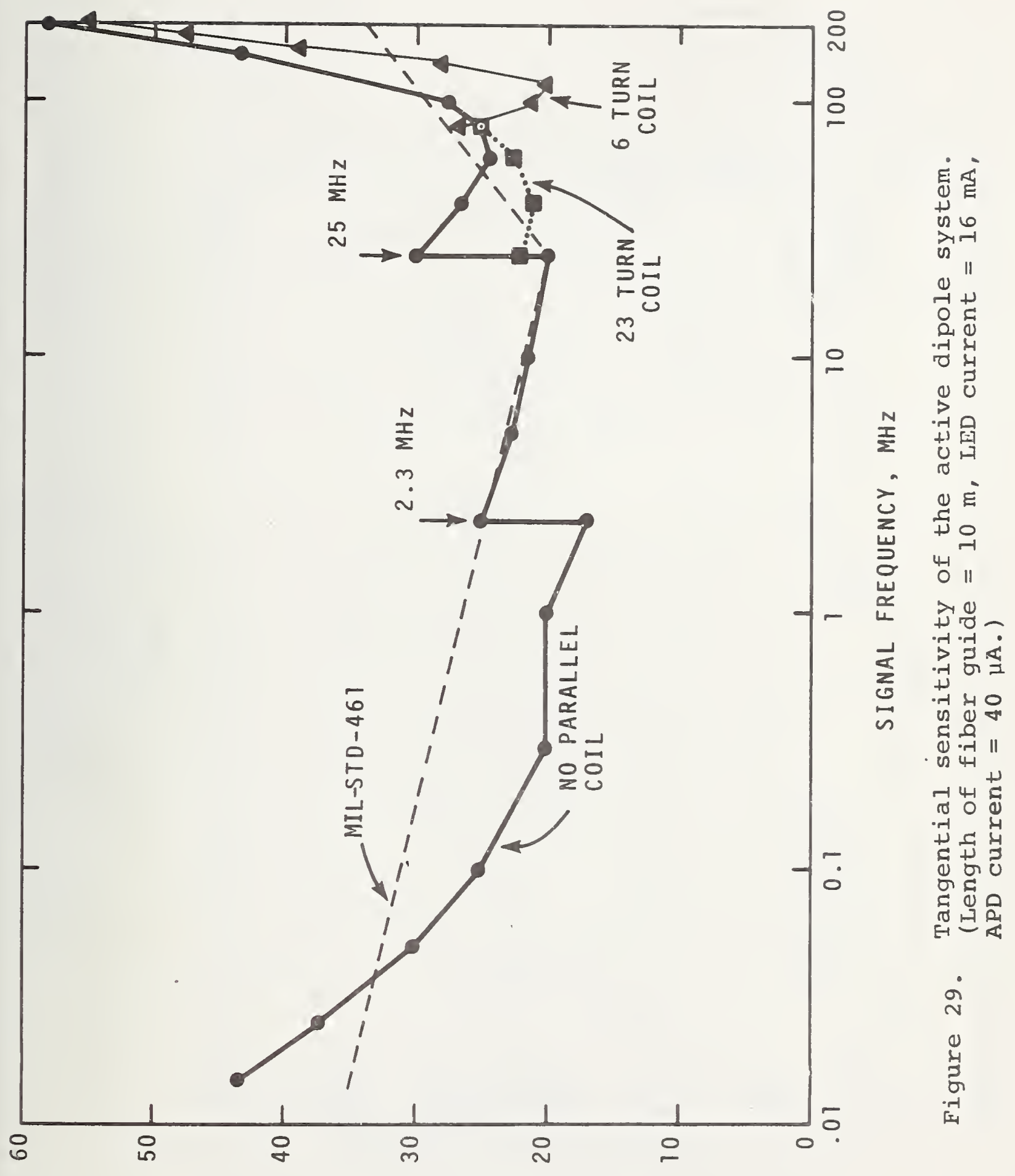

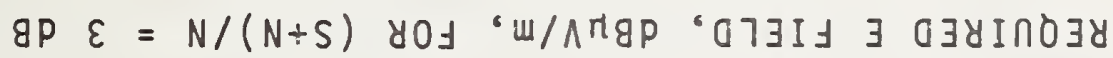




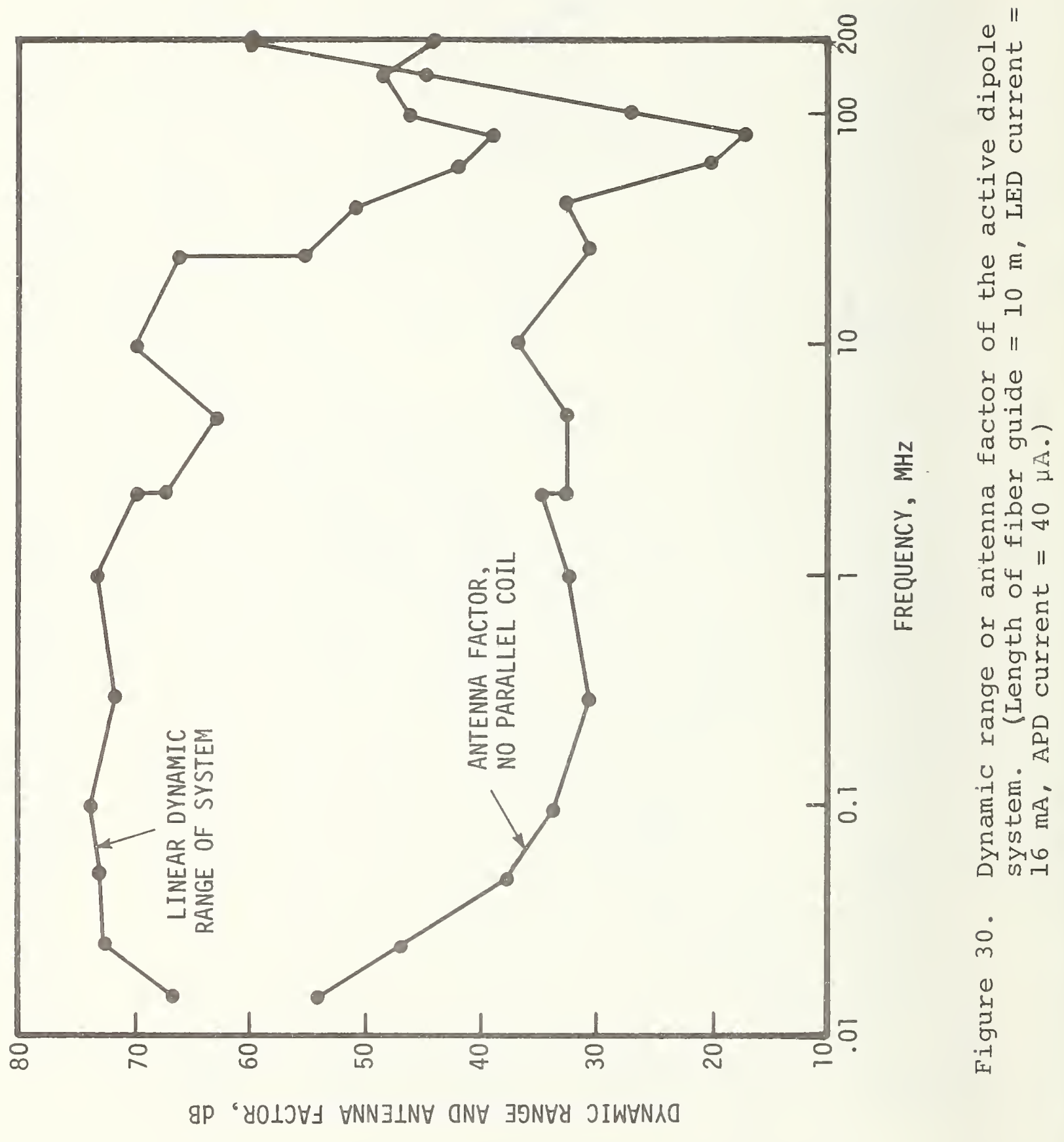




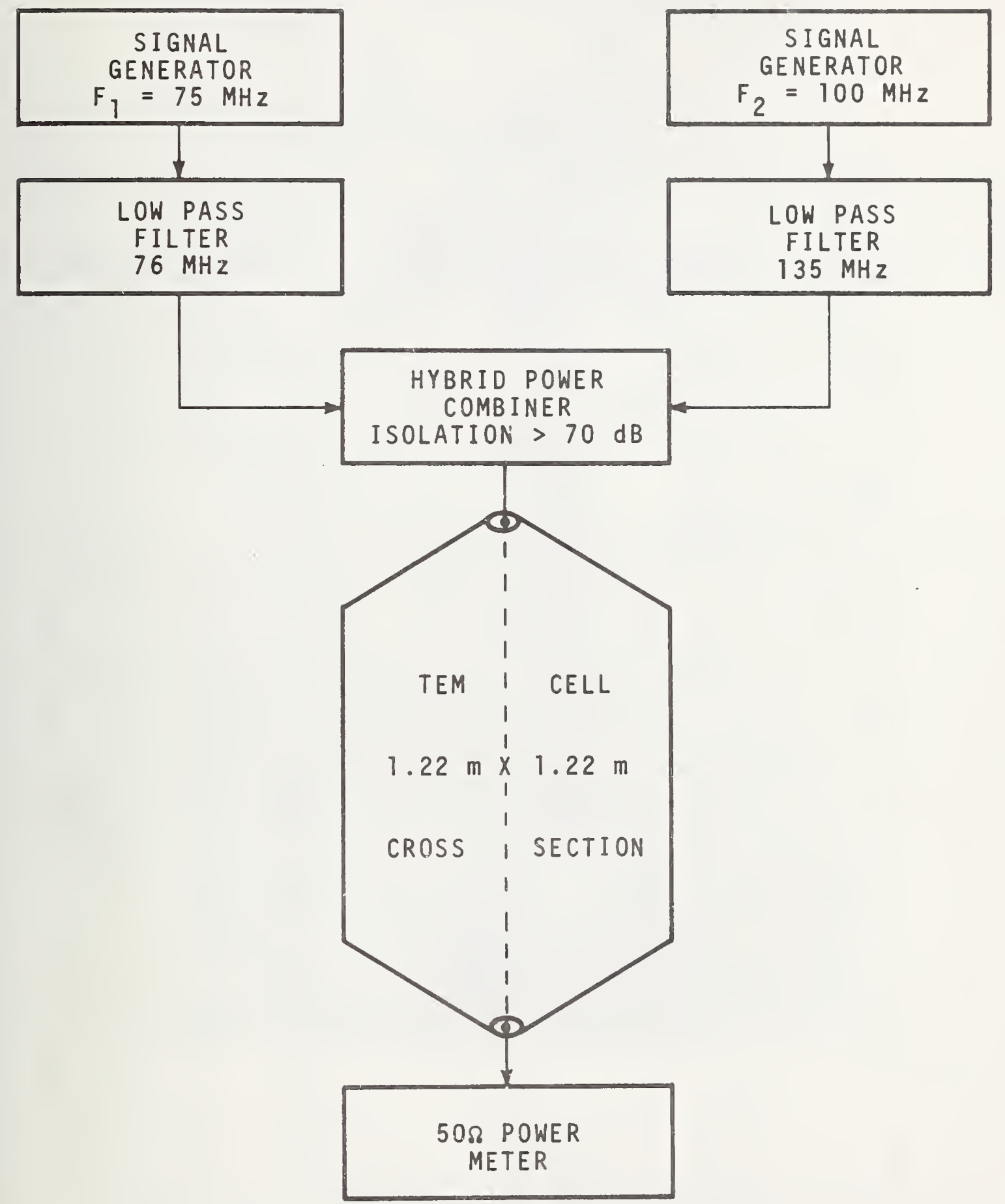

Figure 31. Instrumentation for measuring strong-signal desensitization of the active dipole system. 
Table 12. Desensitization of the active dipole system; measurements of a "desired" signal at $75 \mathrm{MHz}$ in the presence of an

"interfering" signal at $100 \mathrm{MHz}$.

\begin{tabular}{|c|c|c|c|c|c|c|c|}
\hline $\begin{array}{l}\text { (Interfering } \\
\text { Signal) } \\
\text { E field } \\
\text { at } 100 \mathrm{MHz}, \\
\mathrm{dBHV} / \mathrm{m}\end{array}$ & $\begin{array}{c}\text { (Desired } \\
\text { Signal) } \\
\text { E field } \\
\text { at } 75 \mathrm{MHz}, \\
\mathrm{dB} \mu \mathrm{V} / \mathrm{m}\end{array}$ & $\begin{array}{c}\text { Receiver } \\
\text { Indication, } \\
\mathrm{dB} \mu \mathrm{V}\end{array}$ & $\begin{array}{c}\text { Antenna } \\
\text { Factor, } \\
\text { dB } \\
\end{array}$ & $\begin{array}{l}\text { (Interfering } \\
\text { Signal) } \\
\text { E field } \\
\text { at } 100 \mathrm{MHz}, \\
\mathrm{dB} \mu \mathrm{V} / \mathrm{m} \\
\end{array}$ & $\begin{array}{c}\text { (Desired } \\
\text { Signal) } \\
\text { E field } \\
\text { at } 75 \mathrm{MHz}, \\
\mathrm{dB} \mu \mathrm{V} / \mathrm{m} \\
\end{array}$ & $\begin{array}{c}\text { Receiver } \\
\text { Indication, } \\
\mathrm{dB} \mu \mathrm{V}\end{array}$ & $\begin{array}{c}\text { Antenna } \\
\text { Factor, } \\
\text { dB } \\
\end{array}$ \\
\hline 0 & $\begin{array}{l}23.2 \\
27 \\
30 \\
35 \\
40 \\
45 \\
50 \\
55 \\
60 \\
65 \\
70 \\
75 \\
80 \\
85 \\
90\end{array}$ & $\begin{array}{l}6.8 \\
9.7 \\
12.5 \\
18.2 \\
23 \\
28 \\
32.5 \\
38.2 \\
41 \\
42.2 \\
43.5 \\
45.5 \\
47.2 \\
47.8 \\
46\end{array}$ & $\begin{array}{l}16.4 \\
17.3 \\
17.5 \\
16.8 \\
17 \\
17 \\
17.5 \\
16.8 \\
19 \\
22.8 \\
26.5 \\
29.5 \\
32.8 \\
37.2 \\
44\end{array}$ & 70 & $\begin{array}{l}25.5 \\
27 \\
30 \\
35 \\
40 \\
45 \\
50 \\
55 \\
60 \\
65 \\
70 \\
75 \\
80 \\
85 \\
90\end{array}$ & $\begin{array}{l}2 \\
3 \\
5.8 \\
10.8 \\
16 \\
21 \\
26.2 \\
30 \\
34.8 \\
40 \\
42.5 \\
44.5 \\
46.2 \\
47.2 \\
44.7\end{array}$ & $\begin{array}{l}23.5 \\
24 \\
24.2 \\
24.2 \\
24 \\
24 \\
23.8 \\
25 \\
25.2 \\
25 \\
27.5 \\
30.5 \\
33.8 \\
37.8 \\
45.3\end{array}$ \\
\hline 50 & $\begin{array}{l}24.1 \\
27 \\
30 \\
35 \\
40 \\
45 \\
50 \\
55 \\
60 \\
65 \\
70 \\
75 \\
80 \\
85 \\
90\end{array}$ & $\begin{array}{l}7 \\
9 \\
11.8 \\
17.3 \\
22.2 \\
28 \\
31.8 \\
37.2 \\
40.5 \\
42 \\
43.2 \\
45 \\
46.5 \\
47.2 \\
44.5\end{array}$ & $\begin{array}{l}17.1 \\
18 \\
18.2 \\
17.8 \\
17.8 \\
17 \\
18.2 \\
17.8 \\
19.5 \\
23 \\
26.8 \\
30 \\
34.5 \\
37.8 \\
45.5\end{array}$ & 80 & $\begin{array}{l}27.1 \\
30 \\
35 \\
40 \\
45 \\
50 \\
55 \\
60 \\
65 \\
70 \\
75 \\
80 \\
85 \\
90 \\
95\end{array}$ & $\begin{array}{l}-3 \\
-1 \\
3.8 \\
8.3 \\
13.2 \\
18.7 \\
22.5 \\
29 \\
33.5 \\
37.5 \\
41.5 \\
44.2 \\
46.2 \\
45.5 \\
43.7\end{array}$ & $\begin{array}{l}30.1 \\
31 \\
31.2 \\
31.7 \\
31.8 \\
31.3 \\
32.5 \\
31 \\
31.5 \\
32.5 \\
33.5 \\
35.8 \\
38.2 \\
44.5 \\
51.3\end{array}$ \\
\hline 60 & $\begin{array}{l}24.7 \\
27 \\
30 \\
35 \\
40 \\
45 \\
50 \\
55 \\
60 \\
65 \\
70 \\
75 \\
80 \\
85 \\
90\end{array}$ & $\begin{array}{l}6.8 \\
8.7 \\
11.3 \\
17.2 \\
22 \\
27.5 \\
31.5 \\
36.7 \\
40 \\
41.8 \\
43 \\
44.8 \\
46.3 \\
47.2 \\
45.5\end{array}$ & $\begin{array}{l}17.9 \\
18.3 \\
18.7 \\
17.8 \\
18 \\
17.5 \\
18.5 \\
18.3 \\
20 \\
23.2 \\
27 \\
30.2 \\
33.7 \\
37.8 \\
44.5\end{array}$ & 90 & $\begin{array}{l}36.1 \\
40 \\
45 \\
50 \\
55 \\
60 \\
65 \\
70 \\
75 \\
80 \\
85 \\
90 \\
95 \\
100 \\
105\end{array}$ & $\begin{array}{l}-4.8 \\
-1.5 \\
3.5 \\
8 \\
12.8 \\
18 \\
23.5 \\
29 \\
34 \\
39.5 \\
42 \\
45 \\
45.5 \\
45.7 \\
45.8\end{array}$ & $\begin{array}{l}40.9 \\
41.5 \\
41.5 \\
42 \\
42.2 \\
42 \\
41.5 \\
41 \\
41 \\
40.5 \\
43 \\
45 \\
49.5 \\
54.3 \\
59.2\end{array}$ \\
\hline
\end{tabular}




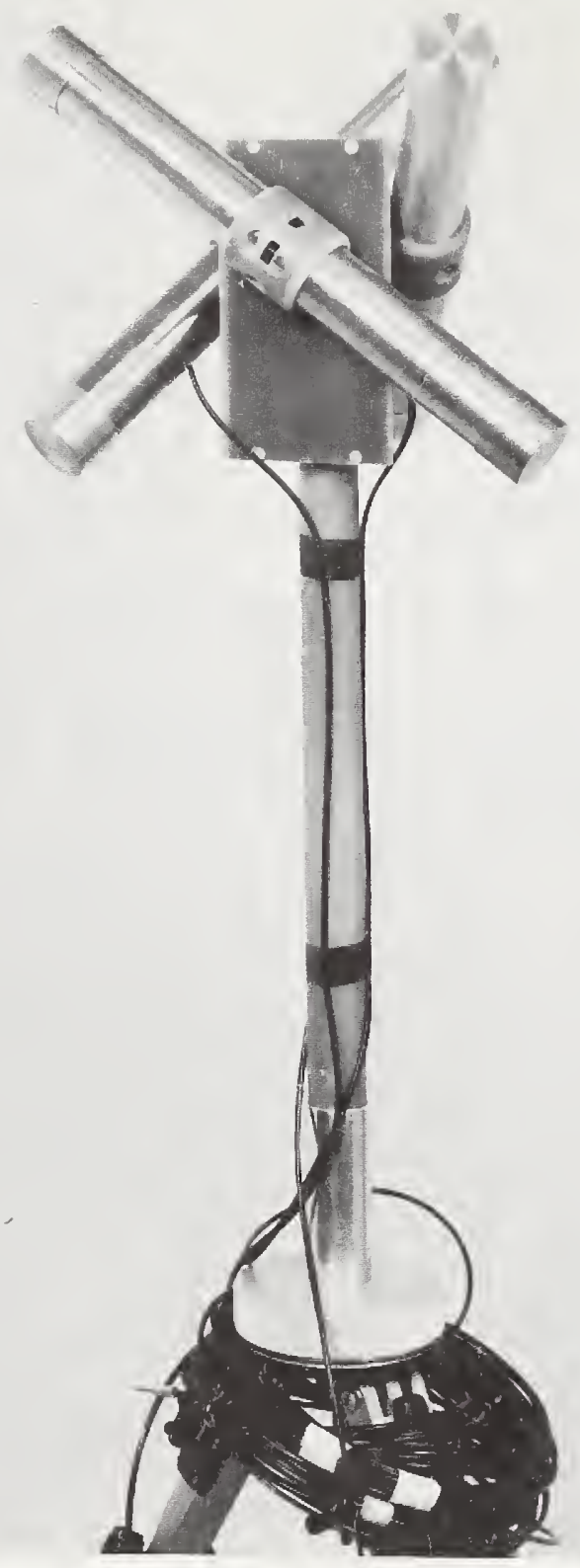

Figure 32. Photograph of the isotropic antenna. 


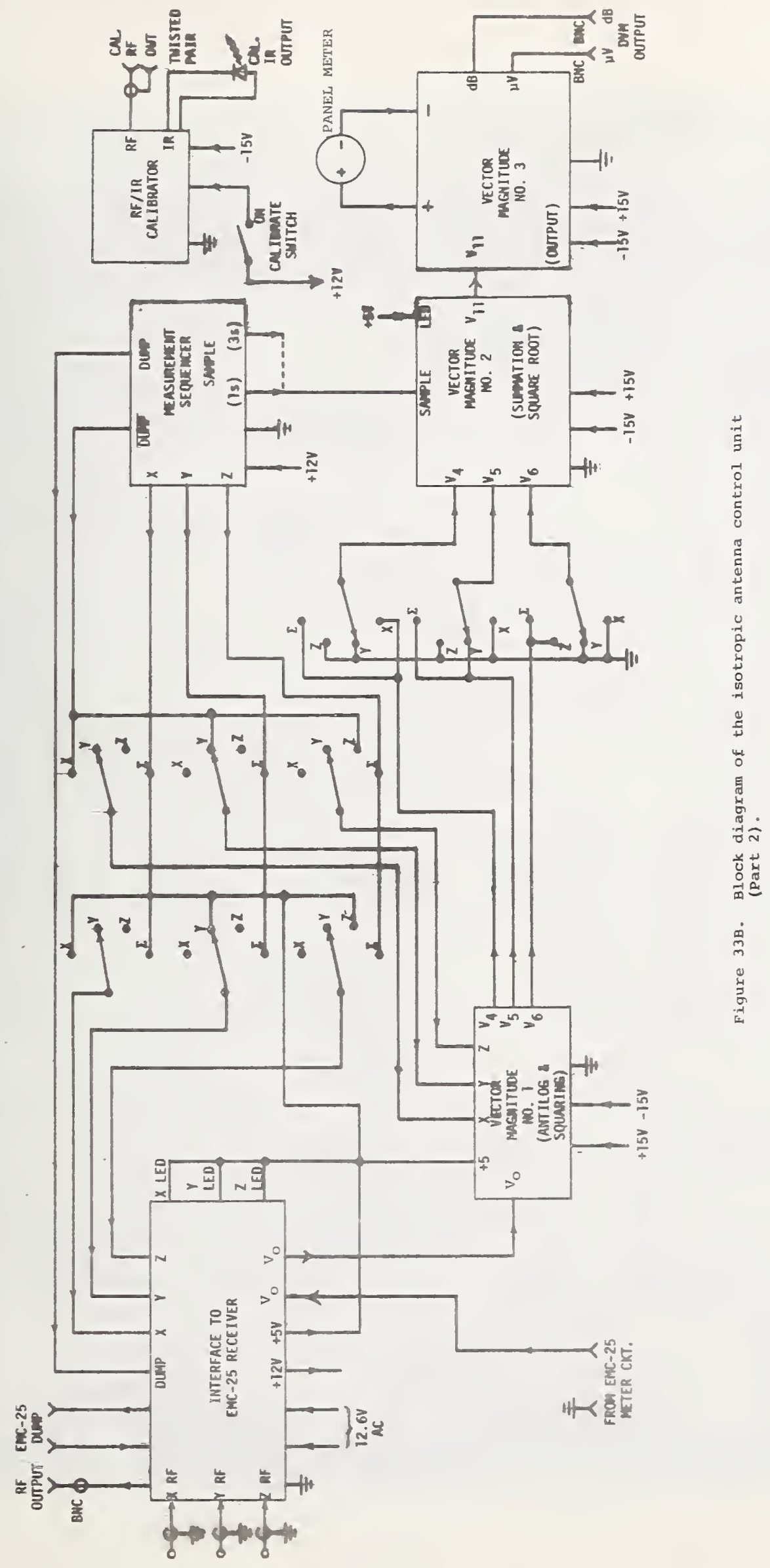




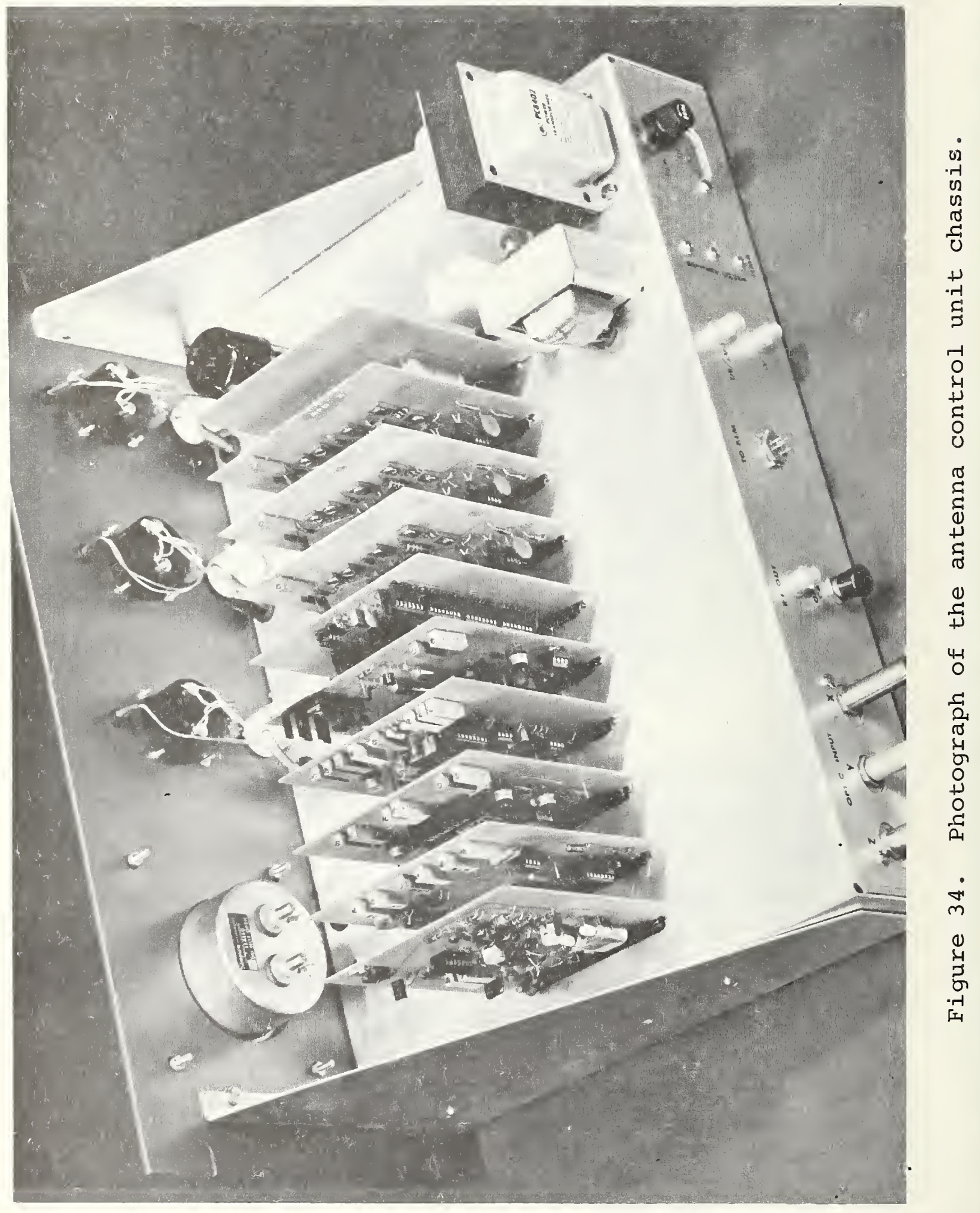




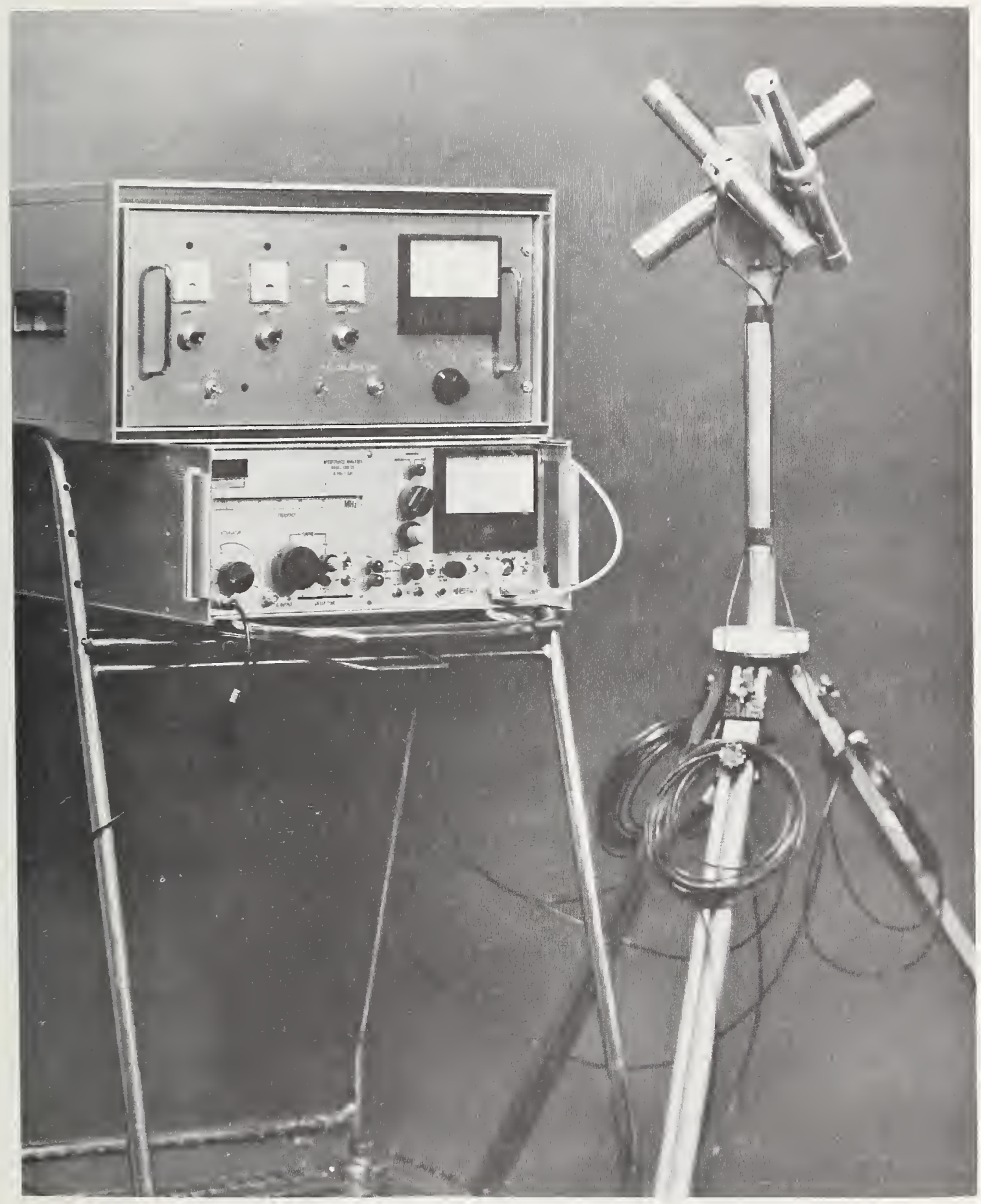

Figure 35. Photograph of the complete f'iber-optic antenna measurement system including the crossed dipoles, fiber guides, control unit and conventional receiver. 


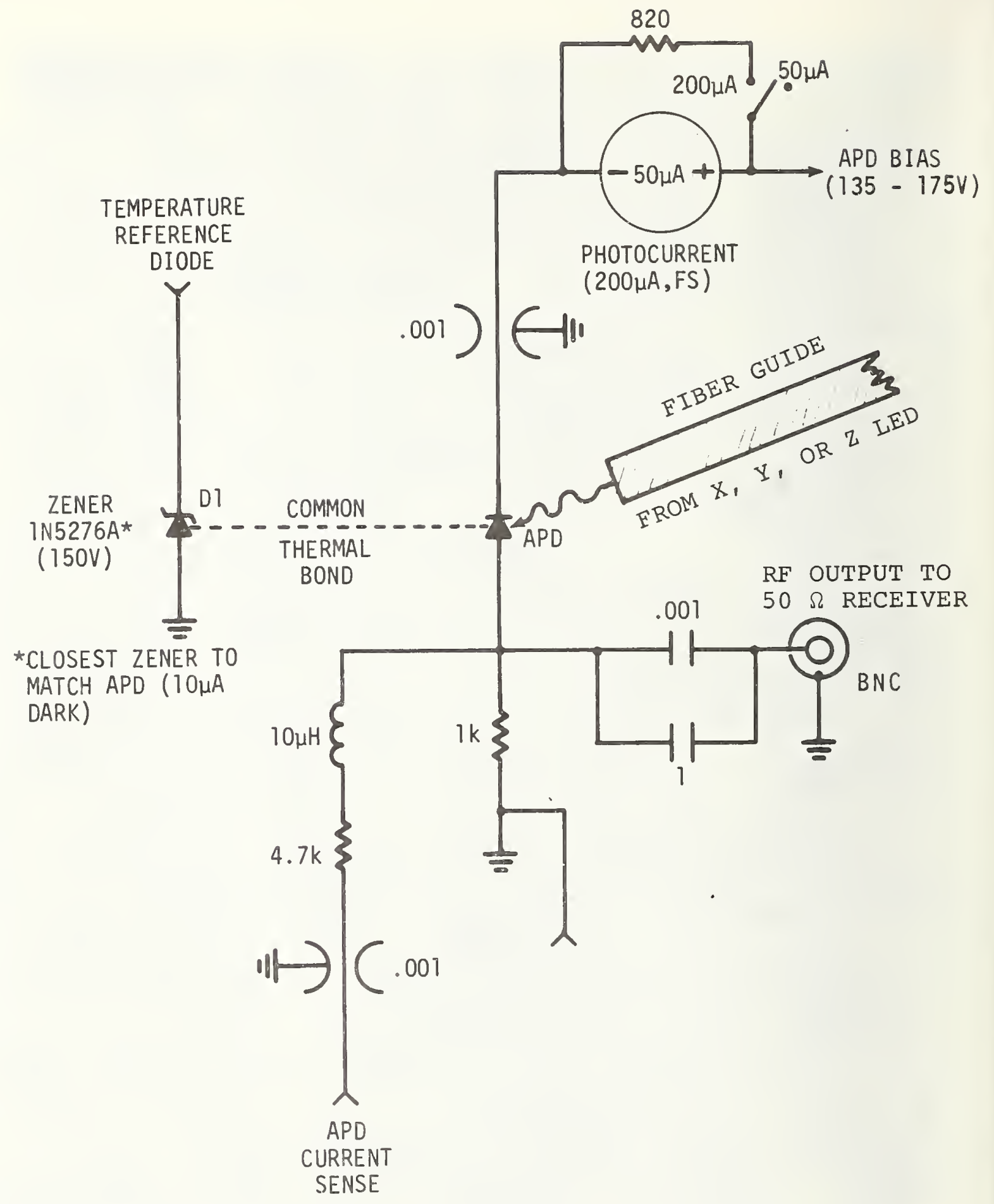

Figure 36. Schematic of each avalanche photodiode circuitry. 


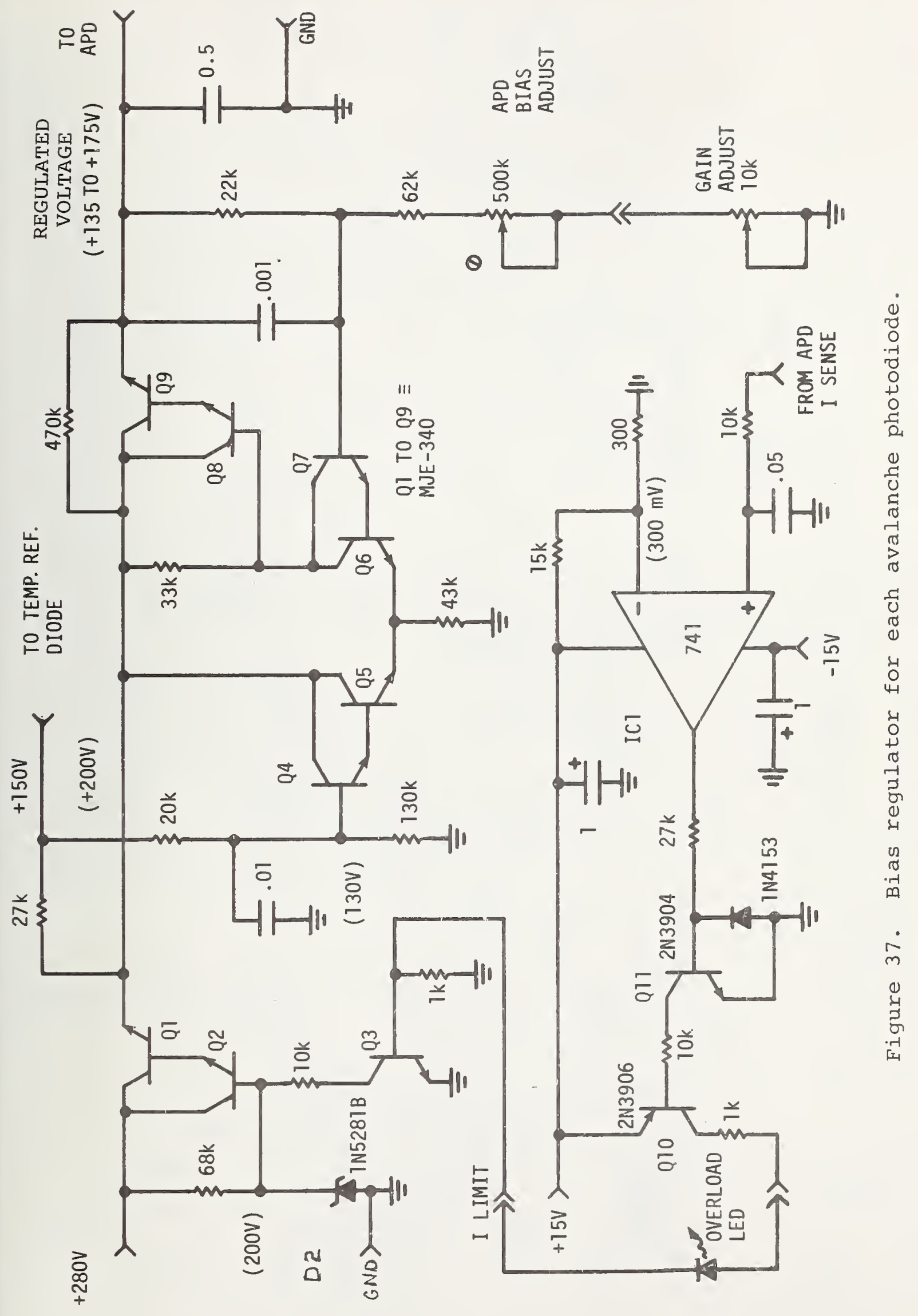




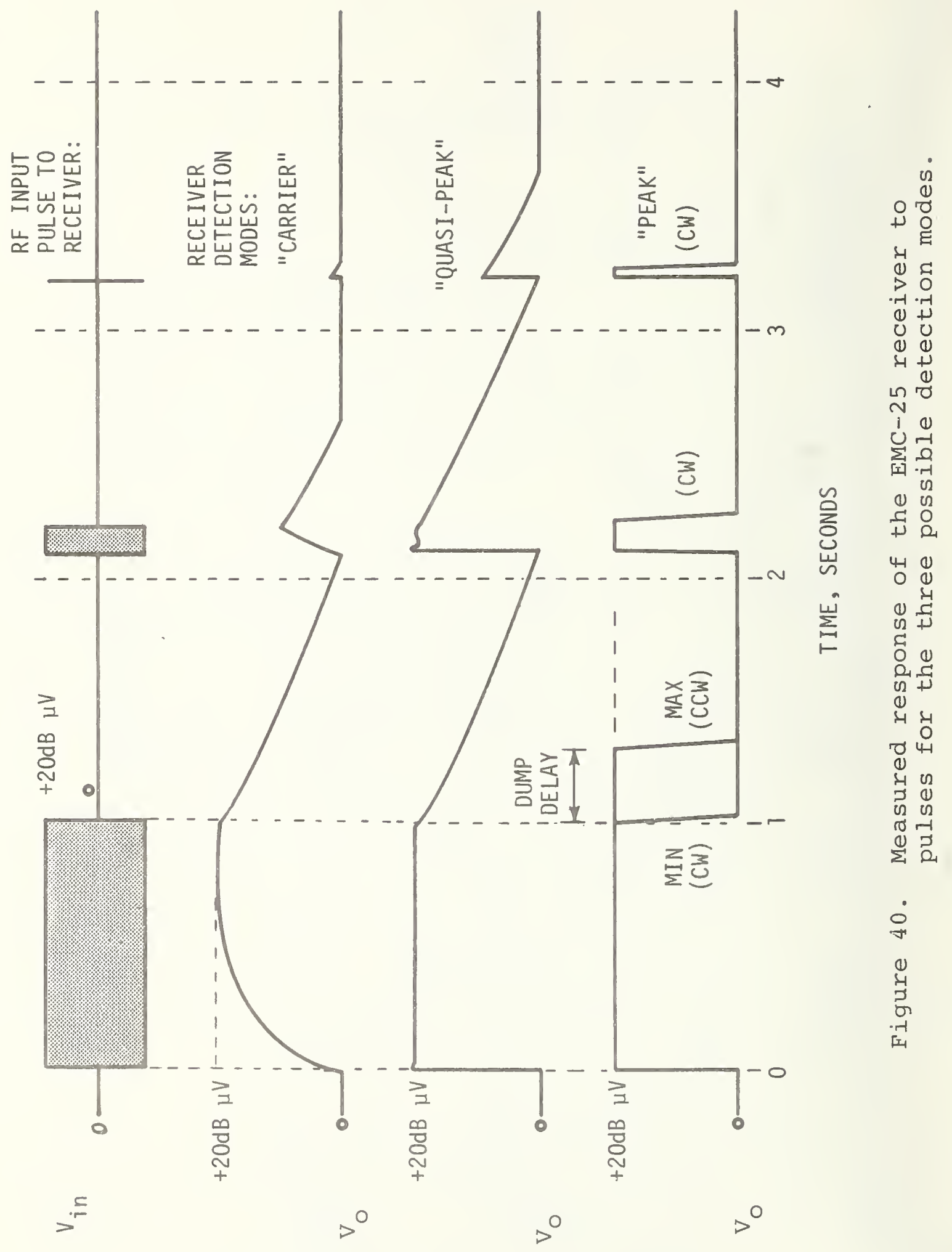




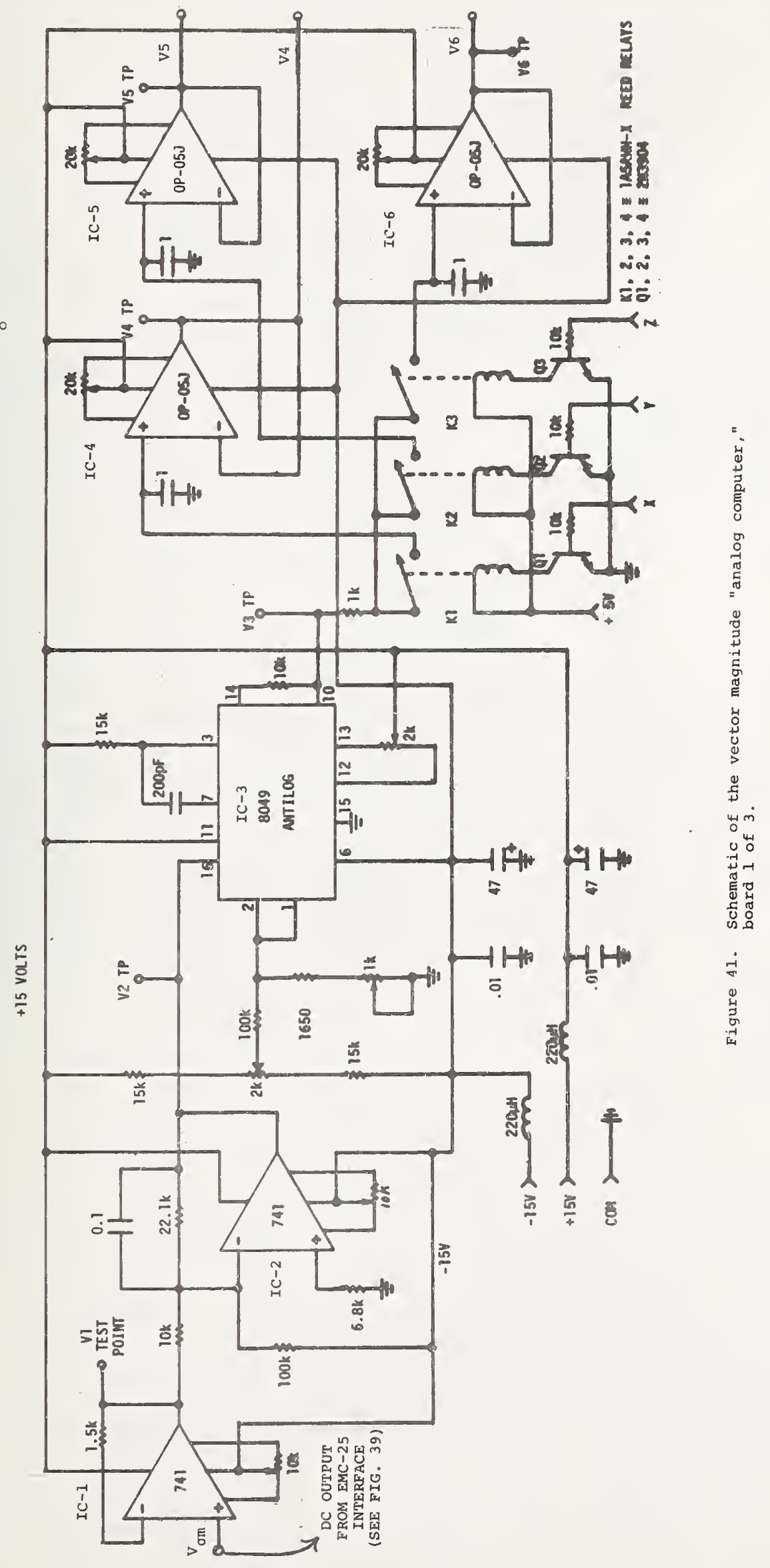




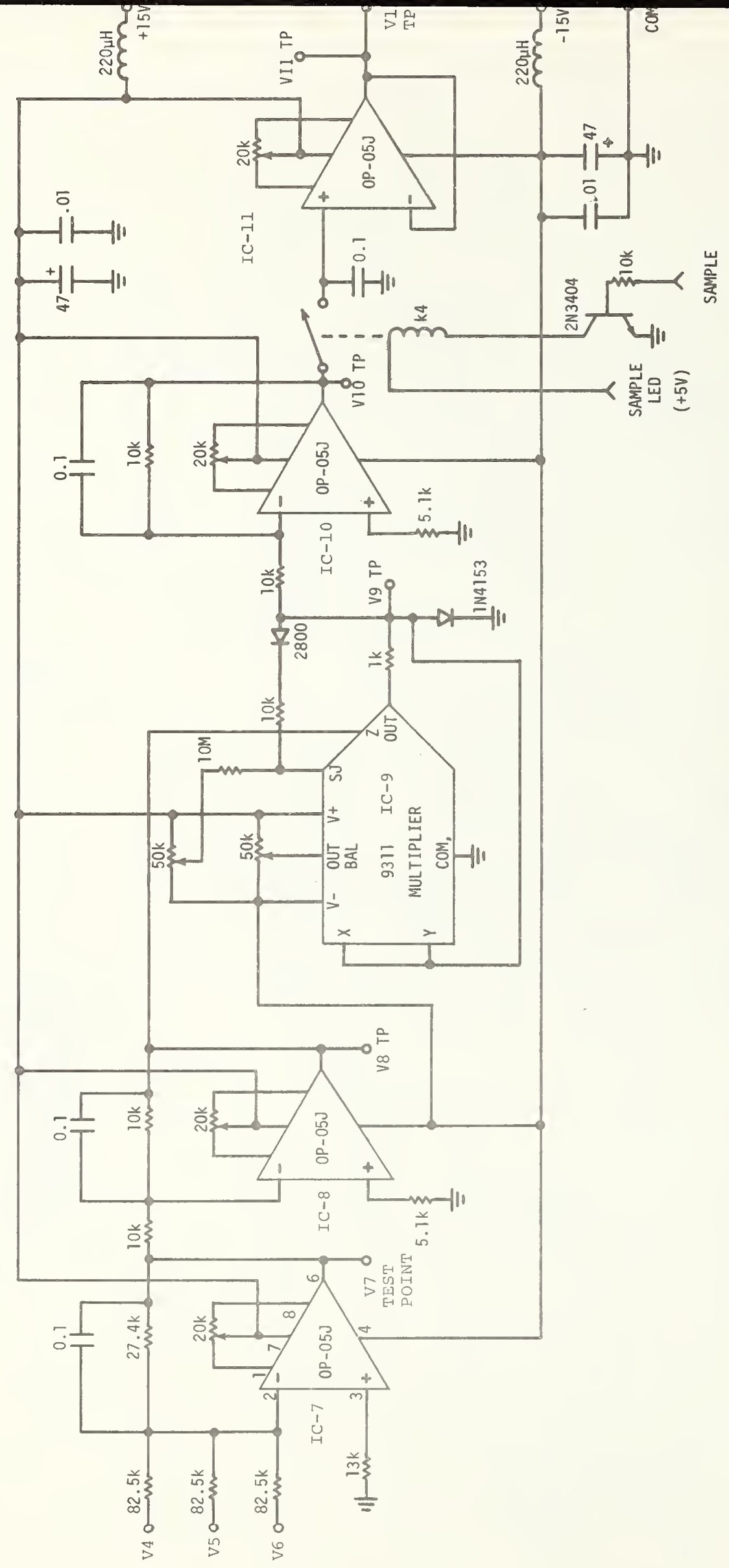

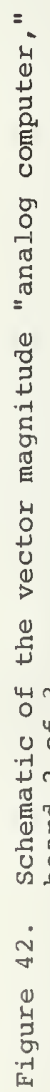




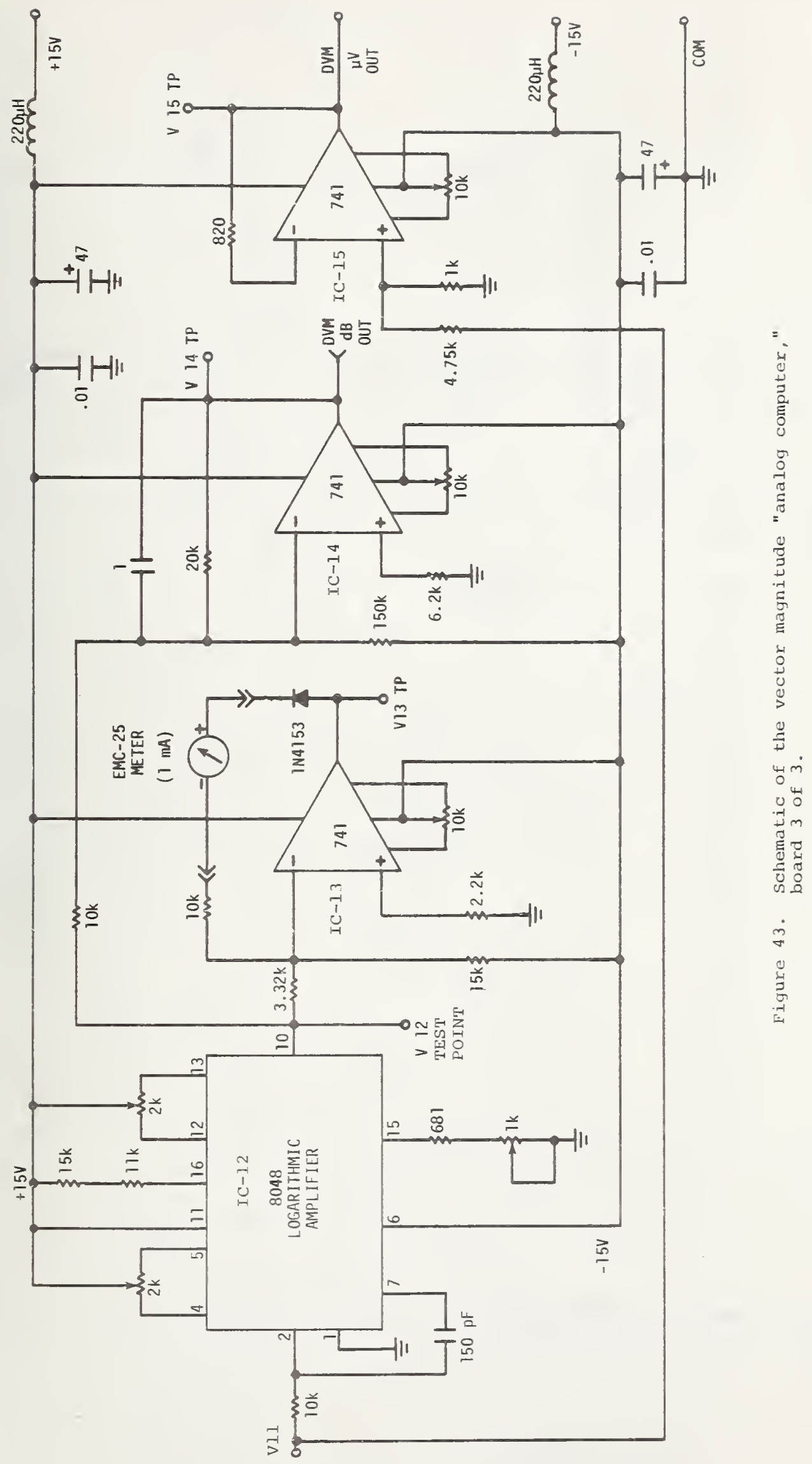


Table 13. "Analog computer" voltages for various antenna input voltages.

\begin{tabular}{|c|c|c|c|c|c|}
\hline & Channel & $X, Y$ or $Z$ & antenna $\mathrm{v}$ & 1tage & $\begin{array}{l}\text { Vector } \\
\text { Magnitude }\end{array}$ \\
\hline & $\begin{array}{c}0.01 \mu \mathrm{V} \\
(-40 \mathrm{~dB} \mu \mathrm{V}) * \\
\end{array}$ & $\begin{array}{ccc}0.1 & \mu \mathrm{V} \\
(-20 & \mathrm{dB} & \mu \mathrm{V})\end{array}$ & 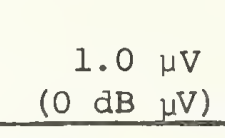 & $\begin{array}{r}10 \mu \mathrm{V} \\
(+20 \mathrm{~dB} \quad \mu \mathrm{V}) \\
\end{array}$ & $\begin{array}{l}17.32 \mu \mathrm{V} \\
\text { i.e. } 10 \mu \mathrm{V} \text { on } \\
\text { each channel) }\end{array}$ \\
\hline$V_{o}, V_{o m}, V 1$ & $0.15 \mathrm{~V}$ & $0.60 \mathrm{~V}$ & $1.05 \mathrm{~V}$ & $1.50 \mathrm{~V}$ & $1.50 \mathrm{~V}$ \\
\hline $\mathrm{v}_{2}$ & $3.00 \mathrm{~V}$ & $2.00 \mathrm{~V}$ & $1.00 \mathrm{~V}$ & $0.00 \mathrm{~V}$ & $0.00 \mathrm{~V}$ \\
\hline$v_{3}, v_{4}, v_{5}, v_{6}$ & $10 \mu \mathrm{V}$ & $1 \mathrm{mV}$ & $100 \mathrm{mV}$ & $10.0 \mathrm{~V}$ & $10.0 \mathrm{~V}$ \\
\hline $\mathrm{v}_{7}$ & $-3.33 \mu \mathrm{V}$ & $-333 \mu \mathrm{V}$ & $-33.3 \mathrm{mV}$ & $-3.33 \mathrm{~V}$ & $-10 \cdot V$ \\
\hline$v_{8}$ & $3.33 \mu \mathrm{V}$ & $333 \mu \mathrm{V}$ & $33.3 \mathrm{mV}$ & $3.33 \mathrm{~V}$ & $10 \mathrm{~V}$ \\
\hline $\mathrm{V}_{9}$ & $-5.77 \mathrm{mV}$ & $-57.7 \mathrm{mV}$ & $-577 \mathrm{mV}$ & $-5.77 \mathrm{~V}$ & $-10 \mathrm{~V}$ \\
\hline $\mathrm{v}_{10}, \mathrm{v}_{11}$ & $5.77 \mathrm{mV}$ & $57.7 \mathrm{mV}$ & $577 \mathrm{mV}$ & $5.77 \mathrm{~V}$ & $10 \mathrm{~V}$ \\
\hline $\mathrm{v}_{12}$ & $3.0 \mathrm{~V}$ & $2.0 \mathrm{~V}$ & $1.0 \mathrm{~V}$ & $0.0 \mathrm{~V}$ & $-239 \mathrm{mV}$ \\
\hline $\mathrm{v}_{13}$ & $1.0 \mathrm{~V}$ & $4.0 \mathrm{~V}$ & $7.0 \mathrm{~V}$ & $10.0 \mathrm{~V}$ & $10.7 \mathrm{~V}$ \\
\hline I (meter) & $0.1 \mathrm{~mA}$ & $0.4 \mathrm{~mA}$ & $0.7 \mathrm{~mA}$ & $1.0 \mathrm{~mA}$ & $1.07 \mathrm{~mA}$ \\
\hline $\mathrm{v}_{14}(\mathrm{~dB}$ out $)$ & $-4.0 \mathrm{~V}$ & $-2.0 \mathrm{~V}$ & $0.0 \mathrm{~V}$ & $2.0 \mathrm{~V}$ & $2.48 \mathrm{~V}$ \\
\hline $\mathrm{v}_{15}(\mu \mathrm{V}$ out $)$ & $1 \mathrm{mV}$ & $10 \mathrm{mV}$ & $100 \mathrm{mV}$ & $1.0 \mathrm{~V}$ & $1.73 \mathrm{~V}$ \\
\hline Meter Reading & $0.01 \mu \mathrm{V}^{*}$ & $0.1 \mu \mathrm{V}$ & $1.0 \mu \mathrm{V}$ & $10 \mu \mathrm{V}$ & off scale \\
\hline
\end{tabular}

*Note: Actual analog computer voltages and outputs are invalid for antenna input voltage less than $0.1 \mu \mathrm{V}$. 


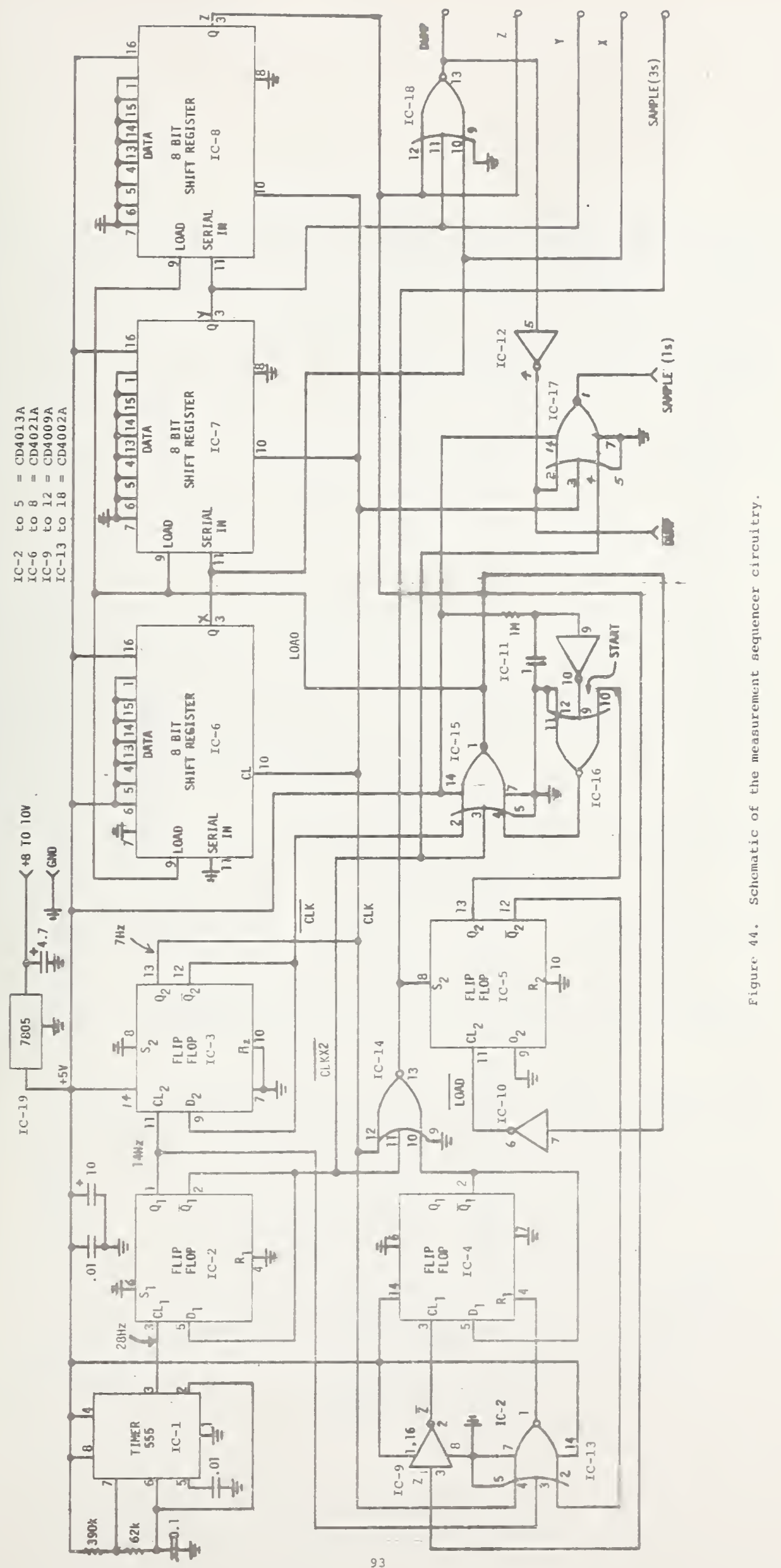




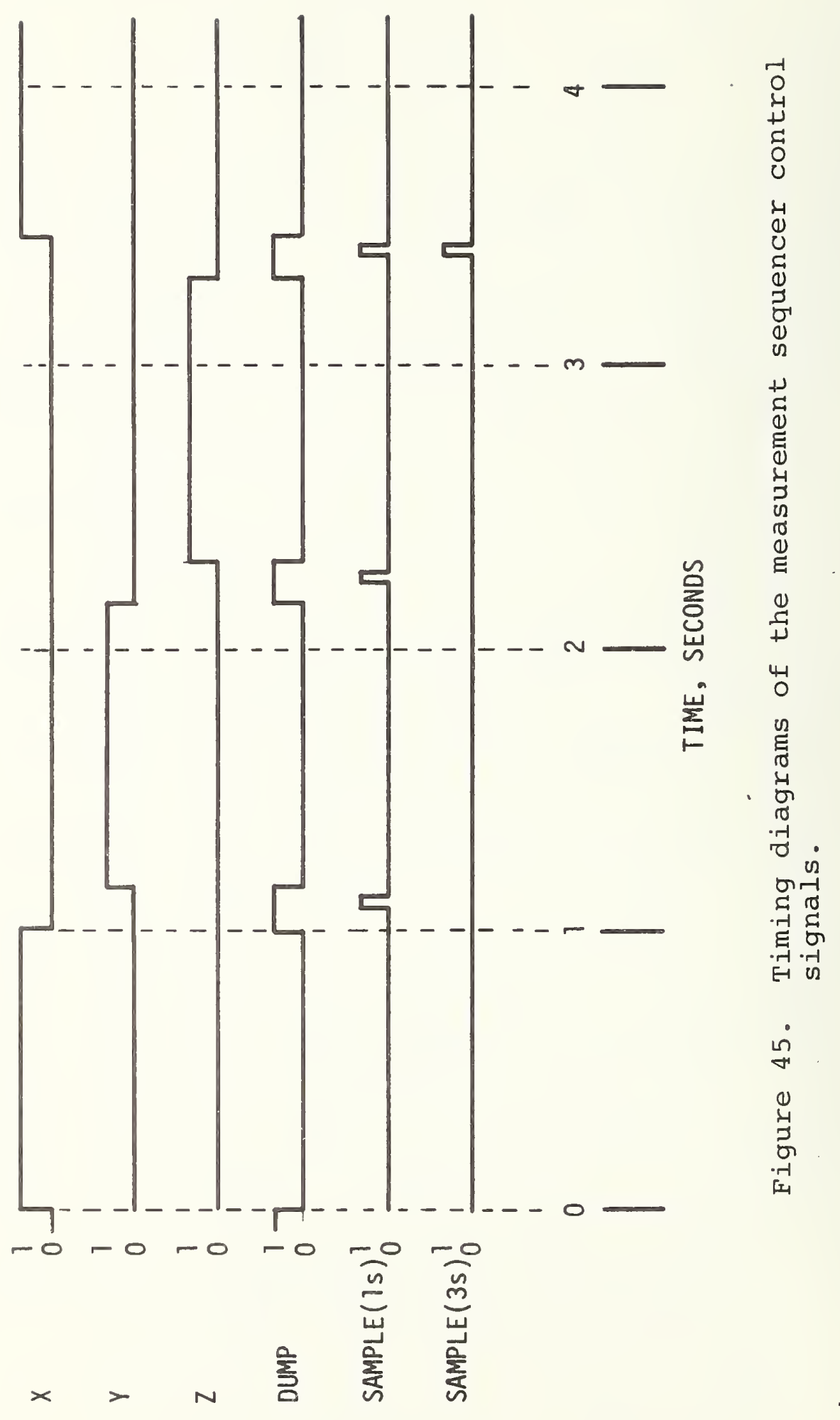




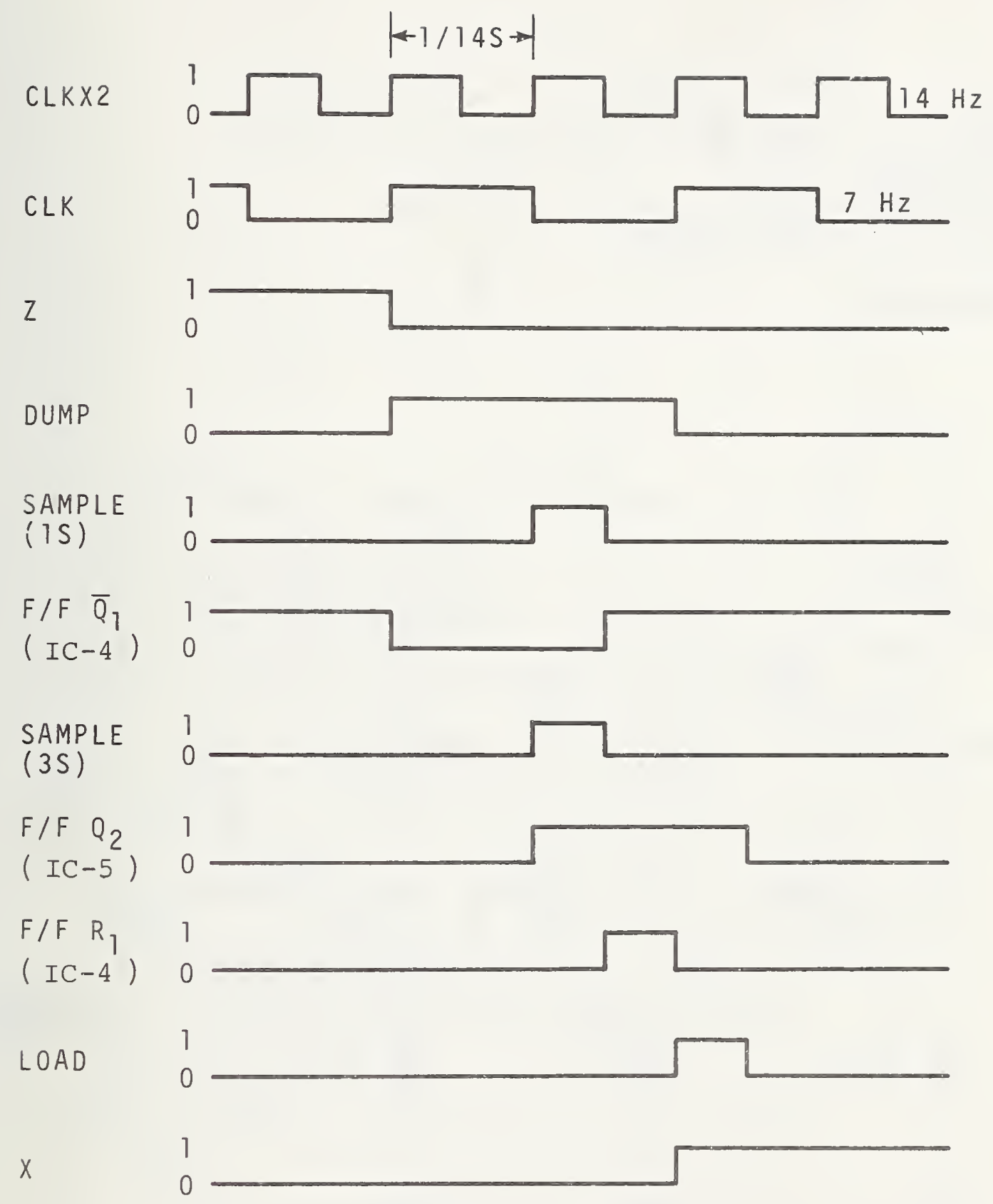

Figure 46. Timing diagrams of the measurement sequencer interval signals. 

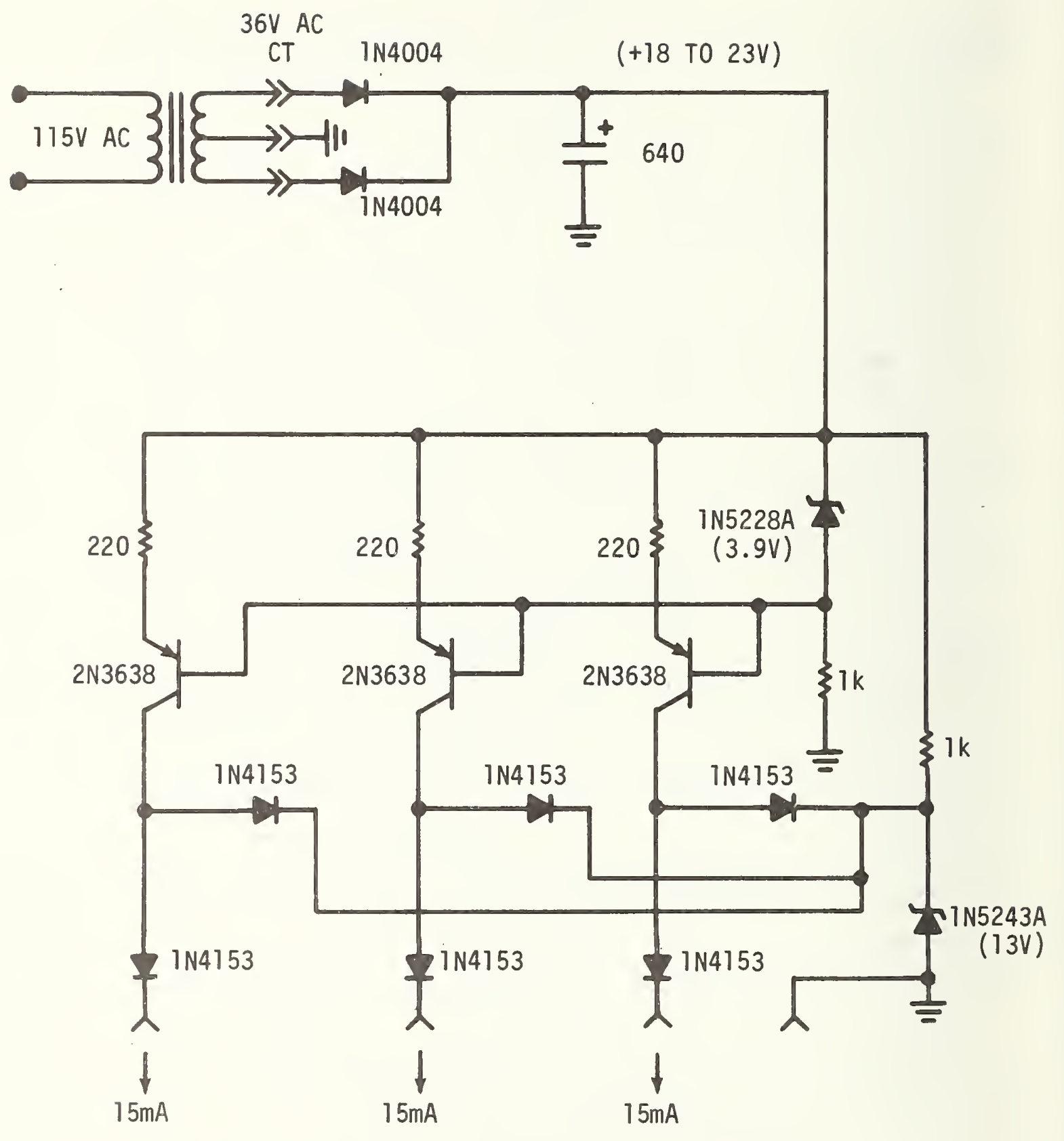

Figure 47. Schematic of the charger for the Nicd batteries. 


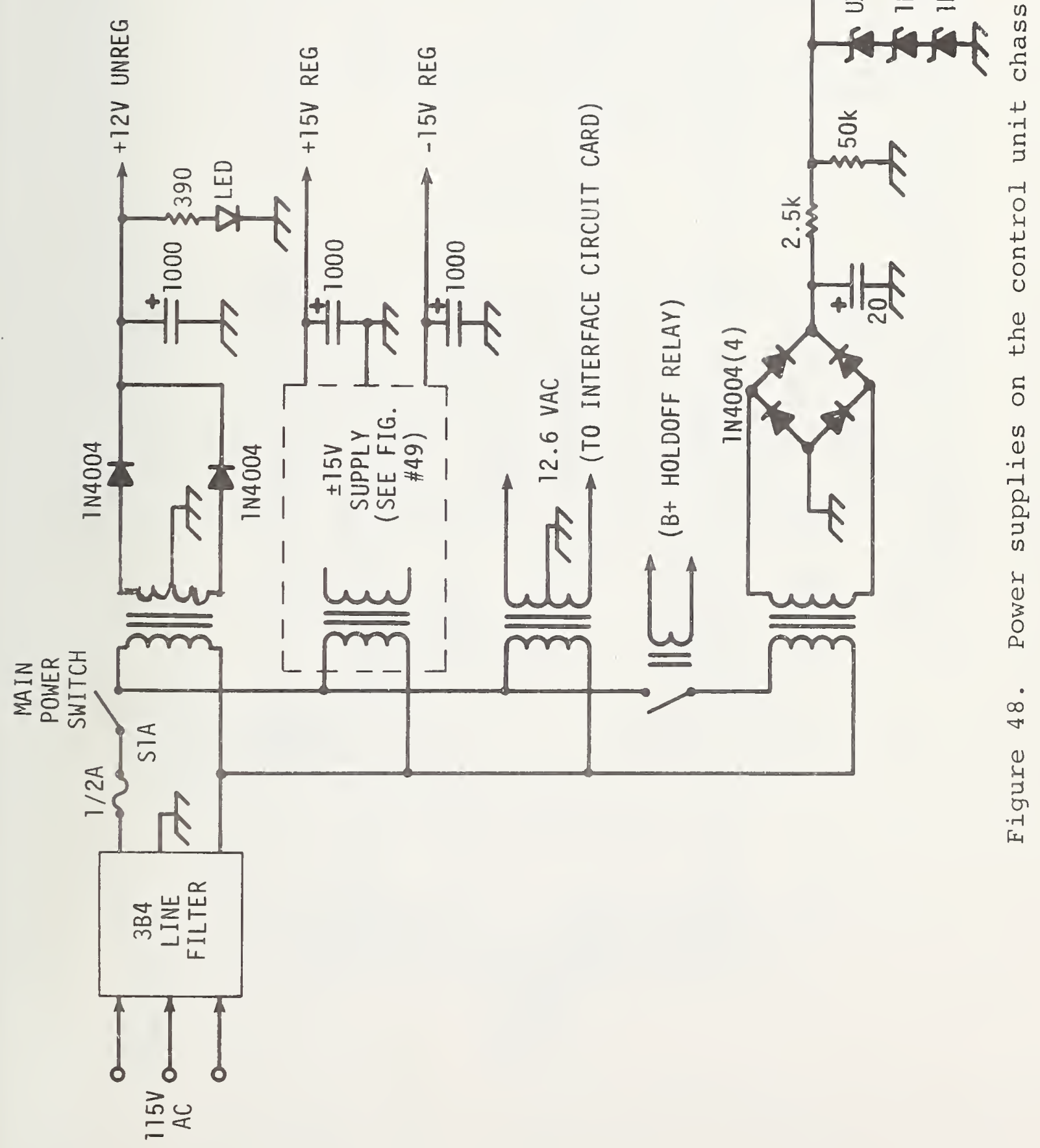




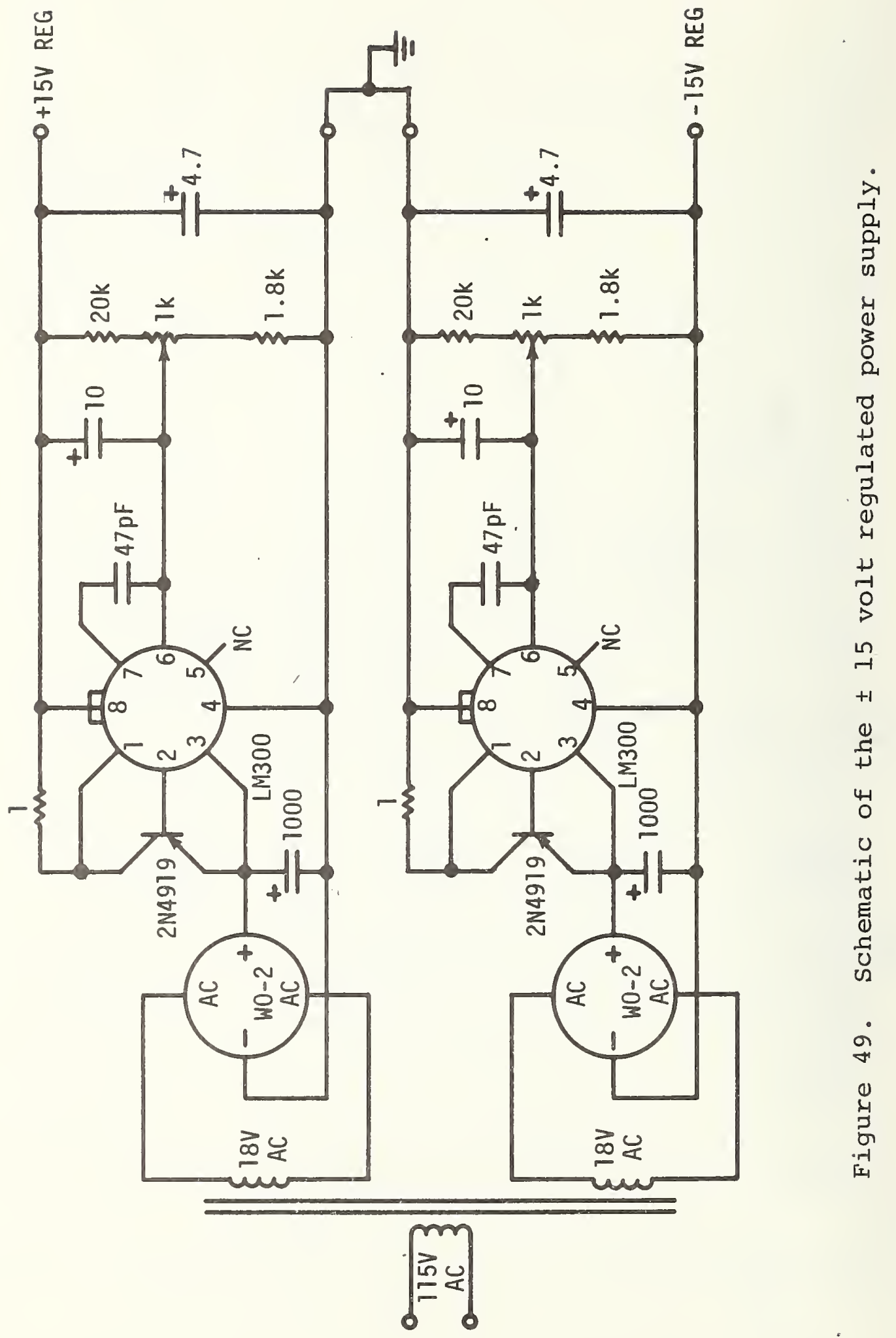




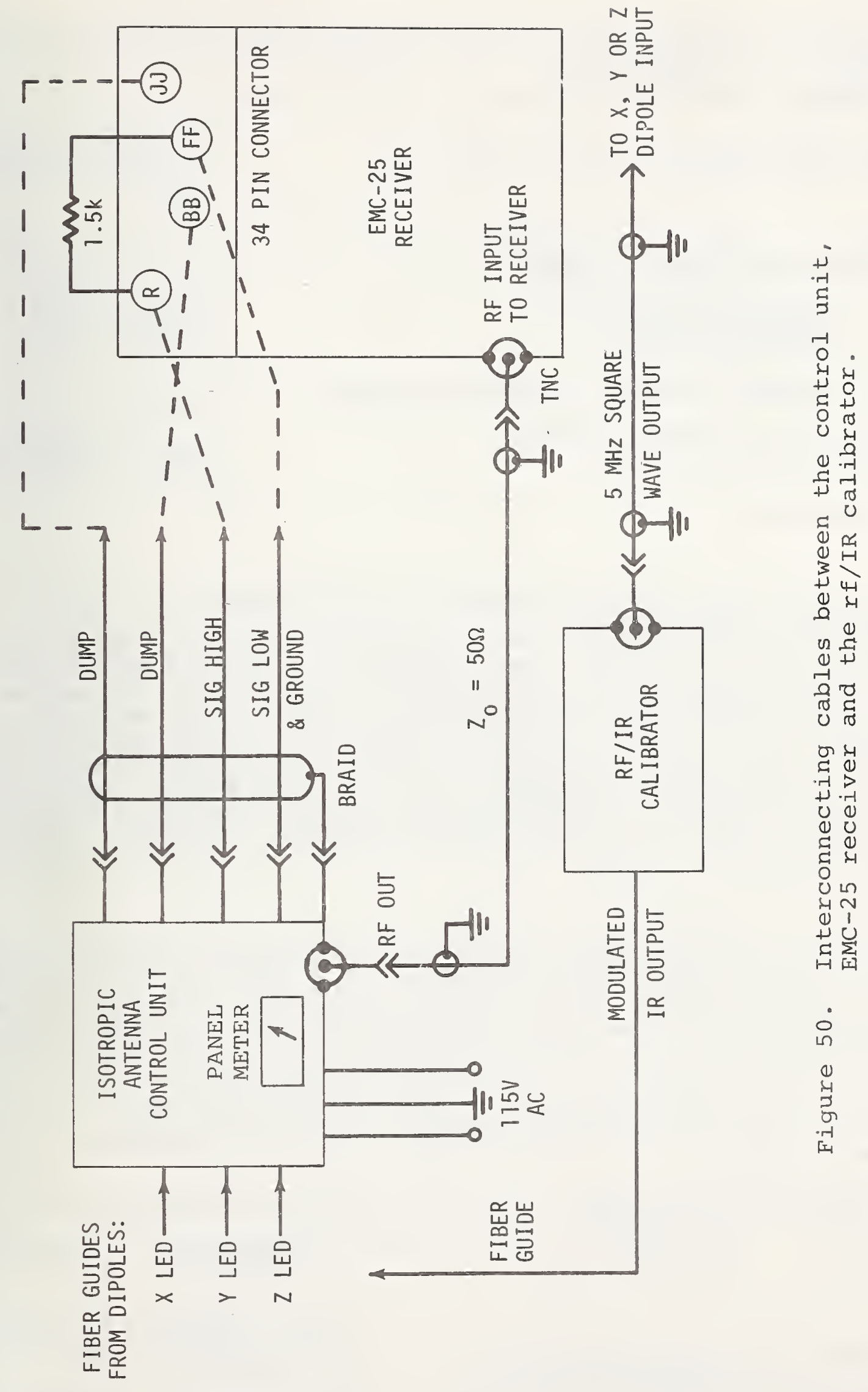


NBS.114A (REV. 7.73)

\begin{tabular}{|c|c|c|c|}
\hline $\begin{array}{l}\text { U.S. DEPT. OF COMM. } \\
\text { BIBLIOGRAPHIC DATA } \\
\text { SHEET }\end{array}$ & $\begin{array}{l}\text { 1. PUBLICATION OR REPORT NO. } \\
\text { NBSIR } 75-819\end{array}$ & $\begin{array}{l}\text { 2. Gov't Accession } \\
\text { No. }\end{array}$ & 3. Recipient's Accession No. \\
\hline \multirow{3}{*}{\multicolumn{3}{|c|}{$\begin{array}{l}\text { 4. TITLE AND SUBTITLE } \\
\text { Sensitive Isotropic Antenna with Fiber-Optic Link } \\
\text { to a Conventional Receiver }\end{array}$}} & 5. Publication Date \\
\hline & & & September 1976 \\
\hline & & & \begin{tabular}{|l} 
6. Performing Organization Code \\
276
\end{tabular} \\
\hline \multicolumn{3}{|c|}{$\begin{array}{l}\text { 7. AUTHOR(S) } \\
\text { E.B. Larsen, J.R. Andrews, E.E. Baldwin }\end{array}$} & 8. Performing Organ. Report No. \\
\hline \multicolumn{3}{|c|}{$\begin{array}{l}\text { 9. PERFORMING ORGANIZATION NAME AND ADDRESS } \\
\text { NATIONAL BUREAU OF STANDARDS } \\
\text { DEPARTMENT OF COMMERCE } \\
\text { WASHINGTON, D.C. } 20234\end{array}$} & $\begin{array}{l}\text { 10. Project/Task/Work Unit No. } \\
\text { NBS No. } 2767402 \\
11 . \text { Contract/Grant No. } \\
\text { ECOM No. 74-93095 }\end{array}$ \\
\hline \multicolumn{3}{|c|}{$\begin{array}{l}\text { 12. Sponsoring Organization Name and Complete Address (Street, City, State, ZIP) } \\
\text { U.S. Army Electronics Command, AMSEL-NL-C } \\
\text { Fort Monmouth, New Jersey } 07703\end{array}$} & $\begin{array}{l}\text { 13. Type of Report \& Period } \\
\text { Covered } \quad \text { Final } \\
\text { Apri1 1973-Sept. } 1974 \\
\text { 14. Sponsoring Agency Code }\end{array}$ \\
\hline
\end{tabular}

15. SUPPLEMENTARY NOTES

16. ABSTRACT (A 200-word or less factual summary of most significant information. If document includes a significant bibliography or literature survey, mention it here.)

A broadband, active, isotropic receiving antenna was developed at NBS for the frequency range $15 \mathrm{kHz}$ to $150 \mathrm{MHz}$. It was designed for use with a conventional receiver to measure weak, near-zone electric fields of unknown polarization, such as leakage emanations from electronic equipment placed within a shielded enclosure. The antenna system consists of three mutually-orthogonal active dipoles, each $31 \mathrm{~cm} 1$ long by $3.5 \mathrm{~cm}$ diameter. The entire frequency range of each of the three field components is amplified and used to modulate a high-speed light emitting diode (LED) located inside the dipole. The modulated infrared (IR) signals are guided through glass fibers 10 meters long which connect the "isolated" dipoles to avalanche photodiodes at the far end of the fiber guides. These photodetectors recover the rf modulation from the IR carrier for input to the receiver.

The fiber-optic antenna system described in this paper has high sensitivity (down to $10 \mu \mathrm{V} / \mathrm{m}$ ) and fast response time ( $\mathrm{ff}$ modulations up to $150 \mathrm{MHz}$ ). The readout indication at each receiver frequency is proportional to the Hermitian magnitude of $E$, which is the root-sum-square value of three orthogonal E field components at the measurement point. The linear dynamic range of the antenna system depends on the receiver bandwidth and signal frequency. It is 70 to $75 \mathrm{~dB}$ at frequencies between 0.02 and $2 \mathrm{MHz}$ (for $0.5 \mathrm{kHz}$ receiver bandwidth), 60 to $70 \mathrm{~dB}$ between 2 and $25 \mathrm{MHz}$ (for $5 \mathrm{kHz}$ receiver bandwidth) and 40 to $55 \mathrm{~dB}$ between 25 and $200 \mathrm{MHz}$ (for $50 \mathrm{kHz}$ bandwidth).

17. KEY WORDS (six to twelve entries; alphabetical order; capitalize only the first letter of the first key word unless a proper name; separated by semicolons)

Electromagnetic compatibility; fiber optics; field strength measurement; isolated EMC antenna; sensitive isotropic probe.
18. AVAILABILITY
(x) Unlimited

For Official Distribution. Do Not Release to NTIS

Order From Sup. of Doc., U.S. Government Printing Office Washington, D.C. 20402, SD Cat. No. C13

X Order From National Technical Information Service (NTIS) Springfield, Virginia 22 I 51

\begin{tabular}{|l|c|}
\hline $\begin{array}{l}\text { 19. SECURITY CLASS } \\
\text { (THIS REPURT) }\end{array}$ & 21. NO. OF PAGES \\
UNCL ASSIFIED & 107 \\
\hline $\begin{array}{l}\text { 20. SECURITY CLASS } \\
\text { (THIS PAGE) }\end{array}$ & 22. Price \\
UNCLASSIFIED & $\$ 5.50$ \\
\hline
\end{tabular}



, 


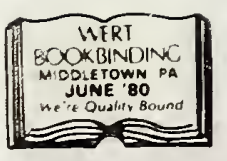


